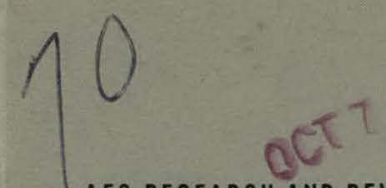

AEC RESEARCH AND DEVELOPMENT REPORT

i) 4

\title{
THE SEPARATION OF POTASSIUM ISOTOPES BY MOLECULAR DISTILLATION
}

\section{AUTHORS:}

R. M. McGill

R. W. Browell

J. W. Grisard

S. Blumkin

E. Von Halle

D. B. Janivey

RBETEASIED TOR ANDIOUNCEMENI

IN NUCLEAR SOIETCE ABSTRACIS

\section{UNION \\ UNION CARBIDE CORPORATION NUCLEAR DIVISION}

Operating the

OAK RIDGE GASEOUS DIFFUSION PLANT OAK RIDGE Y-12 PLANT
OAK RIDGE NATIONAL LABORATORY

- PADUCAH GASEOUS DIFFUSION PLANT 


\section{DISCLAIMER}

This report was prepared as an account of work sponsored by an agency of the United States Government. Neither the United States Government nor any agency Thereof, nor any of their employees, makes any warranty, express or implied, or assumes any legal liability or responsibility for the accuracy, completeness, or usefulness of any information, apparatus, product, or process disclosed, or represents that its use would not infringe privately owned rights. Reference herein to any specific commercial product, process, or service by trade name, trademark, manufacturer, or otherwise does not necessarily constitute or imply its endorsement, recommendation, or favoring by the United States Government or any agency thereof. The views and opinions of authors expressed herein do not necessarily state or reflect those of the United States Government or any agency thereof. 


\section{DISCLAIMER}

Portions of this document may be illegible in electronic image products. Images are produced from the best available original document. 
Printed in USA. Price $\$ 4.00$. Available from the Clearinghouse for Federal Scientific and Technical Information, National Bureau of Standards,

U.S. Department of Commerce, Springfield, Virginia

\section{LEGAL NOTICE}

This report was prepared as an account of Government sponsored work. Neither the United States, nor the Commission, nor any person acting on behalf of the Commission:

A. Makes any warranty or representation, expressed or implied, with respect to the accuracy, completeness, or usefulness of the information contained in this report, or that the use of any information, apparatus, method, or process disclosed in this report may not infringe privately owned rights; or

B. Assumes any liabilities with respect to the use of, or for damages resulting from the use of any information, apparatus, method, or process disclosed in this report.

As used in the above, "person acting on behalf of the Commission" includes uny employee or contractor of the Commission, or employee of such contractor, to the extent that such employee or contractor of the Commission, or employee of such contractor prepares, disseminates, or provides access to, any information pursuant to his employment or contract with the Commission, or his employment with such contractor. 
Date of Issue: September 29, 1965 Report Number: K-1650

Subject Category: ISOTOPE SEPARATION

TID-4500 (44th Ed.)

THE SEPARAIITON OF POTASSIUM ISOTOPES BY MOLECULAR DISTILIATION

R. M. McGill, Editor, R. W. Browell, J. W. Grisard Chemical Development Department

Technical Division

S. Blumkin, E. Von Halle

Operations Analysis Division

and

D. B. Janney

Engineering Division

UNION CARBIDE CORPORATTON

NUCLEAR DIVISION

Oak Ridge Gaseolus Diffusion Plant

Oak Ridge, Tennessee 


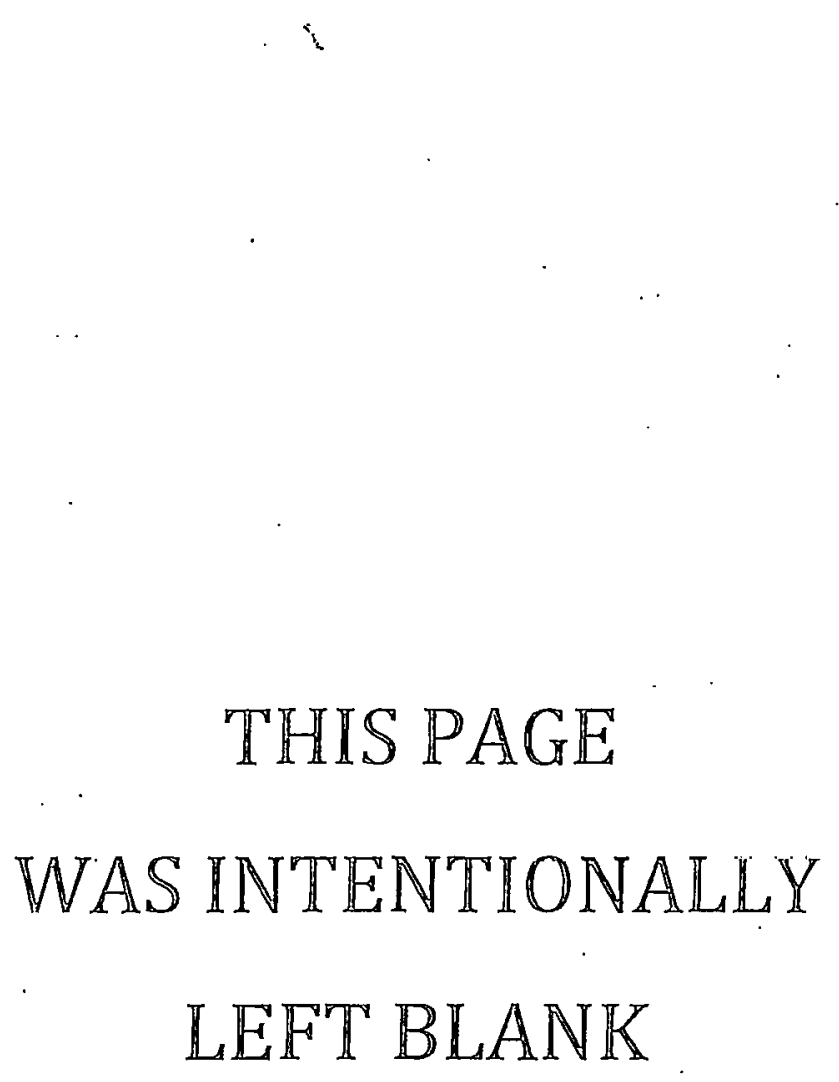




\section{Title: THE SEPARATION OF POTASSIUM ISOTOPES BY MOLECULAR DIS- TILIATION}

Authors: R. M. McGill, Editor, R. W. Browell, J. W. Grisard, S. Blumkin, E. Von Halle, and D. B. Janney

\section{A B S T R A C T}

The technical feasibility of accomplishing the separation of the principal potassium isotopes $\mathrm{K}-39$ and $\mathrm{K}-41$ on a large scale by the molecular distillation of potassium metal has been established. Following preliminary tests, a 10-stage experimental molecular still was designed, constructed, and operated to locate the optimum operating temperature and to investigate the effect on the separation factor of several process variables. The experiment was successful and led to the design and construction of a 15-stage Prototype cascade unit for operation at the optimum evaporating temperature of $270^{\circ} \mathrm{C}$. This equipment is now in operation. Conceptual design of a molecular distillation cascade to produce one ton per year of potassium enriched to $99.93 \% \mathrm{~K}-39$ has been completed; analysis of the cascade construction and annual operating costs leads to an estinated unit cost of product of about $\$ 420 / 1 b$. Economic effects of operating this cascade at other $\mathrm{K}-4 \mathrm{I}$ depletion factors and other production rates are discussed. 
THIS PAGE

\section{WAS INTENTIONALLY LEFT BLANK}


THE SEPARATION OF POTASSIUM ISOTOPES BY MOLECULAR DISTHLLATION

TABLE OF CONTENTS

INTRODUCTION . . . . . . . . . . . . . . . . . 9

SUMMARY. . . . . . . . . . . . . . . . . . . . 11

$\underline{\text { Part } 1}$

PROCESS THEORY . . . . . . . . . . . . . . . . . . . . 17

PRELIMINARY EXPERIMLNTS. . • . . . . . . . . . . . . . . . . 27

RAYLEIGH DISTILLATIONS. . . . . . . . . . . . . . 26

WETTING EXPERIMENTS ..................... 31

TEST STAGE. . . . . . . . . . . . . . . . . . . 32

CONCLUSIONS . . . . . . . . . . . . . . . . . . . . . 41

MULTISTAGE EXPERIMENT, MODEX .................. . . . 44

DESIGN. . . . . . . . . . . . . . . . . 44

CONSTRUCTION. . . . . . . . . . . . . . . . 45

EXPERIMENTAL WORK . . . . . . . . . . . . . . . . . 61

CONCLUSIONS . . . . . . . . . . . . . . . . . . 86

$\underline{\text { Part. } 2}$

CASCADE CHARACTERISTICS AND OPERATING TEMPERATIRE. . . . . . . . . 91

SPECIFICATION OF THE SEPARATION TASK. . . . . . . . . . . . . . . 91

MAGNITUDE OF THE SEPARATION TASK. . . . . . . . . . . . . . 91

CASCADE DESIGN. . . . . . . . . . . . . . . . . . . . . . 92

OPTIMUM OPERATING TEMPERATURE . . . . . . . . . . . . . . . . . 92

CHARACTERISTICS OF THE DESIGN CASCADE . . . . . . . . . . . . . 94

PROTOTYPE CASCADE TRAY . . . . . . . . . . . . . . . 98

CASCADE CONCEPTUAL DESIGN. . . . . . . . . . . . . . . 105

Part 3

CoSTS. . . . . . . . . . . . . . . . . . . . . 117

CONSTRUCTION. . . . . . . . . . . . . . . . . . 117

OPERATION . . . . . . . . . . . . . . . . . . . 117

UNIT PRODUCT COSI . . . . . . . . . . . . . . . . 117

ECONOMICS OF VARYING TARGET PRODUCT CONCENTRATIONS AND PRODUCTION

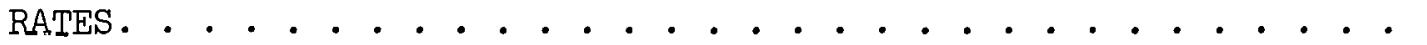




\section{THIS PAGE}

\section{WAS INTENTIONALLY \\ LEFT BLANK}


ACKINOWLEDGMENTS . . . . . . . . . . . . . . . . . . 123

BIBLIOGRAPHY. . . . . . . . . . . . . . . . . 124

APPENDIXES. . . . . . . . . . . . . . . . . . . . . . . 125

A. PHYSICAL PROPERTIES OF POTASSIUM AND XYLENE. . . . . . . . 126

B. POTASSIUM ISOTOPIC ANALYSIS. . . . . . . . . . . . . . . . 129

C. SPECIAL CALCULATIONS . . . . . . . . . . . . . . . . . 131

D. METAL FLOW CALCULATIONS. . . . . . . . . . . . . . 134

E. TRAY CONSTRUCTION COSTS. . . . . . . . . . . . . 140 
THIS PAGE

\section{WAS INTENTIONALLY \\ LEFT BLANK}


THE SEPARATION OF POTASSIUM ISOTOPES BY MOLECULAR DISTILLATION

\author{
INTRODUCTION
}

Metallic potassium has a number of desirable properties which recommend its use as a nuclear reactor coolant and/or working fluid; these properties have been thoroughly discussed in reactor literature. One undesirable property associated with such use of normal potassium metal, however, involves the neutron capture of the naturally occurring isotope of mass 41 , converting it to gamma-emitting $\mathrm{K}-42$. Although this latter isotope decays with a 12.47-hr. half-life, its prescnce nevertheless requires additional shielding during reactor operation and after shutdown necessitates a longer cooling-off period before maintenance can be performed. Especially in the case of compact nuclear reactors, where weight and personnel proximity to the reactor are important factors, a considerable advantage could be realized by reducing the concentration of $\mathrm{K}-4 \mathrm{I}$ in the potassium coolant by a factor of about 100. Normal potassium contains about 6.9 atom per cent of this isotope, the remainder being predominantly $\mathrm{K}-39$ (see Appendix A).

An examination was made of isotope separation processes which might be applied to this task. Since no stable, volatile compounds of potassium exist which would permit the use of a conventional gas phase isotope separation process, the survey was restricted to those processes which involve a liquid phase, such as chemical exchange, ion exchange, electromigration, and molecular distillation. The chemical exchange process involving an isotopic exchange between potassium amalgam and aqueous potassium hydroxide solution was originally thought to be promising, but experimental work indicated that a much smaller separation factor was attainable than had been anticipated on the basis of published data. The ion exchange and electromigration processes were not expected to be attractive because of their inherently low throughput capacity and high holdup requirements, resulting in a prohibitively long cascade equilibrium time before ariy of the desired product could be withdrawn; calculationo based on available electromigration data verified this. The molecular distillation process, however, appeared very promising, especially in vicw of the successful application of this technique at ORGDP to the separation of the lithium isotopes $(6,7)$.

A prcliminary estimate was made at ORGDP of the construction and operating costs of a molecular distillation cascade sized to produce one tun per ycar of potassium enriched to $99.93 \% \mathrm{~K}-39$. In preparing this estimate, assumptions were necessarily made of the fraction of the theoretical stage separation factor which would be attained in a cascade. In the absence of experimental data, these were based on experience with the lithium distillations. When these preliminary estimates were presented to the AEC Division of Reactor Development, they were considered sufficiently encouraging to prompt authorization of a project on the separation of 
potassium isotopes by molecular distillation. This project was undertaken jointly by the Technical, Engineering, and Operations Analysis Divisions of ORGDP and had as its goal the establishment of the technical feasibility and the economic evaluation of the large scale separation of potassium isotopes by the molecular distillation process. Establishment of process feasibility was interpreted as involving the following areas of effort:

1. Design, construction, and operation of experimental molecular distillation equipment for the purpose of evaluating the effects of operation parameters on the separative efficiency and to provide adequate bases for estimating the cost and reliability of such equipment. It will be recognized that the closer such experimental equipment approximates production scale equipment the more thoroughly one can identify troublesome areas in fab- . rication or operation.

2. Analysis of the separation and cost data for the purpose of establishing the optimum operating conditions, i.e., those which lead to the minimum unit cost of product. With these data, it is then possible to specify the process equipment necessary to accomplish the desired-sepurative-work.

3. Design, construction, and operation of prototype process equipment for the purpose of further refining cost estimation data and providing operational experience with proposed cascade equipment.

4. Conceptual design. and cost estimation of a complete cascade to accomplish the specified separation task. From these data a more refined estimate of the unit cost of product can be specified.

The present report details the results of studies made in these areas auring the period from september, 1963, to september, 1965. 
SUMMARY

\section{TECHINICAL FEASIBILITY}

The technical feasibility of carrying out the separation of potassium isotopes on a large scale by molecular distillation of the metal has been established. Small scale experiments verified that the predicted enrichment of $\mathrm{K}-39$ in the condensate under molecular distillation conditions did actually occur, while construction and operation of a test stage was used to establish design criteria for a multistage experiment. In this experiment, Modex, ten molecular distillation stages were constructed in two trays with all interstage fllows produced by gravity. The experiment was designed to determinc the variation of stage separation factor with evaporating temperature, since these data are essential in determining an optimum operating temperature and in sizing proposed cascade equipment for specif'ied separative tasks.

The Modex experiment was highly successful. Flow and separation data were ob $\doteqdot$ ained over the temperature range $222^{\circ}$ to $296^{\circ} \mathrm{C}$., indicating that maximum separative capacity would be obtained at $283^{\circ} \mathrm{C}$. with a stage separation factor, $\Psi$, of 0.0166 . Combination of these data with power and equipment cost factors, however, showed that operation at $270^{\circ} \mathrm{C}$. with a $\Psi$-value of 0.0183 would result in the minimum unit cost of product. Other experiments conducted with the Modex still showed that the process was easily controlled, since the separation factor was not extremely sensitive to such operating parameters as residual inert gas pressure, balance of interstage flows, or the potassium condenser temperature. Runs were also conducted in which normal potassium was fed to the system and product and reject streams withdrawn at rates commensurate with the production of up to 2 tons per year of enriched K-39. As far as cari be determined, this was the first instance in which a molecular still for isotope separation was operated with feed and withdrawal streams. The oxide content of metal which had been refluxed in the still about 6 months had not increased from that of the metal originaj.].y charged.

The operation of the Modex still also showed that the concept of the multistage tray could be realized in practice and that the design used was sound. In spite of the high reactivity of potassium.metal and flammability of the xylene evaporative coolant, the experimental work, including some maintenance work on trays containing molten potassium, was all conducted without incident.

Using the separation-tcmperature data from the Modex experiments, it was determined that a molecular distillation cascade could be constructed lo produce one ton per year of potassium enriched to $99.93 \% \mathrm{~K}-39$. Such a cascade would require 525 stages, each of 2.1 -sq.ft. evaporating area, operating at $270^{\circ} \mathrm{C}$. Feed to the cascade would be about 2 tons per year and power consumption would be about $3.6 \mathrm{Mw}$. It is estimated that the lime required from the initiation of cascade design until the withdrawal 
of the first product level material would be about 36 months. About 5 months equilibrium time is involved in this estimate.

Redesign of the multistage tray was next completed to the take advantage of the optimized evaporating temperature and stage area. The Prototype cascade tray contained 15 stages arranged in a 3-by-5 array and was considerably simplified in construction and function from the experimental Modex trays. This tray arrangement lends itself well to cascading; the conceptual cascade would require 35 of these trays. The Prototype tray was constructed using fabrication techniques devised for the Modex trays and is being installed in conjunction with the Modex system to constitute a 25-stage test facility. Testing of this unit will be completed shortly; performance data are to be presented in a subsequent report.

The 15-stage Prototype tray was next used as a basis for the conceptual design of a molecular distillation cascade, which was then examined with respect to construction and operating costs to establish an estimated unit cost of the product. Cascade construction and operation do not appear to involve any unusual problems.

In the course of construsting the Modck and Frulutype stills, valuable experience has been accumulated on techniques of fabrication and installation of this type of molecular distillation equipment. In addition, the operation of these stills has provided an opportunity to develop procedures for conducting the routine phases of still operation and for handling emergency situations which can arise.

ECONOMIC FACTORS

Studies have also been conducted on the economic factors involved in the molecular distillation process. These studies included:

1. Cost estimation for construction of the 525-stage cascade for the production of one ton per year of $99.93 \% \mathrm{~K}-39$. These estimates indicate that the cascade could be built at a cost of $\$ 2,720,000$, which includes operation for the first 4.6 months to establish the isotopic gradient.

2. Estimation of the unit cost of $99.93 \% \mathrm{~K}-39$ product from this facility, assuming a 10-year amortization period for the cascade and annual operating costs applicable to the ORGDP area. A unit value of $\$ 420 / 1 b$. was obtained.

3. Estimation of the production rate and unit cost of product for the operation of the facility at K-4l depletion factors lower than the factor of 100 for which the cascade was designed. Curves have been prepared presenting this information.

4. Estimation of the unit cost of product at various $K-41$ depletion factors for cascades designed to produce product at rates higher than one ton per year; curves presenting this information have been extended to production rates of 50 tons per year. 
Whether the unit costs arrived at in these studies establish economic feasibility is beyond the scope of this report, inasmuch as it involves the value placed on the product in its end use. Since highly enriched K-39 would find use as a coolant and/or working fluid in many types of nuclear reactors, its value will be dependent upon the specific application. It may be noted, however, that the very success of certain sophisticated reactor concepts is dependent upon the availability of enriched K-39, and that no other isotope separation process for this task is known at this time which could compete economically with the molecular distillation method. 


\section{THIS PAGE}

\section{WAS INTENTIONALLY \\ LEFT BLANK}


PART 1 
THIS PAGE

\section{WAS INTENTIONALLY \\ LEFT BLANK}


PROCESS THEORY

According to the kinetic theory of gases (9), the rate at which gas molecules strike each square centimeter of wall of the confining vessel is given by the equation

$$
\mathrm{n}=\frac{\mathrm{N} \bar{v}}{4}
$$

where $\mathrm{n}=$ collision rate in molecules $/ \mathrm{sq} \cdot \mathrm{cm} \cdot-\mathrm{sec}$.

$\mathbb{N}=$ density of molecules in the gas in molecules $/ \mathrm{cu} . \mathrm{cm}$.

$\bar{v}=$ average speed of molecules in $\mathrm{cm} \cdot / \mathrm{sec}$.

If the terms $\mathbb{N}$ and $\bar{v}$ are expressed in terms of the more readily measured variables of gas pressure, $P$, and temperature, $T$, with the assumption that the gas is a perfect one, equation 1 may be written in the form

where $\overline{\mathrm{N}}=$ Avogadro's number

$$
\mathrm{n}=\mathrm{PN} \sqrt{\frac{1}{2 \pi R M T}} \text {, }
$$

$\mathrm{R}=$ gas constiant

$\mathrm{M}=$ molecular weight of the gas.

Langmuir (8) showed that equation 2 was equally valid for expressing the theoretical rate of evaporation of a substance from a square centimeter of surface at temperature $T$ where the substance had an equilibrium vapor pressure $P$. This theoretical rate of evaporation can be closely verified experimentally if the surface is kept clean and if precautions are observed to assure that no molecule leaving the surface is reflected back to the surface by intermolecular collisions in the vapor space above it. Measurement of the evaporation rate under these conditions is often used to estimate the vapor pressure of substances having very high boiling points, e.g., refractory metals.

If the substance bcing evaporated contains two types of molecules, for example light and heavy isotopic species, equation 2 leads to two evaporation rates whose ratio at a given temperature will be

$$
\frac{\mathrm{n}_{\ell}}{\mathrm{n}_{\mathrm{h}}}=\frac{\mathrm{P}_{\ell}}{\mathrm{P}_{\mathrm{h}}} \sqrt{\frac{\mathrm{M}_{\mathrm{h}}}{\mathrm{M}_{\ell}}} \text {. }
$$

Except for the hydrogen isotopes, the equilibrium vapor pressures of most pure isotopic species, $\mathrm{P}_{\ell}$ and $\mathrm{P}_{h}$, are not significantly different and equation 3 reduces to

$$
\alpha=\frac{\mathrm{n}_{l}}{\mathrm{n}_{\mathrm{h}}}=\sqrt{\frac{\mathrm{M}_{\mathrm{h}}}{\mathrm{M}_{\ell}}},
$$

where $\alpha$ is the ideal point separation factor for the evaporation process carried out under the conditions described. Equation 4 expresses the theoretical separation factor in terms of the molecular. weights of the evaporating species. Note that the light component evaporates faster and is concentrated in the distillate. Such distillation processes dre called molecular distillations. 
The requirements which will lead to securing the largest possible fraction of $\alpha$ in practice may now be interpreted in terms of the equipment design and operating conditions. The efficient trapping of escaping molecules before intermolecular collisions return some of them to the evaporating surface demands a condensing surface closely spaced from the evaporator. Ideally, the evaporator-condenser spacing should be small compared to the mean free path of the molecules of the distilling substance at its operating temperature and vapor pressure. This mean free path may be estimated by the kinetic theory and is given by the expression

$$
\ell=\frac{k T}{\sqrt{2 \pi \sigma^{2} P}}
$$

where $\ell=$ mean free path in centimeters

$$
\begin{aligned}
& \mathrm{k}=\text { Boltzmann constant, } 1.38 \times 10^{-16} \mathrm{erg} /{ }^{\circ} \mathrm{K} \text {-mole } \\
& \mathrm{T}=\text { Absolute temperature in }{ }^{\circ} \mathrm{K} . \\
& \mathrm{P}=\text { pressure of the gas in dynes } / \mathrm{sq} . \mathrm{cm} . \\
& \sigma=\text { collision diameter of the molecules in centimeters. }
\end{aligned}
$$

For the molecular distillation process, the gas pressure $\mathrm{P}$ is the vapor pressure of the substance, and since the vapor pressure increases exponentially with temperature, the mean free path will decrease sharply with increasing temperature. Mean free paths calculated from equation 5 must be used with considerable reservation in molecular distillation design, since the true equilibrium vapor pressure characteristic of the evaporator temperature $\mathrm{T}$ is not really obtained in the vapor space between the evaporator and condenser, and molecular motion in this space is not truly random. The calculations do serve, however, to indicate the order of magnitude of the spacing required.

To aid further in minimizing the number of detrimental intermolecular collisions in the short path from evaporating to condensing surface, foreign gases must be excluded by conducting the distillation under vacuum conditions and the condenser must be operated at a temperature low enough that re-evaporation of condensate is insignificant. This normally rcquires a condenser temperature about $100^{\circ} \mathrm{C}$. cooler than the evaporator. It is also desirable that the ratio of condenser area to evaporator area be as large as possible (1), consistent with other process requirements. Equation 2 may be divided by Avogadro's number, $\overline{\mathrm{N}}$, to obtain the theoretical evaporation rate in gram moles/sq.cm.-sec. If the heat of vaporization of the substance is known, this quantity allows calculating the ideal process heat requirement per unit area as a function of temperature.

Figure 1 summarizes the variation of three important molecular distillation design variables with evaporating temperature, viz., rate of evaporation, power required, and the mean free path, all calculated for the vaporization of potassium metal. The vapor pressure equation for molten potassium as well as other numerical data used in the calculations are summarized in Appendix A. 
DWG. NO. G-65-489

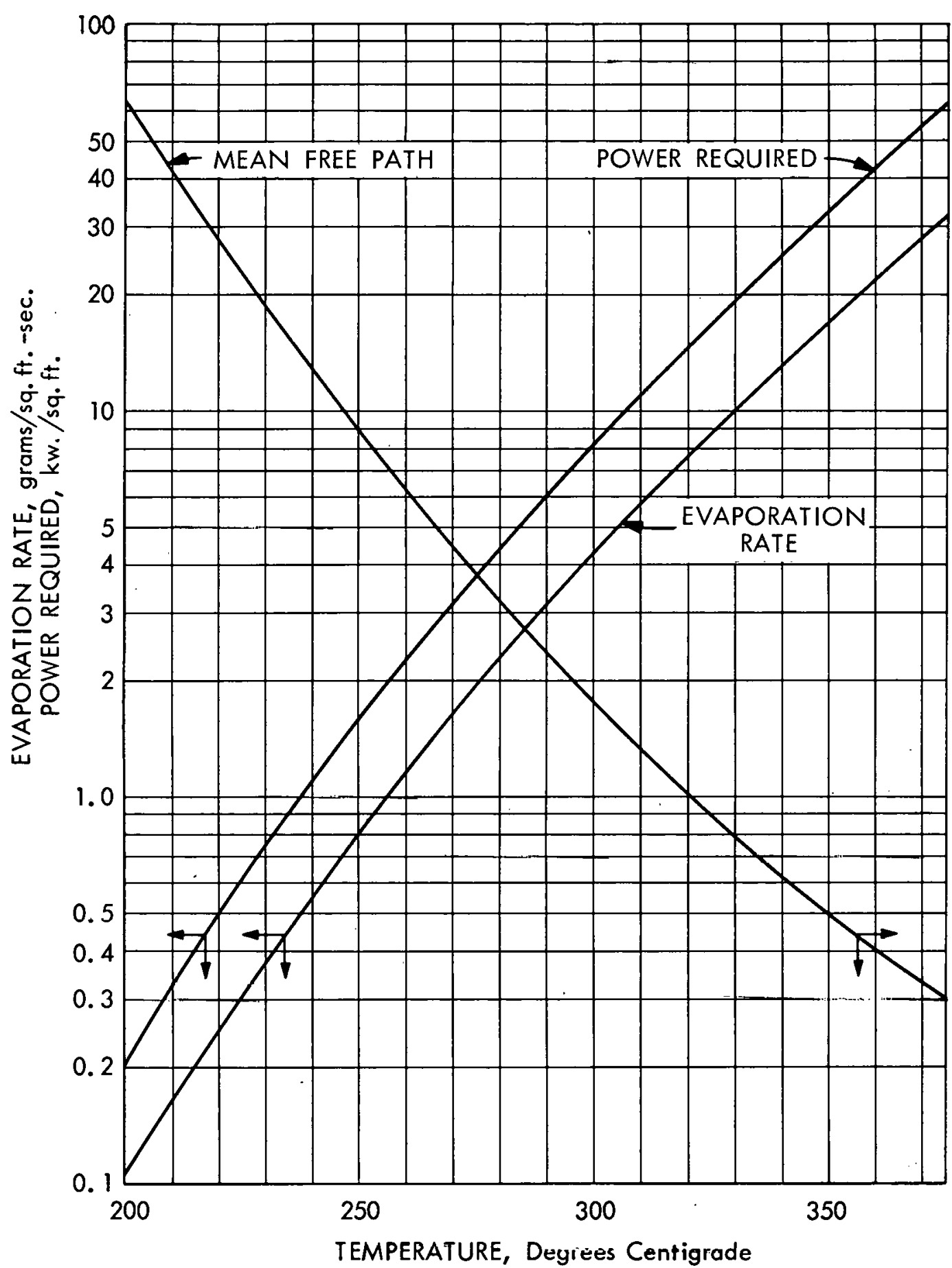

1.0

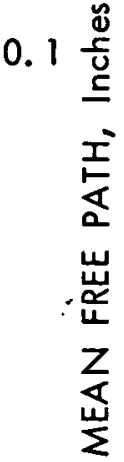

0.01

Figure 1

POTASSIUM MOLECULAR DISTILLATION DESIGN PARAMETERS 
The temperature range shown in figure 1 is one over which molecular stills for the separation of potassium isotopes might assume practical sizes and shapes, since, as will be pointed out, the dimensions of such stills change markedly with the operating temperature. It is clearly impractical to consider evaporator to condenser spacings comparable in size to some of the calculated mean free paths shown in figure 1 ; a more practical approach would be to fix this spacing at some reasonable value which could be achieved in a large scale still and to determine experimentally the change of separation factor with temperature. In such an arrangement, the separation factor must decrease with increasing temperature since the fixed spacing permits more of the detrimental intermolecular collisions as higher temperatures are attained. Thus, a fixed spacing of 0.75 inch would represent only about one mean free path at $200^{\circ} \mathrm{C}$., but about 150 times the mean free path at $350^{\circ} \mathrm{C}$.

While this consideration recommends operating such a still at very low temperatures in order to obtain a good separation factor, there is another compensating factor shown in figure 1, viz., the evaporation rate. Since the still must produce enriched product at a finite rate, there must be sufficient interstage flow of potassium to sustain the required net upflow of light product. This requi rement san bc mct at luw lemperatires, say below $200^{\circ} \mathrm{C}$., only by resorting to stages which have large areas, since the evaporation rate per unit area is low. At the other extreme, a high temperature stage operating at about $350^{\circ} \mathrm{C}$. could well be of very small size to achieve useful interstage flow, though the separation obtained per stage would be low because a physically practical evaporator-condenser spacing would allow many intermolecular collisions. Another restriction met at high temperatures is impliod by the curve showlng the power density in kilowatts/sq.ft. required to sustain given evaporating temperatures. These power density levels become prohibitively large at temperatures over $350^{\circ} \mathrm{C}$. for most materials of construction.

Figure 1 thus illustrates one of the major problems which was to be solved experimentally - that of fixing the optimum operating temperature so that a separation cascade could be designed for the most efficient operation. As just described, the number of stages in a cascade, the area of each stage, and the power consumption are all strongly dependent upon this operating temperature.

From equation 4 the theoretical maximum point separation factor for the separation of the potassium isotopes of masses 39 and 41 can be calculated:

$$
\alpha=\sqrt{\frac{41}{39}}=1.0253
$$

Even if this factor could be attained experimentally, it is apparent that a cascade of many stages would be required to enrich natural potassium containing $93.1 \% \mathrm{~K}-39$ to the desired product containing $99.93 \% \mathrm{~K}-39$. While it is beyond the scope of this report to discuss the theory of cascades, several terms will repeatedly arise in discussing the experimental 
data which may require definition. A complete treatment of the theory is presented elsewhere (2).

Each stage of a molecular distillation cascade accepts a feed stream of potassium from neighboring stages and by the distillation process divides it into a product stream of distillate slightly enriched in $\mathrm{K}-39$ and a reject stream slightly depleted in $\mathrm{K}-39$. The concentration of $\mathrm{K}-39$ in each stream depends on the average separation factor achieved by the stage and on the fraction of the feed stream which has been vaporized in passing through the stage. This latter fraction when expressed on a molar basis is termed the cut of the stage and is usually designated by $\theta$.

It is the purpose of the cascade to route the product and reject streams from each stage, combining them to form feed streams such that the enriched K-39 streams are continuously moved from stage to stage toward the product withdrawal end or top of the cascade and the depleted K-39 streams move toward the reject end or bottom of the cascade. To accomplish this task, the cascade must mix streams, the feed stream to a given stage being a mixture of a product stream from a stage lower in the cascade and a reject stream from a stage higher in the cascade. One of the properties of an ideal cascade is that streams of different concentrations are never mixed, since this would undo some of the separative work already performed. While it is not practical to construct a perfectly ideal cascade, real cascades are built to approximate them closely. It can be shown that if the separation factor is near unity, as it is-for most isotope separation processes, a cut of one-half at each stage will closely approximate the no-mixing requirement for adjacent stages of the cascade. Since the product and reject streams from each stage are equal in magnitude, the cascade is readily assembled as shown in figure 2. Values of the stage cut other than one-half may be used in ideal cascades by feeding a stage with streams from non-adjacent stages, but these cascades are more difficult to construct and control and offer no advantages in separation.

Equation 4 yields a point separation factor for the molecular distillation process, i.e., it expresses the ideal ratio of mole ratios of isotopes in the distillate and liquid residue for each point on the evaporating surface:

$$
\alpha=\frac{\left(\frac{\mathrm{C}_{39}}{\mathrm{C}_{41}}\right)}{\left(\frac{\mathrm{C}_{39}}{\mathrm{C}_{41}}\right)} \text { Distillate }
$$

This factor could be measured for a stage, however, only if the amount of distillate were infinitesimal, i.e., the cut approaching zero. For a cascade stage with a finitc cut value, the two concentrations which are important and measurable are those of the product and reject streams. As the feed stream flows through an ideal stage and is partially evaporated, it becomes progressively depleted in $\mathrm{K}-39$ until the residue is finally discharged as the reject stream. While equation 7 gives the ratio of 
DWG. NO. G-65-518

PRODUCT RESERVOIR
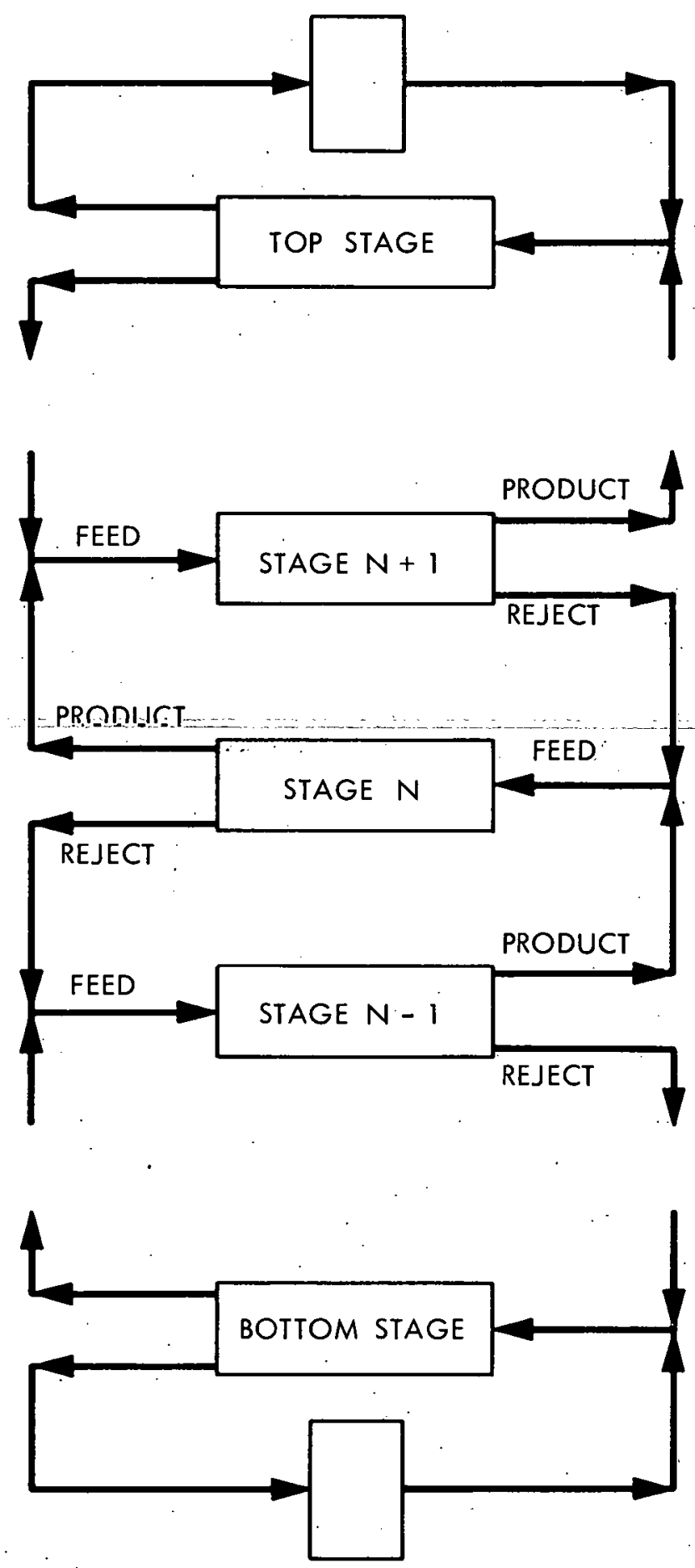

TAILS RESERVOIR

Figure 2

CASCADE STAGE ARRANGEMENT 
isotopic ratios at each point along the flow path, it does not apply to the actual concentrations in the two streams leaving the stage. The corresponding ratio can be calculated for the overall stage by applying to $\alpha$ a cut correction factor:

$$
\Psi \doteq(\alpha-1)\left[\frac{1}{\theta} \ln \frac{1}{1-\theta}\right],
$$

where $\Psi$ is a stage separation factor:

$$
\Psi=\left[\begin{array}{ll}
\left(\frac{\mathrm{C}_{39}}{\mathrm{C}_{41}}\right) & \text { Product stream } \\
\left(\frac{\mathrm{C}_{39}}{\mathrm{C}_{41}}\right) & \text { Reject Stream }
\end{array}\right]-1
$$

The bracketed quantity in equation 8 , the cut correction factor, represents a multiplier greater than unity for all values of $\theta>0$; actual values are plotted in figure 3. It is apparent, therefore, that the degree of separation performed by a properly designed cascade stage will exceed that calculated by equation 4 for any single point within the stage. For a cut of one-half, equation 8 shows that

$$
\Psi=1.386(\alpha-1) \text {. }
$$

Note in figure 3 that as $\theta$ approaches unity the overall stage separation factor becomes much larger; this fact is the basis of high-cut separation testing, or Rayleigh distillation, to be discussed later.

Since evaporation is occurring only from the surface of the molten potassium and since $\mathrm{K}-39$ is evaporating at a higher rate than $K-41$, it is apparent that the surface layer can quickly become depleted in K-39 unless it is replenished by mixing the surface layer with the body of metal underneath it by diffusion or by turbulence. If surface depletion of $\mathrm{K}-39$ does occur due to poor liquid mixing efficiency, the stage separation factor will be reduced below that calculated by equation 10. These losses can be minimized by using a relatively shallow depth of metal and by eliminating stagnant arcan within the otage.

The method which is used to determine the optimum operating temperature of a molecular distillation cascade can now be outlined. As indicated previuusly, the important quantities in the operation of a cascade are the stage separation factor $\Psi$ and the interstage flow rate, designated by I. From the theory of cascades, it can be shown that the operating conditions which minimize the size of a cascade with stages of fixed area will maximize the product

$$
\Psi^{2} I
$$

which is directly proportional to the separative capacity of a stage. Under these conditions, the power supplied to the cascade performs the maximum amount of separative work. 
Both $\Psi$ and $\mathrm{L}$ are functions of the evaporating temperature, but while the variation of $\mathrm{L}$ with temperature can be estimated by the Langmuir equation (see figure 1 ), the variation of $\Psi$ with temperature is not known. Two experimental approaches are possible:

1. Construct a single stage molecular still and determine how $\Psi$ varies with temperature at total reflux, assuming that $\mathrm{L}$ is correctly given by the Langmuir equation or measuring $\mathrm{L}$ experimentally.

2. Construct a short cascade containing several stages, measuring $\Psi$ and $\mathrm{I}$ directly at various temperatures.

While the first approach should yield the required data at lower cost, several advantages strongly recommend the multistage experimental approach in firmly establishing the feasibility of the process. First, the overall degree of separation is increased in a multistage distillation, which decreases the effect of analytical error and improves the precision of the single stage $\Psi$ measurement. This was an important consideration at the start of the experimental work, since the precision of mass spectrometric analyses on potassium by the method available at that time was not high. The multistage approach also offers the opportunity of designing and testing the operation of cascade scale stages and auxiliary equipment, with the result that the conditions are tested and optimized on the same type equipment which would be used in a production facility. The added value of obtaining construction and maintenance cost data as well as operating experience on such a facility led to the decision to adopt this approach to the problem.

There remains a consideration of the processing of analytical data from a multistage experiment to obtain the single stage $\Psi$ value for the test conditions. Equation 9 represents the Fenske relationship for a single stage; for $j$ stages operated at total reflux, the corresponding isotopic ratio comparing the product from the $j$-th stage with the reject from the first stage is simply

$$
(\Psi+1)^{j}=\frac{\left(\frac{C_{39}}{C_{41}}\right)}{\left(\frac{C_{39}}{C_{41}}\right)} \text { Product } \text { Reject }
$$

The isotopic concentration ratio is obtained directly by mass spectrometric analyses of the two samples. In logarithmic form, equation 12 is

$$
\log S=j \log (\Psi+1) \text {, }
$$

where $S$ represents the ratio of concentration ratios in equation 12 . If the values of $\log S$ for various stages of the cascade are plotted as functions of the stage number $j$, a straight line will be obtained whose slope is $\log (\Psi+1)$. By measuring $S$ for various stages along the cascade, all referred to the first stage reject concentration, and obtaining the 
slope by least squares treatment, an average value of $\Psi$ can be found much more accurately than from a single value of $S$ measured from the top to bottom stages.

The intercept of equation 13 is the origin, as it must be if all stages are identical. It is possible to operate the bottom stage at total reflux in a non-typical fashion which requires a cut correlation to the values of $S$ referred to the stage 1 reject concentration. This correction will be treated later. 
PRELIMINARY EXPERIMENTS

Previous work at ORGDP on the separation of the lithium isotopes by molecular distillation of the metal provided valuable background data on the potassium process. In particular, the decision was made to adopt the same type of design for the lower surface of the condenser section, in which the surface is covered with a series of thin metal channels bent down at one end. These channels serve to hold the liquid condensate on the lower surface of the condenser and to convey it by gravity to one edge where it can be collected for transfer to the next higher stage. Undesirable reflux within a stage is thereby minimized and the design allows use of a much flatter condenser surface than would be possible otherwise. Before attempting the design of a multistage distillation experiment, however, several problems involved in the design had to be solved. These were:

1. What fraction of the theoretical separation factor of 1.0253 could be expected, using an evaporator-condenser spacing of practical proportions in the temperaturo range of $200^{n}$ to 300 C.? This influences the choice of the number of stages which would be most useful in the experiment.

2. What set of dimensions for the condenser conveying channels would serve the potassium process requirements? From the lithium distillation experience it was known that the condensate surface tension, density, and wetting properties affect this choice.

3. By what technique could the interstage flow of potassium, I, be measured or estimated in a multistage assembly?

To provide answers to these questions, three preliminary experiments were carried out.

\section{RAYLEIGH DISTILIATIONS}

A valuable method of measuring small distillation separation factors is through use of the Rayleigh technique. Briefly, this involves the use of a high cut batch evaporation to increase the overall separation and improve the accuracy of measurement. Figure 3 shows that the residue of a batch evaporation becomes strongly depleted in the lighter component as the evaporation approaches completion, the equivalent of several stages of separation being obtainable.

For the present purpose, Rayleigh distillations were carried out by evaporating weighed quantities of potassium at constant temperature under vacuum conditions, using a closely spaced condenser, until only a small residue remained. The residue was carefully weighed and assayed with respect to the original charge assay to determine the separation ratio $\mathrm{S}$. The weights of the original charge and small residue then determine the 
DWG. NO. G-65-515

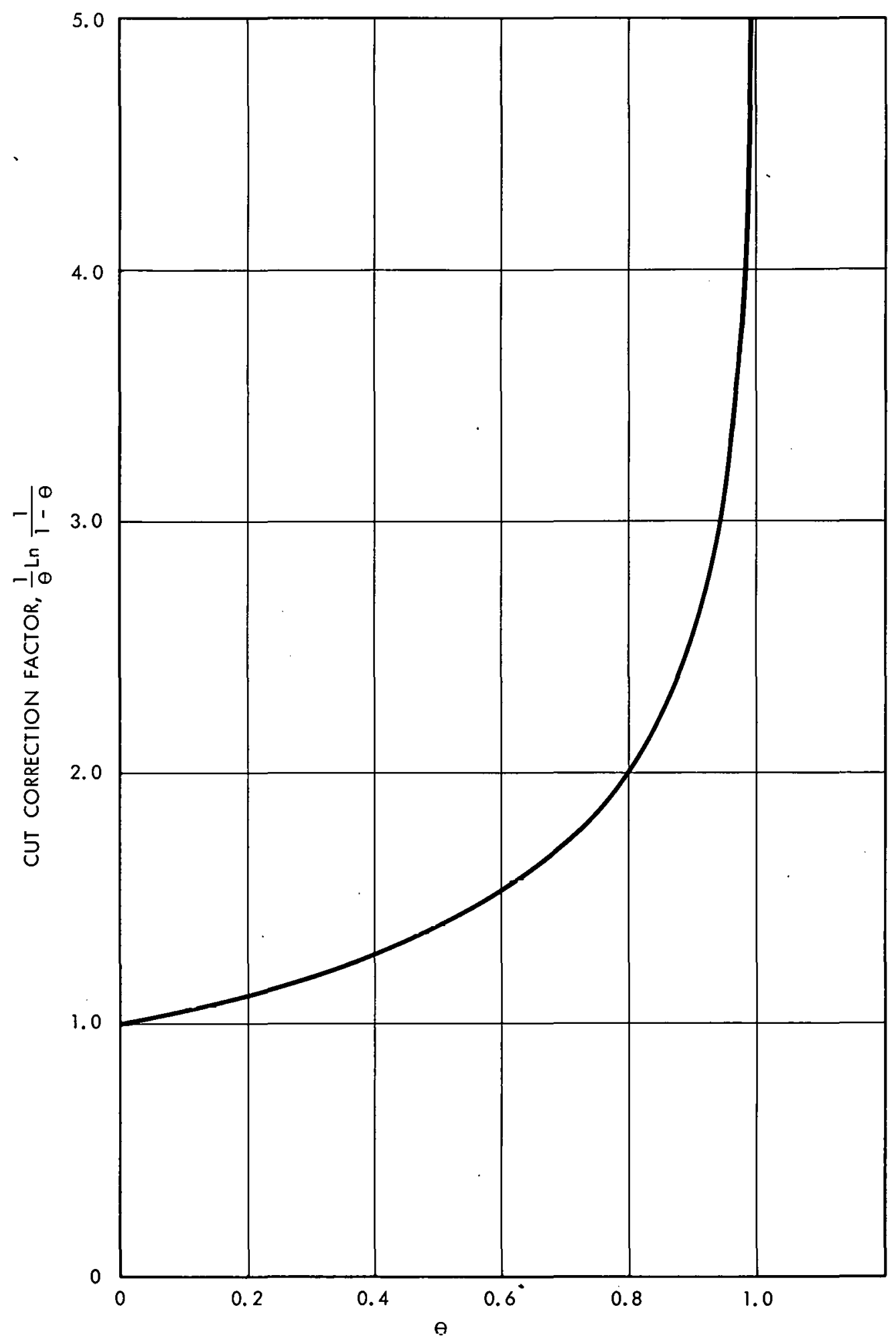

Figure 3

CUT CORRECTION FACTOR 
effective cut $\theta$, from which the single stage point separation factor $\alpha$ is calculated by the Rayleigh equation. This is a form of the cut correcting equation adapted to batch evaporation:

$$
(\alpha-1)=\frac{\log S}{\log \left[\frac{\frac{1}{\theta}(s+14)}{15 s}\right]}
$$

The constants in equation 14 apply to the case of distillation of normal potassium metal only.

Apparatus. A small Rayleigh still for molecular distillations was constructed as shown in figure 4. It consisted of a small, electrically heated stainless steel cup with a conical bottom and equipped with a thermocouple. The flat condenser plate was spaced about $1 \mathrm{~cm}$. above the top of the cup and was cooled by circulating ice water. A glass dome allowed the assembly to be operated in a vacuum while the progress of the evaporation was observed.

The cup was charged with 11 to $17 \mathrm{~g}$. of pure potassium metal, transferred either under vacuum or an inert gas to avoid formation of oxide or hydroxide scum on the surface. An accurate weight was obtained using an analytical balance after removal of a few milligrams for isotopic analysis. The still was then assembled in a dry box, evacuated with a diffusion pump, heated quickly to the desired test temperature, and the evaporation observed until only a small residue remained. The distillate collected as a solid on the condenser. The residue was rapidly cooled and weighed with an analytical balance before isotopic analysis.

Data obtained by this procedure are summarized in figure 5, where point separation factors obtained from the Rayleigh equation are shown as a function of the evaporation temperature. Bars about the points indicate the limits of uncertainty associated with the isotopic analyses; the improved precision obtained by a revised analytical technique described in Appendix $B$ is shown here. A maximum temperature of $285^{\circ} \mathrm{C}$. was attainable with the electrical heater used in this still. Cut values illustrated here varied from 0.950 to 0.982 . As was expected, the separation values decreased with increasing temperature, though no well-defined relation can be established from these data. With the exception of the single point at $285^{\circ} \mathrm{C} .$, all of the separations were over $60 \%$ of the theoretical value and every distillation showed enrichment of $\mathrm{K}-39$ in the distillate as predicted theoretically.

These data demonstrate the feasibility of the process for potassium and show that an adequate fraction. of the theoretical separation factor can be attained experimentally. It is not feasible, however, to employ this Rayleigh still exclusively to obtain the required variation of separation factor with temperature, particularly since the collection of condensate as a solid is not representative of the condition which must be met in a multistage still. Nor is it practical to redesign the still to simulate very many stages of separation, since, as figure 3 shows, this requires 


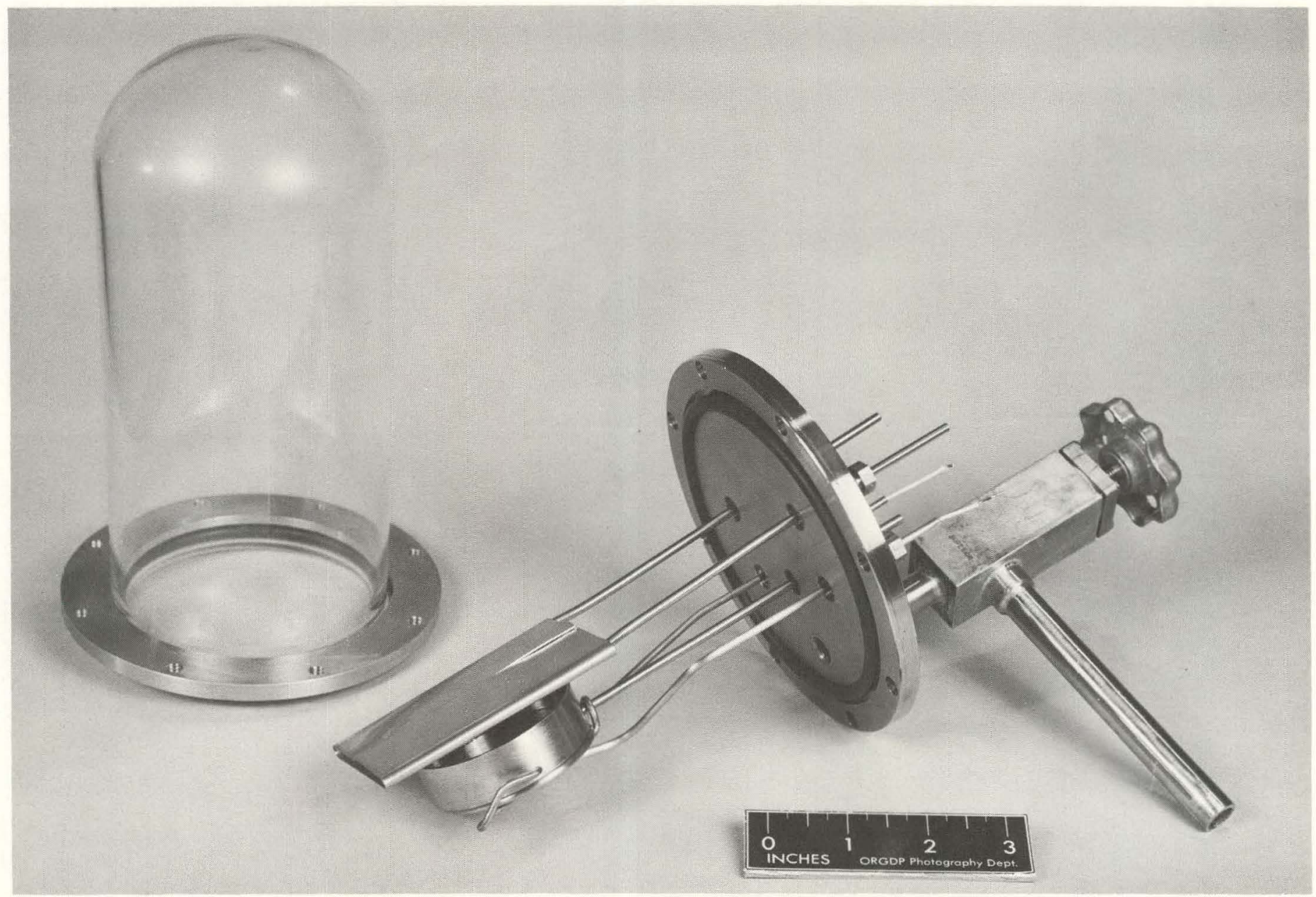

Figure 4

RAYLEIGH STILL 
DWG. NO. G-65-509

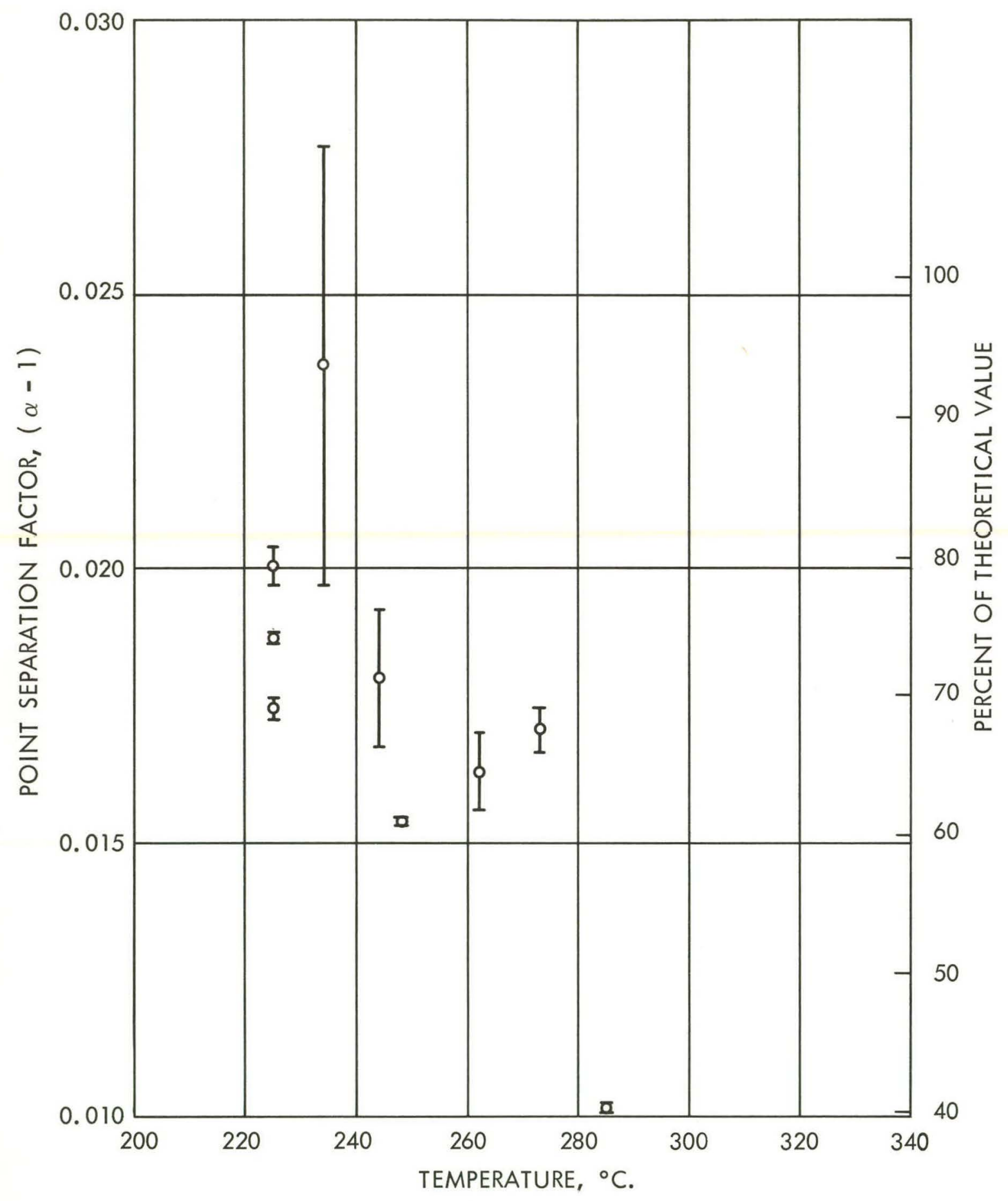

Figure 5

VARIATION OF SEPARATION FACTOR WITH TEMPERATURE

FROM RAYLEIGH EXPERIMENTS 
values of $\theta$ very near unity which must be determined with great accuracy. WETTING EXPERIMENTS

The experience with the lithium molecular stills indicated that the design of an economical cascade depends strongly on the ability to collect the metal condensate from the flat condensing surface completely and convey it properly by gravity to the feed point of the next cascade stage. Expensive interstage pumps are unnecessary with this arrangement. As noted earlier, these problems were successfully solved in the lithium still by using channels on the condenser surface which retained the metal by surface tension; the channels were curved down over distillate collection troughs and the wetted surface at a lower level provided a force which drew the metal off the condenser efficiently. It was proposed to use a similar arrangement in the potassium still, but since potassium differs from lithium considerably both in surface tension and density, experiments were indicated to verity that potassium could be collected and transported the desired distance with the small liquid head produced by molecular distillation.

Apparatus for conducting these tests was similar to that of the Rayleigh distillations, except that a rectangular cup was used to hold the potassium and the condensing surface was cooled by a nitrogen gas stream so that the condensate would remain liquid. Wetting tests were conducted by suspending small strips of various metals vertically in the potassium cup and observing the meniscus at the contact surface. Channel flow tests were made by constructing model condensers with channels of various depths and widths and observing how reflux flow occurred on wetted surfaces.

The Liquid Metals Handbook (4) suggests a number of metals suitably resistant to attack by molten potassium in the temperature range of interest, i.e., below $400^{\circ} \mathrm{C}$. Stainless steel was given special consideration for construction since it is also resistant to atmospheric corrosion at high temperatures, though its poor thermal conductivity poses problems of heat transfer. The wetting properties of potassium on a number of possible metals of construction were tested as a function of temperature. Samples of copper, aluminum, steel, titanium, nickel, stainless steels, and Inconcl were examined; all of these metals were wetted if lite lemperature had been raised to $250^{\circ} \mathrm{C}$. or higher. None were wetted in a short period of time until they had been conditioned by exposure to potassium at this temperature, but once wetted they retained this property at lower temperatures.

It was also found that a flat stainless steel condenser surface, with or without conveying channels, would collect condensing potassium in discrete droplets unless it had been conditioned at $250^{\circ} \mathrm{C}$. or higher. Such droplets grew until they fell back into the evaporator pool instead of being curlducted to one edge of the condenser as desired. When the condenser surface was wetted, however, the condensing potassium collected in a smooth film which was conducted off the surface by conveying channels. It was found that channels about $1 / 8$-inch deep and about $1 / 2$-inch wide spaced 
on l-inch centers would be adequate to collect and convey the potassium. Without channels present, a condenser slope angle of $10^{\circ}$ or more was found necessary to cause the condensing potassium to flow to one edge. Such a large slope is undesirable as it involves an evaporator-condenser spacing which is not constant.

\section{TEST STAGE}

Several design features remained to be resolved. First, it was necessary to evaluate methods of estimating the interstage flow of potassium, I. It was also highly desirable to know how accurately the theoretical evaporation and power curves shown in figure 1 describe the actual case, and to verify the efficiency of the condenser collecting channels on much larger condenser surfaces than those just described. Finally, it was necessary to develop an evaporative cooling system to maintain the potassium condenser at the desired temperature. Air cooling was used in the lithium stills, but the low condenser temperatures required for the potassium still, $150^{\circ}$ to $200^{\circ} \mathrm{C}$, do not provide enough temperature differential to transfer the heat flux at reasonable air flow rates. To resolve these problems, a small test stage was constructed whose design was primarily aimed toward testing methods of measuring potassium flow and transporting the liquid rather than measuring separating efficicney.

Construction. The test unit which was designed and constructed contained approximately 2 sq.ft. of evaporating surface; it measured 1 foot wide and 2 feet long externally. A cross section sketch is shown in figure 6, with views of the evaporator and condenser during assembly shown in figures 7 and 8 . The evaporator section contained baffles welded to the bottom as shown which directed flow of potassium along a folded path 24 feet long and 1 inch wide. A raised trough ran along the back edge to collect condensate drained from the separate condenser surface; the condensate then flowed by gravity through an external reflux loop of $1 / 2$-inch tubing and returned to the evaporator at one edge. Lucite-flanged pots were provided at each end of the evaporator section to allow measurement of the liquid depth and to permit withdrawing metal samples for isotopic analysis. The condenser consisted of a box-like structure which contained the evaporative coolant; the bottom surface shown in figure 8 served as the potassium condenser and was supplied with conveying channels which dropped at one edge to drain the metal into the collection trough. The 2-inch diameter vacuum line is also partly shown in figure 8. Evaporatorcondenser spacing was 1 inch in this still.

Construction of the still was of type 304 stainless steel; an aluminum gasket was used to seal the two sections together. Heat was supplied to the still by means of flat ceramic furnace forms containing coiled Nichrome wire heating elements. A l/2-inch thick aluminum plate was orginally placed between the heating element and the still bottom in an attempt to attain a uniform heating surface next to the stainless steel. The heaters were fed from a 208-volt 3- $\phi$ circuit equipped with Powerstat controls and an accurate wattmeter. The still was evacuated by an oil diffusion pump with liquid nitrogen cold traps and a Welch 1397-B backing pump. Ion 


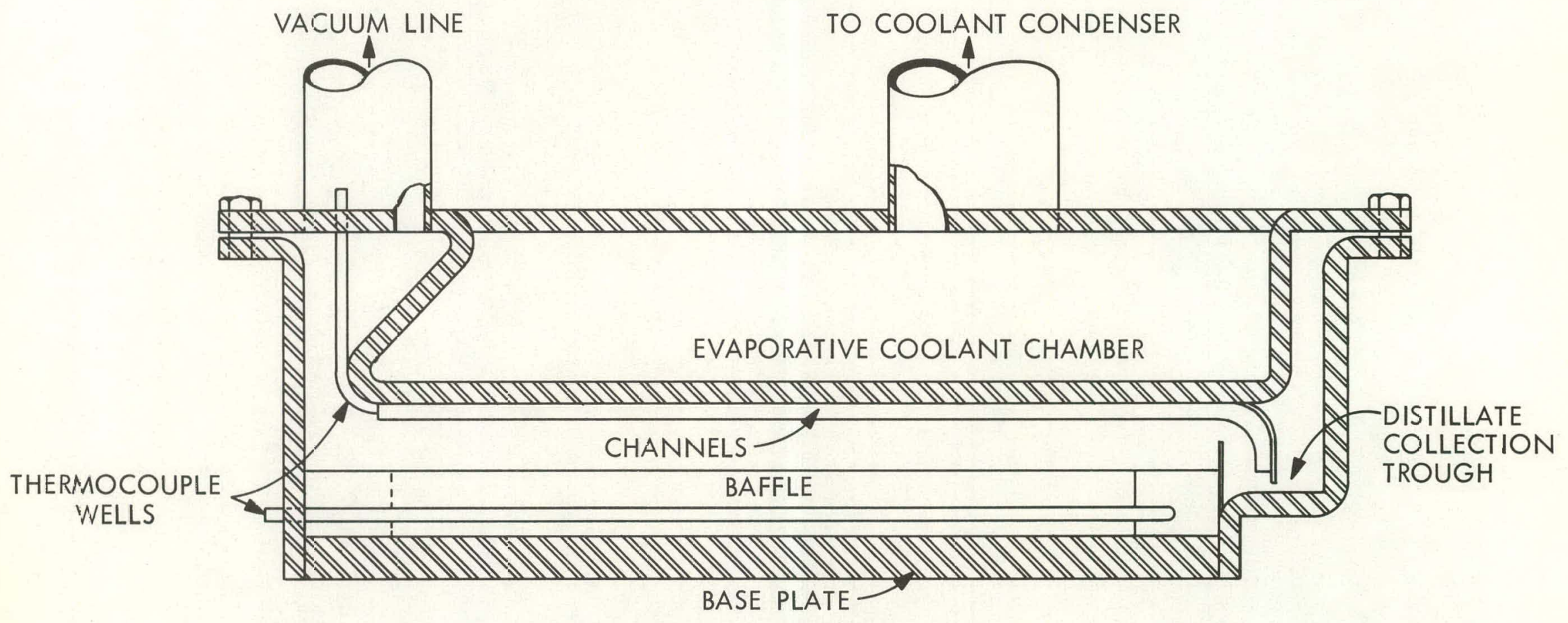

Figure 6

CROSS SECTION OF TEST STAGE 


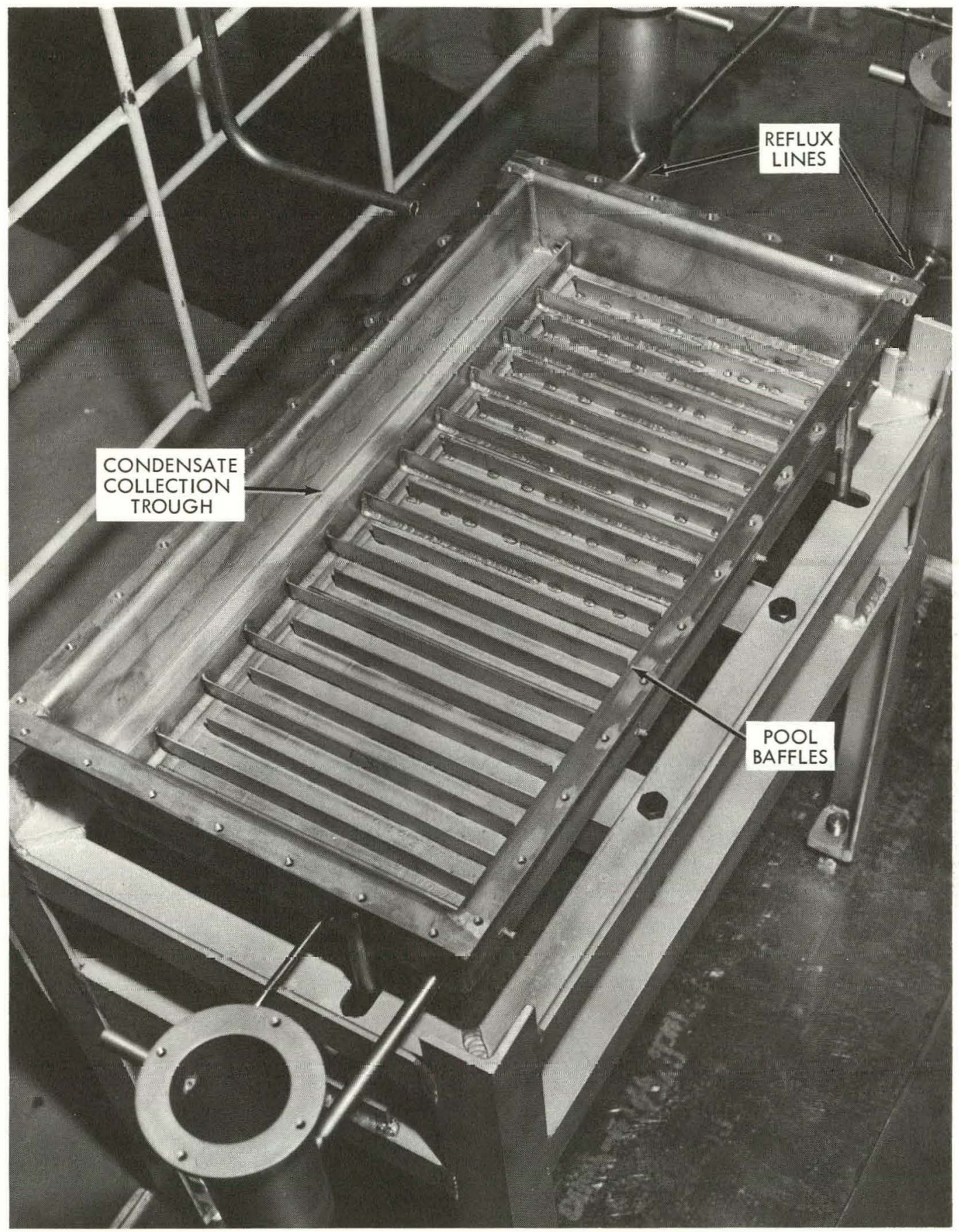

Figure 7

TEST STAGE EVAPORATOR SECTION 


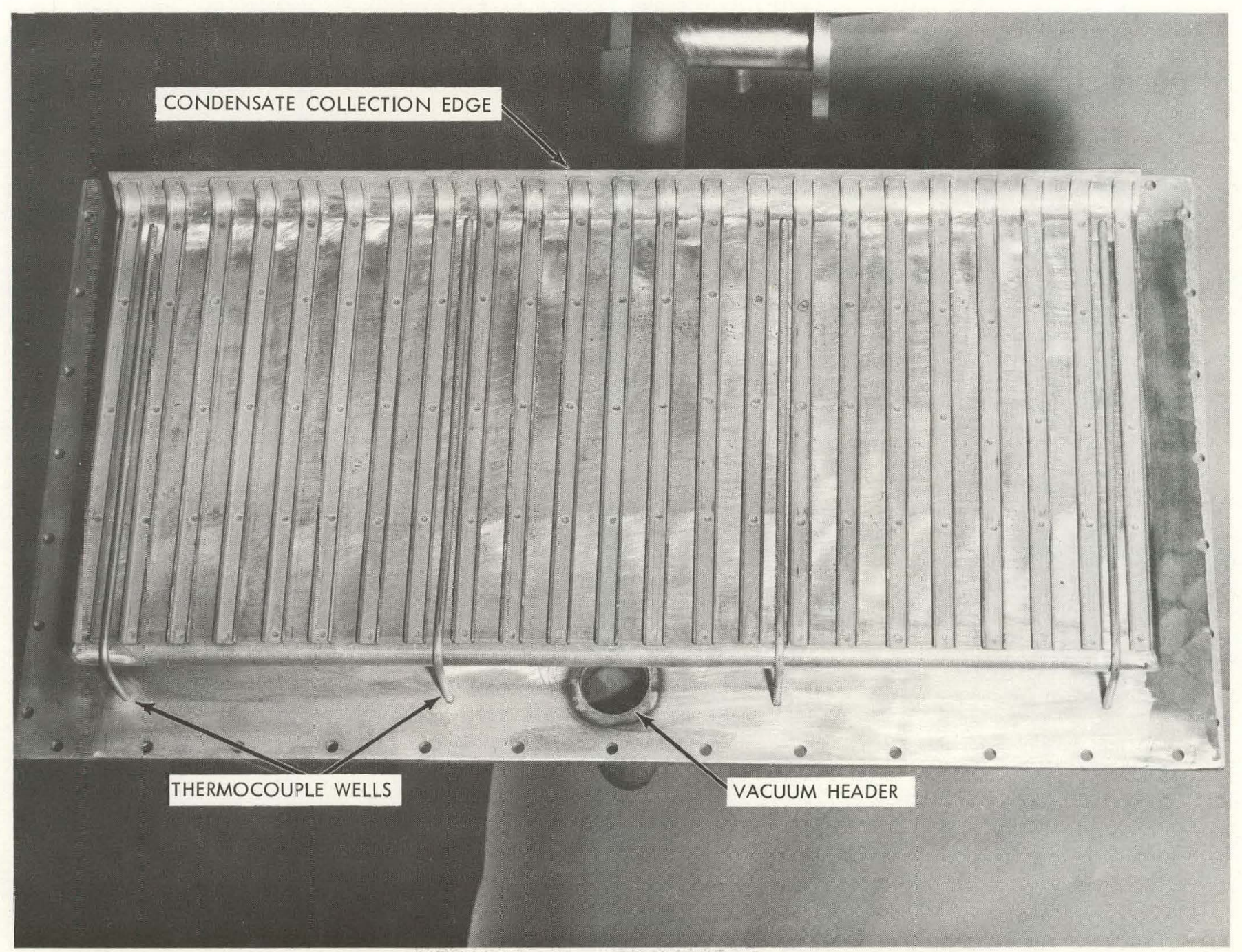

Figure 8

TEST STAGE CONDENSER SECTION 
gages were used to measure the residual gas pressure in the still. The evaporative coolant boiled off the potassium condenser was carried through a 2 -inch diameter vapor line to a 6 -inch diameter vertical condenser cooled with circulating water. The reflux from the coolant condenser passed through a flowmeter and then returned to the potassium condenser system. The evaporative coolant originally used in the condenser was biphenyl, a heavy hydrocarbon melting at about $70^{\circ} \mathrm{C}$. and boiling at $255^{\circ} \mathrm{C}$. Being a hydrocarbon, it is unreactive toward potassium and a coolant leak would not cause an explosion. However, the necessity of using heated transfer lines to avoid solidification and of operating the biphenyl system at low pressure, about 30 torr, to obtain a $150^{\circ}-\mathrm{C}$. boiling point, led to the replacement of biphenyl by xylene. Xylene, or dimethylbenzene, is also inert toward potassium, is a liquid at room temperature, and the usual isomeric mixture boils at about $140^{\circ} \mathrm{C}$., so that atmospheric pressure can be used in the coolant system. It is somewhat more flammable than biphenyl, but since the coolant system can be closed this is not a serious detriment. An electromagnetic flow meter was placed on the $1 / 2$-inch potassium reflux line to measure flow rates. This meter employed a nominal 8250-gauss permanent magnet. The entire still assembly before insulation is shown in figure 9.

'l'he unit was equipped to correlate four factors with the temperature of operation, viz., the power input, the reflux rate of the evaporative coolant, the reflux rate or boilup rate of the potassium, and the pressure head of liquid metal across the 24-foot path in the evaporator caused by the potassium evaporation. Metal samples could also be withdrawn from the still for analysis, though this was not a primary objective of its operation.

Operation. The still was charged to a depth of about 0.25 inch with high purity potassium obtained from MSA Research Corp. With an atmosphere of argon to suppress evaporation of the potassium, a power level of less than 300 watts was required to sustain a $250^{\circ} \mathrm{C}$. temperature. The system was then pumped to a residual gas pressure of about $2 \times 10^{-6}$ torr and the power input increased as evaporation of the potassium began. Data were taken at a number of different power input levels, recording the xylene coolant reflux rate and the rcflux rate of potassium as indicated by the electromagnetic flowmeter. At each power level temperature surveys were made of the evaporating pool of metal with a thermocouple probe and metal depth measurements were made with probes through vacuum locks on the pots at each end of the evaporator.

These data quickly indicated that several modifications would be needed. Temperature distributions over the metal pool were poor, and examination showed that the aluminum heat distributor plate had warped sufficiently to make poor contact with the still bottom. Much improvement was noted when this plate was removed and the heating elements clamped directly to the base plate of the evaporator.

Flow data from the electromagnetic flowmeter also indicated a defect. A signal of about $60 \mu \mathrm{V}$ could be obtained at $2 \mathrm{kw}$. power input to the still, 
PHOTO NO. PH-65-710

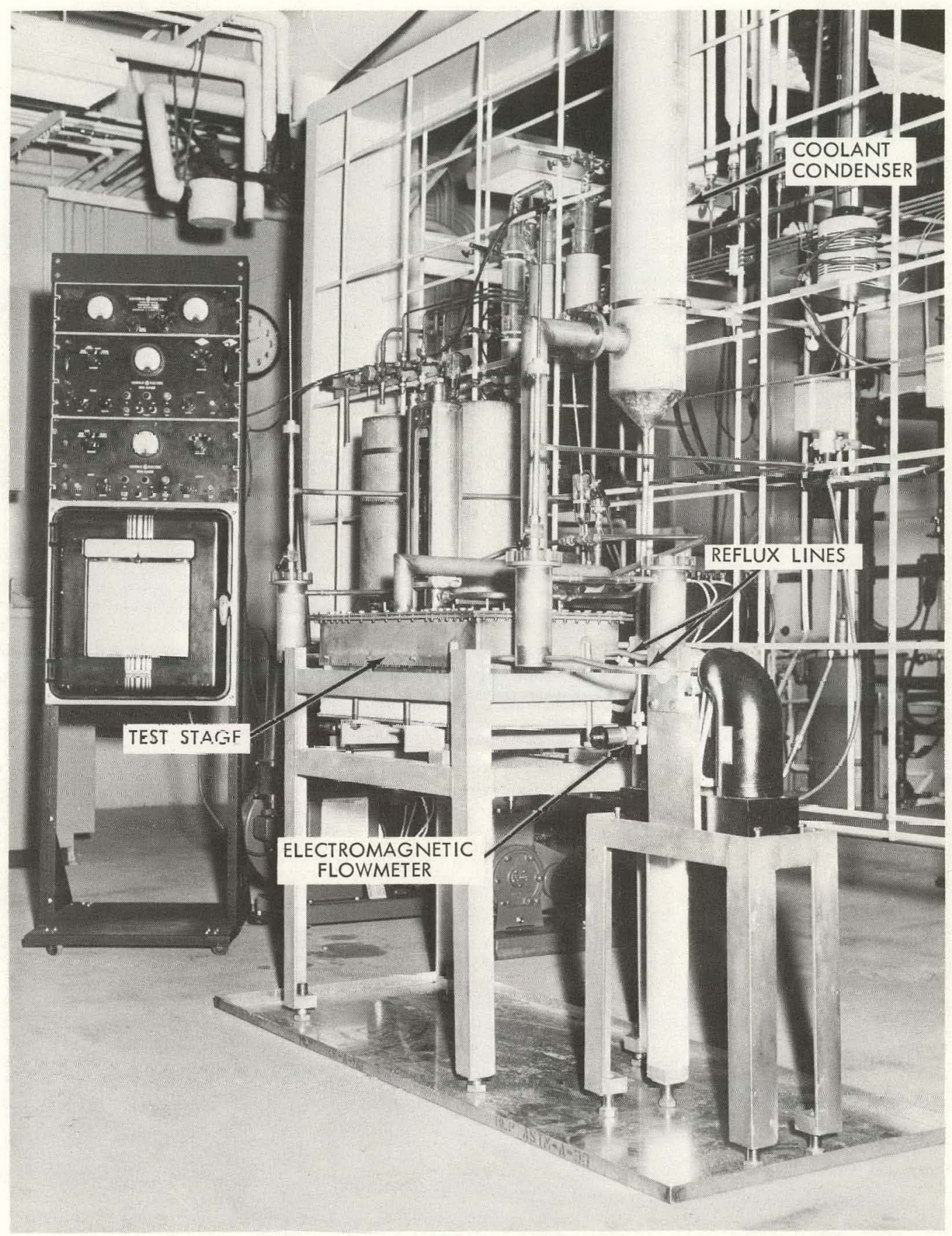

Figure 9

TEST STAGE ASSEMBLY 
but the signal did not change at higher power levels. It appeared that the liquid head of 0.5 -inch of potassium was not sufficient to force more than about $70 \mathrm{cc} / \mathrm{min}$. potassium through the reflux line; excess distillate above this rate was apparently accumulating in the collection trough and overflowing within the still. To correct this effect, a new reflux line was constructed containing a thermal pump or thermal siphon in addition to the electromagnetic flowmeter stubs. The thermal pump is essentially a U-tube, one leg of which is heated, the other cooled. The difference in density of potassium at the two temperatures generates a small but useful additional head of liquid metal. This unit can also function as a thermal flowmeter if it is well insulated and measurements are made of the power input to the heated leg and the corresponding temperature differential generated. A check of the potassium reflux rate is thus obtained independently of the electromagnetic flowmeter.

The new reflux return line was installed with compression fittings while the remainder of the still was filled with potassium. On cleaning up the old line, a loose sampling tip which was being tested for removal of isotopic samples was found in the level pot. Had this tip been lodged. across the reflux line opening to the pot, it would have produced the flow restriction noted.

Final runs were made on the modified unit at electrical power input rates to $12 \mathrm{kw}$. for extended periods and for a short period at $14 \mathrm{kw}$. Measurementís were made at each power level of the xylene reflux rate, the electromagnetic flowmeter output, and the temperature differential and heat input data for the thermal pump. It was possible at all power input levels tin adjust the thermal nump until the eleclromagnetic flowmeter began to show a cyclic flow pattern, indicating that the siphon was draining the distillate collection trough completely. Under such conditions, all of the potassium carried into this trough by the potassium condenser should have been measured by the two flowmeters.

The data obtained in these runs are summarized in figures 10 and 11. These figures do not include some fragmentary data taken at the 14-kw. power level. Operation of the unit was satisfactory at this power levcl, but sustained opcration could not be realized because of overloading of the building power distribution circuit used to supply the heating elements.

Figure 10 illustrates the correlation of electrical power input with the measured xylene reflux rate which has been converted into equivalent kilowatts of power by use of the mean heat of vaporization of xylene. The deviations at high power input rates apparently indicate greater than 100\% power efficiency, but are actually due to some entrainment of liquid xylene in the vapor stream. This effect is insignificant at low boiling rates, but becomes more serious at high power dissipation rates. Design of the condenser system for the multistage unit was made to reduce these entrainment effects.

Figure 11 illustrates the correlation between the electrical power input and the reflux flow of potassium, again expressed in equivalent kilowatts 


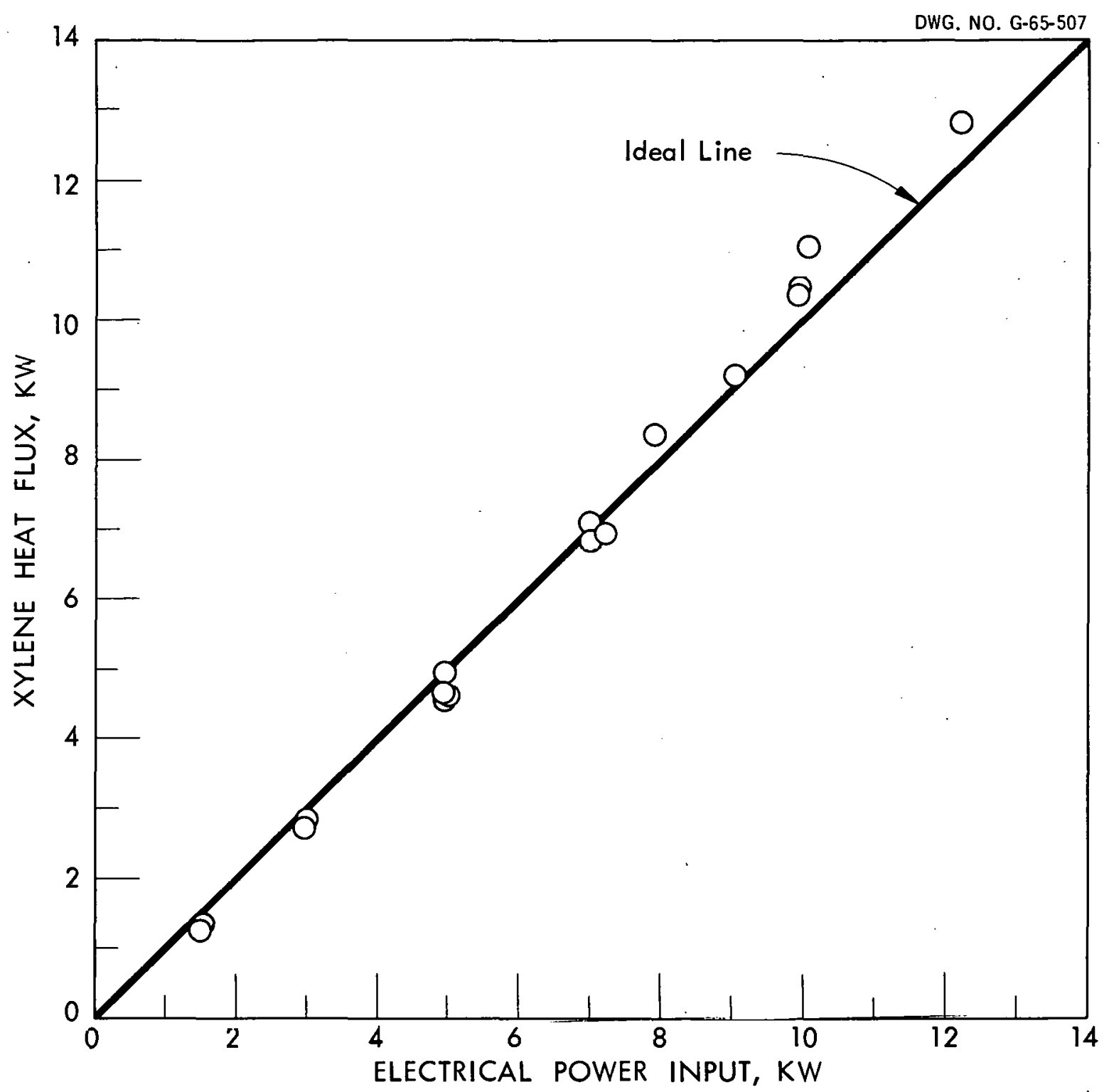

Figure 10

CORRELATION OF COOLANT BOILUP WITH POWER INPUT 


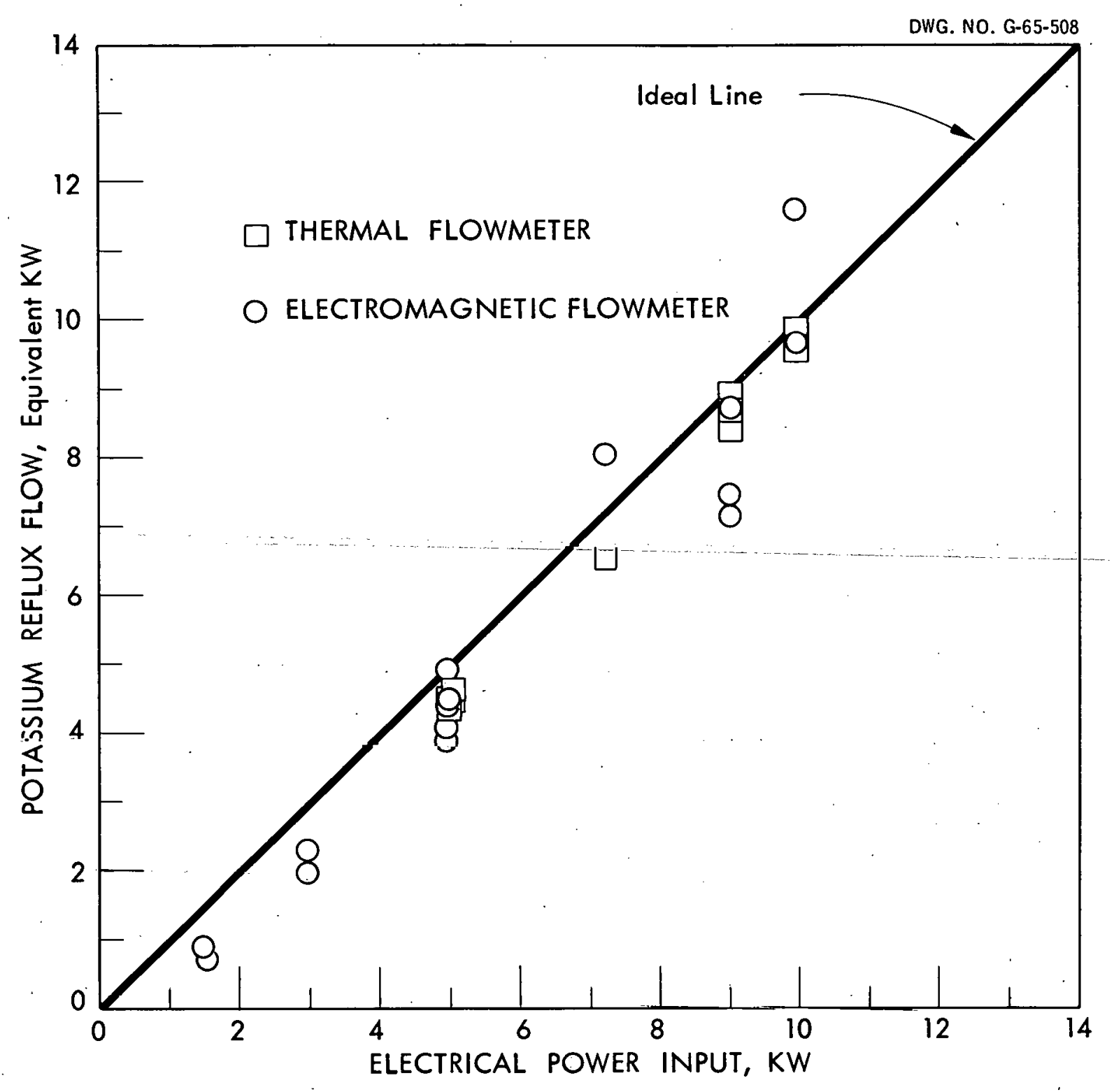

Figure 11

POTASSIUM CONDENSER PERFORMANCE DATA 
absorbed in vaporization, as measured by the electromagnetic flowmeter and by the thermal pump operating as a thermal flowmeter. These points indicate a satisfactory relationship between the amount of potassium evaporated, i.e., power input, and potassium collected by the condenser and returned through the reflux line. Under these conditions, the condenser must have been transporting the distillate with high efficiency and not permitting any appreciable amount of potassium to drip back into the metal pool. Scatter in the flow data for the electromagnetic flowmeter is about normal for this type instrument at these flow rates.

At $250^{\circ} \mathrm{C}$. the differential pressure of metal across the length of the evaporator was about $1 \mathrm{~mm}$.; the flow rate into the evaporator was about $77 \mathrm{~g} . / \mathrm{min}$. at this time. Metal samples were periodically withdrawn from the distillate for isotopic analysis and were referred to the isotopic ratio of a sample removed from the reject end of the still where the evaporating pool was stagnant. Samples removed after 8.0, 25.5, and 38.0 hrs. of operation at $250^{\circ} \mathrm{C}$. had isotopic ratios, $\mathrm{S}$, of $1.038,1.044$, and 1.046 respectively. These enrichments are higher than a theoretical single stage effect because this still actually operates as a high cut Rayleigh still whose cut cannot be readily measured. Potassium-39 was enriched in the distillate.

\section{CONCLUSIONS}

The results of the three preliminary experiments just described can be interpreted in terms of the influence they have on the design of the multistage experiment.

1. The data from the Rayleigh distillations show that the predicted isotopic separation does occur and that an adequate fraction of the theoretical separation factor is attainable in a temperature range where the size and shape of production cascade equipment wold d assume practical proportions.

2. A wide choice of materials of construction is available which would be suitable for the temperature range of interest insofar as wetting and resistance to attack by molten potassium are concerned. Other fuclur's such as structural strength, thermal conductivity, and outgassing characteristics can be used to select the best material. Wetting will require a conditioning pretreatment at $250^{\circ} \mathrm{C}$.

3. The successful operation of the test stage showed that the potassium condenser design, including the conveying channels, was adequate to collect and transport condensate at rates up to the maximum tested value of $0.5 \mathrm{lb} . / \mathrm{min} .-\mathrm{sq}$.ft., equivalent to anl evaporator temperature of about ' $293^{\circ} \mathrm{C}$.

4. Power input densities up to $8 \mathrm{kw} . / \mathrm{sq}$.ft. and operation to $300^{\circ} \mathrm{C}$. can be sustained in a flat stainless steel still with electrical resistance heaters. 
5. Distribution of potassium pool temperatures is satisfactorily uniform at power densities up to $8 \mathrm{kw} . / \mathrm{sq}$. ft.

6. Heat losses from the evaporator can be reduced so that a large fraction of the electrical power expended is consumed in evaporating potassium metal.

7. The evaporation rate of the potassium, and consequently the interstage flow in a multistage unit, can be satisfactorily estimated by measuring the reflux rate of the evaporative coolant. It should be noted that since a distribution of temperatures does exist in the metal pool, the measured evaporation rate of potassium actually should correspond to an averaged evaporator temperature. It may be asked why electrical power input is not used as a suitable measure of interstage flow, especially in view of the good correlation between power input and xylene reflux rate shown in figure 10 . While it would indeed be satisfactory for an isolated stage such as the one tested here, it could not be used effectively in a multistage unit because of the differences in heat losses in various stages due to the presence or absence of adjacent hot stages. Balanced stage powcr input levels would therefore not imply balanced interstage potassium flows. In the type of stage design tested, evaporation and condensation of potassium is overpoweringly the predominant mechanism by which heat is transferred from the evaporator into. the xylene coolant; the low thermal conductivity of the stainless steel walls suppresses conductive transfer, while the low absolute temperature differences and the poor emissivity of the mirror-like potassium surfaces make radiative transfer inefficient.

8. Use of the thermal pump on the modified reflux return line made it possible to extend the flow range of the unit as well as provided for independent measurements of potassium flow rate.

9. Finally, installation of the revised reflux line demonstrated that some maintenance could be satisfactorily performed on a tray containing potassium metal.

Several other features of the test stage operation indicated the need for modifications in further work:

1. Substitution of xylene for biphenyl as the evaporative coolant to allow operation of the condenser system at much higher heat dissipation loads.

2. Observation of the entrainment error which can arise in the measurement of xylene reflux flow at high heat dissipation loads.

3. Improvement in the uniformity of potassium pool temperatures resulting from the elimination of the aluminum heat distributor plate. 
The information obtained from these preliminary experiments was combined with the previous experience with the lithium molecular stills to design a multistage molecular distillation experiment, Modex, for the purpose of obtaining the necessary operating data for cascade design. 
MULTISTAGE EXPERIMENT - MODEX

\section{DESIGN}

The Modex still was designed to obtain the required separation and interstage flow data in the temperature range of $200^{\circ}$ to $300^{\circ} \mathrm{C}$. A cascade of 10 stages was selected, based on the order of magnitude of the stage separation factor in this temperature range as shown by the Rayleigh distillations and information on the precision of mass spectrometric analyses for the potassium isotopes. A stage evaporating area of 3 sq.ft. was adopted as a median size generating measurable amounts of interstage flow at the lowest operating temperatures while not requiring too high an electrical power consumption to attain the upper temperature limit. Power requirements estimated from figure 1 change from 6 to $246 \mathrm{kw}$. over the $100^{\circ}-\mathrm{C}$. design temperature range, emphasizing the need for selecting a relatively narrow design range. The spacing between the evaporating and condensing surfaces was fixed at 0.75 inch as the shortest practical spacing consistent with the requirement that sufficient liquid head be available to draw the distillate off the condenser at its highest lnaring rate. Metal depth in the evaporating pool was chosen to be 0.25 inch, amounting to about I Ib. potassium per square foot of evaporating surface. This depth was also a compromise value, balancing the desirability of thin layers for good liquid mixing efficiency and short equilibrium time with the need for sufficient depth to assure that flow resistance in the liquid would not cause the lowest stages of the cascade to run dry. Since there was some uncertainty on this latter point, provisions were made for tilting the entire still to provide additional liquid head for interstage flow if needed.

Each stage of the still. was equipped with individual power supply and separate condensers with xylene reflux rate measurement to allow estimating and balancing interstage potassium flows at each stage. Examination of the square cascade outlined in figure 2 will show that if the cascade is operated at total reflux with the same product flow from each stage, then a stage cut of one-half is assured above the bottom stage regardless of the size of product flow. Provisions were made for the withdrawal of metal samples from the product stream of each stage and from the reject stream of the bottom stage to allow scanning the isotopic gradient in the still and determining the location of any defective stages.

The test stage just described showed that the condenser channel design was adequate for transporting the maximum condenser loading a distance of 12 inches to the collection edge. This dimension was retained in the Modex design, resulting in a rectangular stage shape of $1 \mathrm{ft}$. by $3 \mathrm{ft}$. Arranging such stages adjacent on the 3-ft. edge, with an odd number of liquid flow passes in the evaporator, makes the cascade arrangement relatively simple. There was a question, however, of putting all 10 stages in a single unit, since this would involve an expansion joint 
between the evaporator and condenser capable of absorbing a $100^{\circ}-\mathrm{C}$. differential thermal expansion over at least a 10-ft. length. To simplify this task, the cascade was designed as two 5-stage units called trays; this arrangement also permitted testing the concept of joining such units, without pumps, into stage groupings for production cascade operations. The top and bottom stages of the cascade require external means of circulating their product and reject streams, respectively, to obtain total reflux conditions with a cut of one-half in the bottom stage. Thermal pumps were designed for this purpose, with separate thermal flowmeters to be used for estimating the metal flow through the reflux loops.

Stainless steel 304I was used for all parts of the still contacted by potassium; however, the base plate of the evaporator section was made of $5 / 8$-inch thick ASTM-A285 steel plate clad only on the top side with a 1/16-inch layer of stainless steel. The thickness required for structural strength could thus be obtained without the sacrifice of thermal conductivity resulting from using solid stainless steel.

A tubular expansion joint was designed to absorb the differential thermal expansion between the evaporator and condenser sections, while allowing all-welded construction to assure vacuum tightness. This joint was open to all stages of a tray and consequently was also used as a vacuum header and as a point for inserting probes to obtain potassium samples.

An outline of the staging arrangement within a tray and a cross-section showing the collection channels and expansion joint are shown in figure 12. Note that since the trays contain an odd number of stages their internal arrangements are mirror images in order to shorten intertray. connections.

\section{CONSTRUC'PIOIN}

Five subassemblies were made during the construction of the Modex trays. The base support provides rigidity to the whole structure and maintains the flatness of the tray floor; the evaporator contains the heating elements and base plate with all the liquid pool baffling required for staging of liquid flows; the potassium condenser contains the evaporative coolant and distillate conveying channels; an expansion joint seals the condenser to the evaporator and is also a vacuum header; while the xylene condensers transfer process heat to the cooling water and provide for reflux rate measurements.

Base Support. A photograph of one of the base support subassemblies is shown in figure 13. The structure consists of three 6 -inch steel I-beams supporting 18 steel pads whose surfaces were machined to within \pm 0.005 inch of a plane after stress relief. These pads support the base plate of the evaporator section through leg assemblies shown in exploded view on one edge of the table in figure 13. The stainless steel disc is attached to the base plate leg and is clamped to the base support pads between a Graphitar ring and pad such that the legs can slide horizontally to accommodate thermal expansion, but are allowed only a few mils of 
DWG. NO. G-65-488
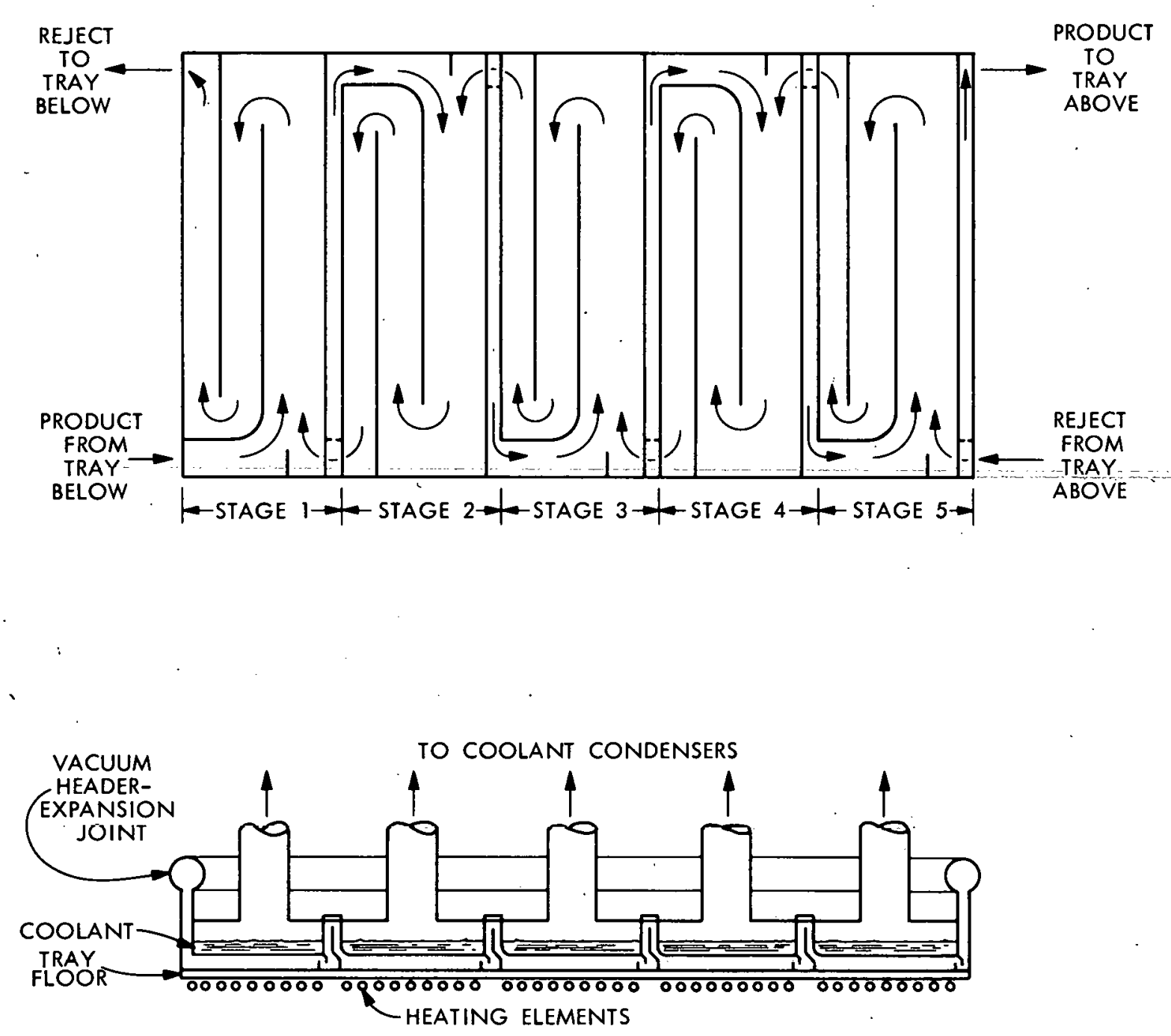

Figure 12

PLAN AND SECTION OF A MODEX TRAY 


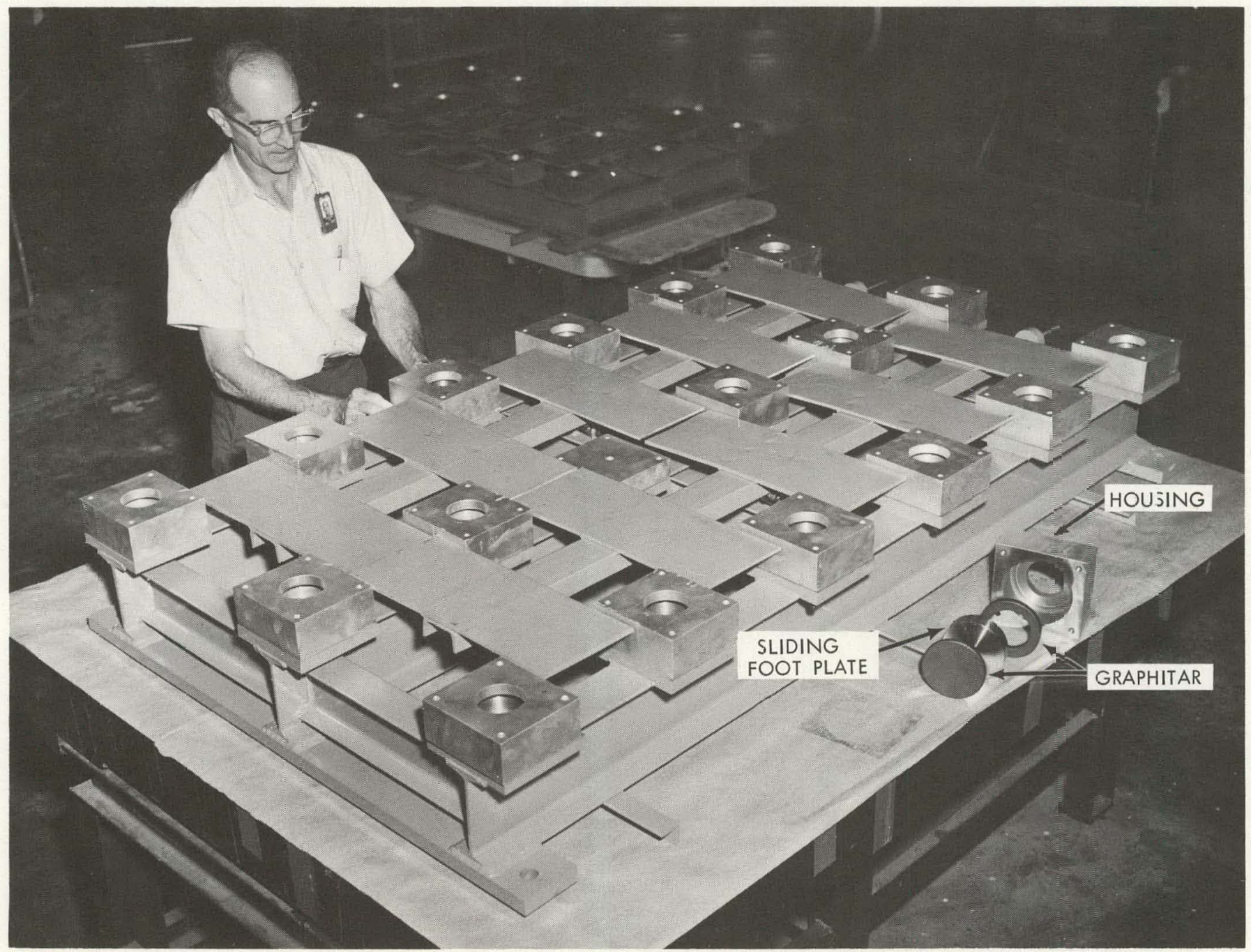

Figure 13

MODEX BASE SUPPORT 
vertical movement. The plate structures between the support pads are used to retain blocks of insulation under the electrical heating elements.

Evaporator Section. Figure 14 shows the evaporator section attached to the base support. The tray floor is a 5/8-inch thick plate of steel clad on one side with l/l6-inch of stainless steel. After welding the legs and side walls on this plate, it was machined internally to an overall flatness of \pm 0.010 inch; in view of the thin layer of potassium which is to be flowing over this floor, it is apparent that the surface must be made and kept flat within small tolerances for proper operation. Division of the 36 by 66 -inch tray into five stages is shown here as well as some interior stage baffling. Corrugated metal sections retain the 18 heating elements under each stage. The pot attached to the tray is used to measure liquid metal depth; this view shows the bottom end of the cascade.

Detail of the stage baffling is shown in figure 15, with the overlay identifying the various stream flow paths. Note the bridges which are used to carry the reject flows under the narrow distillate collection troughs. The short bars welded to the tray walls are the sole support of the condenser section; these bars are machined to a plane parallel to the floor and accurately spaced from it to provide the desired evaporatorcondenser spacing.

Potassium Condenser and Expansion Joint. Figure 16 shows the assembly of the potassium condenser and tubular expansion joint-vacuum header. The conveying channels and forward curved collection edges of each stage condenser are shown. Bars around the sides of the assembly mate with those on the evaporator walls to support the condenser. A I/2-inch expansion slot runs around the pcrimeter of the expansion joint and allows vacuum pumping of each stage as well as admitting sampling probes. The vertical pipe shown on the left is the xylene vapor line for the end stage.

The condensing surface of each stage is assembled with a slope of $1 / 16$ inch toward the collecting edge of the condenser; this feature allows the tilting of the entire tray, if necessary, without interfering with the collection of potassium condensate by gravity.

Xylene Condensers. 'Ihese are vertical coils of 5/8-inch water-cooled copper tubing inside 6-inch diameter jackets. The xylene vapor enters the side of the jacket, condenses, and the reflux drains from the bottom to the potassium condenser section through a quick-acting gate valve. This valve can be closed to allow the condensed xylene to collect in the bottom of the jacket; a plastic sight tube allows observing the depth of condensate as it is collected. By calibrating the sight tube, the time required to collect a given volume of xylene can be readily measured.

The xylene condensers were normally vented to the atmosphere through a common header; however, this header was equipped with a block valve and pressure control system which enabled it to be operated below atmospheric pressure. This feature allowed some adjustment of the potassium condenser temperature while using a single evaporative coolant. 
PHOTO NO. PH-65-707

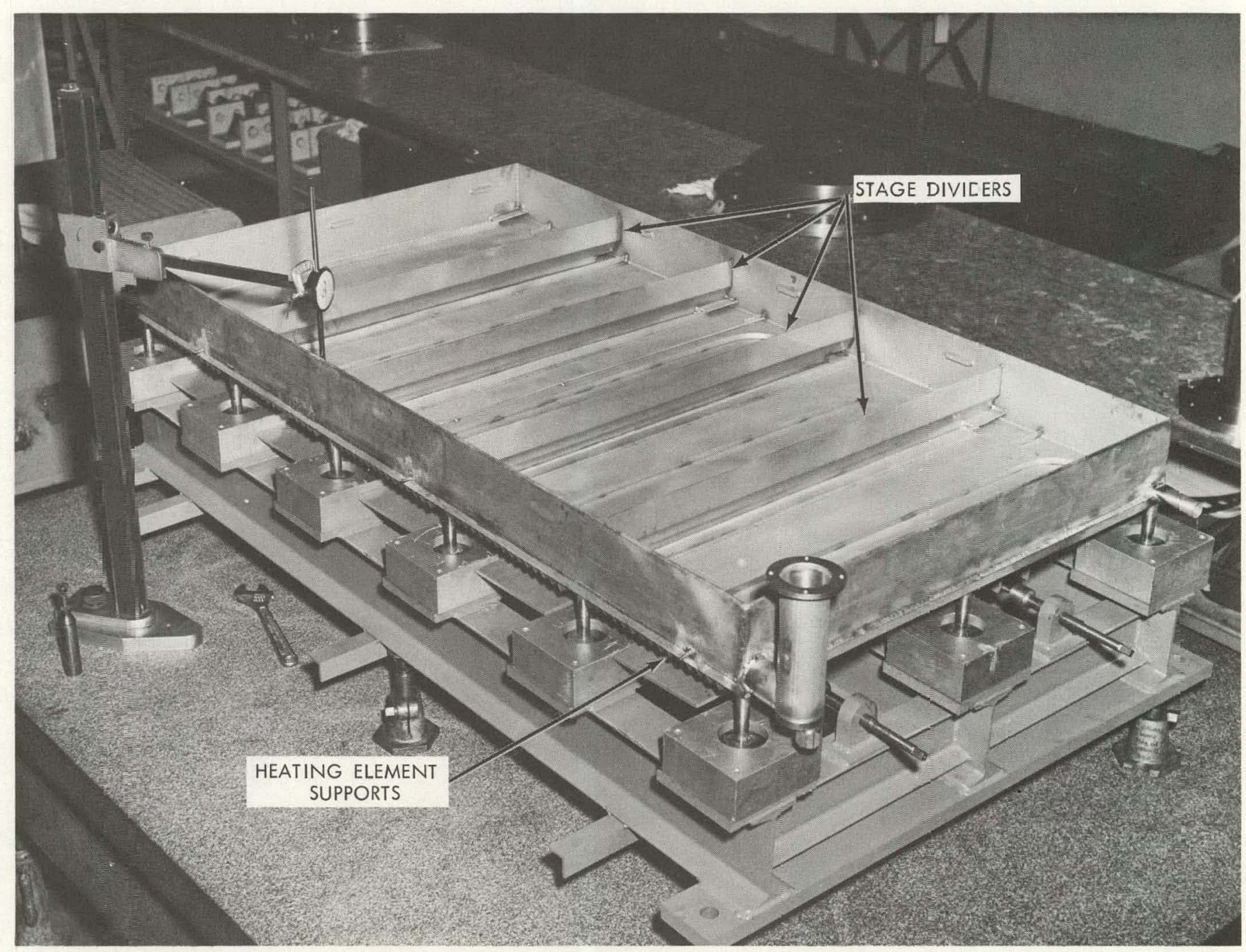

Figure 14

MODEX EVAPORATOR SECTION AND BASE ASSEMBLY 
РHOTO NO. PH-65-1062

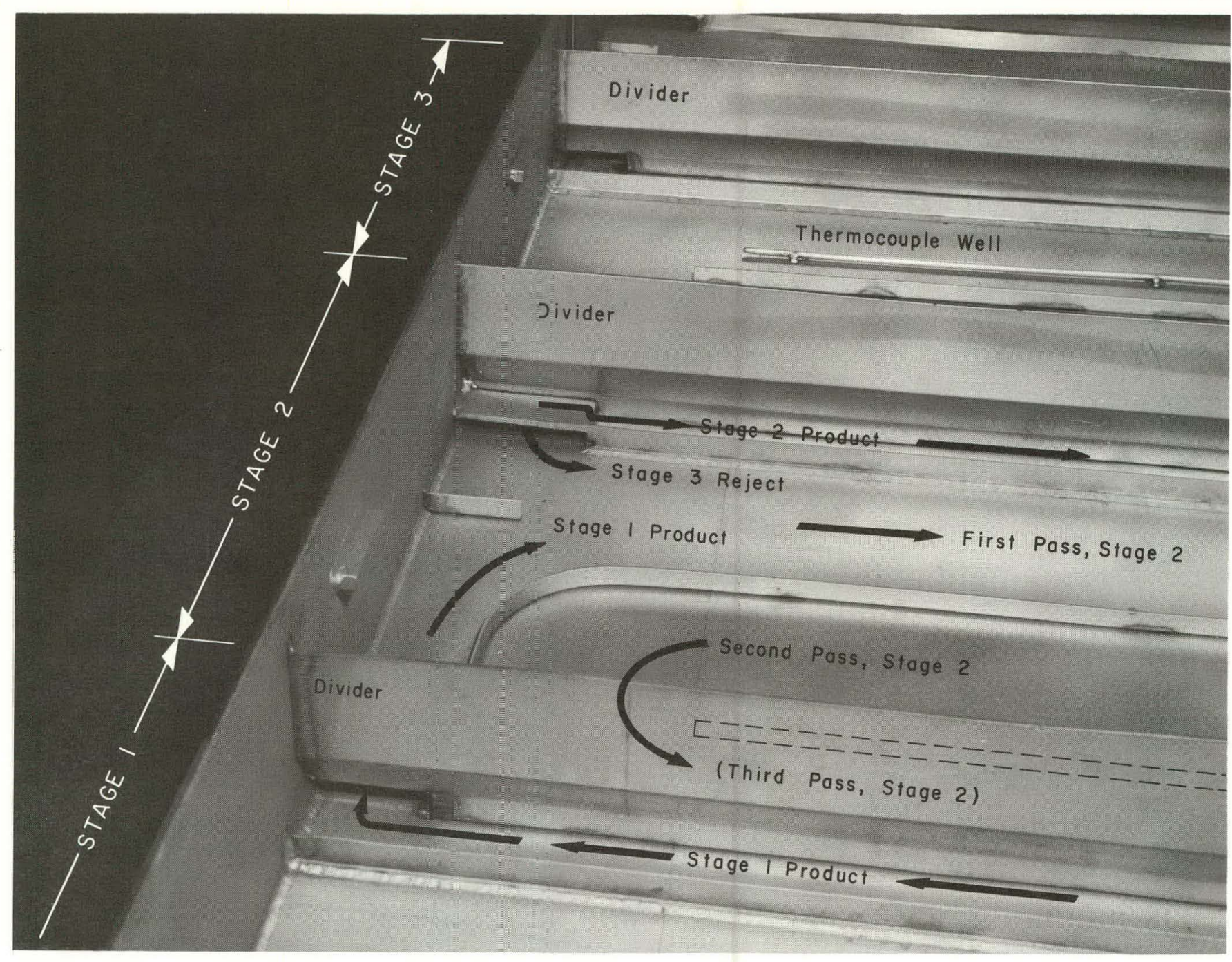

Figure 15

FLOW DETAIL IN MODEX TRAY 
PHOTO NO. PH-65-709

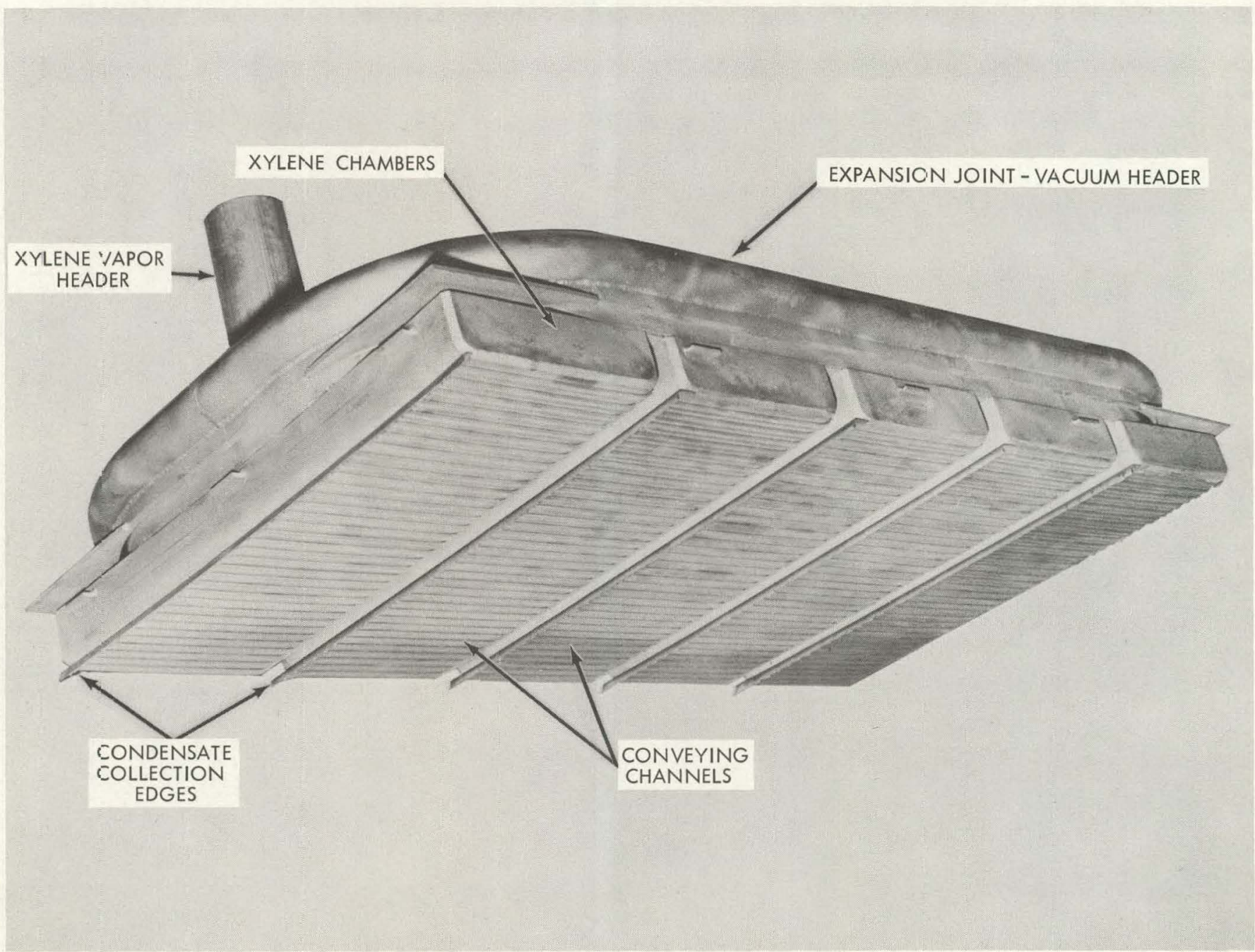

Figure 16

MODEX CONDENSER SECTION AND EXPANSION JOINT 
End Loops, Tray Interconnections. At the product and reject ends of the Modex still, lines are required to recycle product and reject stage flows, respectively, in order to obtain reflux conditions. These lines were fabricated from 3/4-inch diameter stainless steel tubing in a U-form to serve as thermal pumps. Hot metal leaving the end stage passed first through a section equipped with fins for cooling the stream. The cool metal then passed a thermal flowmeter, down the cold leg of the pump, and into a horizontal section where it was reheated before flowing up the hot leg into the end stage again.

The thermal flowmeter consisted of a well-insulated length of 1-1/4-inch diameter tubing with an axial well of 3/4-inch tubing containing a 180-watt electrical cartridge heater. A differential iron-constantan thermocouple circuit across the inlet and exit metal lines measured the change in temperature generated by an accurately measured amount of power fed to the heater. The flowmeter control equipment for the two end loops is shown in figure 17. Weston Model 310 precision wattmeters measure the power input to the heaters, which is adjusted by small Variacs. About 20 to 40 watts served to produce usable temperature differentials; these differentials were measured in microvolts and graphed on a speedomax $\mathrm{H}$ recorder which transferred its input between the two flowmeters every 30 sernnis. A typical display is shown in figure 17.

Tray interconnections between stages 5 and 6 were made with flanged tubing attached to stainless steel bellows to absorb thermal expansive movements of the trays. Aluminum wire gaskets were used on all flanged connections. The tube carrying stage 6 reject flow to stage 5 feed was equipped with a l/4-inch stainless steel bellows-sealed valve to allow feed of normal potassium at this point; similar valves were installed on the end loops for withdrawal of product and reject streams as desired.

Assembly. The subassemblies which were in contact with potassium were cleaned by vapor blasting and degreased prior to final assembly. Argon purges were used in assembly to avoid oxidation of the internal surfaces. Heliarc welding was used throughout, with the first and last weld passes dye-penetrant checked for porosity. The assembled trays were finally given a thorough helium leak test; in one tray small leaks were found in the condenser section which required partial disassembly and repair.

Installation and Auxiliary Systems. The Modex still was installed in an unused cell of the ORGDP Cascade Pilot Plant, since this location provided fireproof housing with adequate electrical load capacity and cooling water supplies. A portion of the area before tray installation is shown in figure 18. Tray support posts extend through the steel plate floor and are anchored to the concrete foundation. The high vacuum system on the wall is partially completed. Two 4-inch oil diffusion pumps equipped with liquid nitrogen traps are manifolded so that either or both of the pumps will serve either tray. Cenco Hyvac 45 roughing pumps are used. Overhead pipes are the xylene condenser vent header and cooling water lines. 
PHOTO NO. PH-64-493

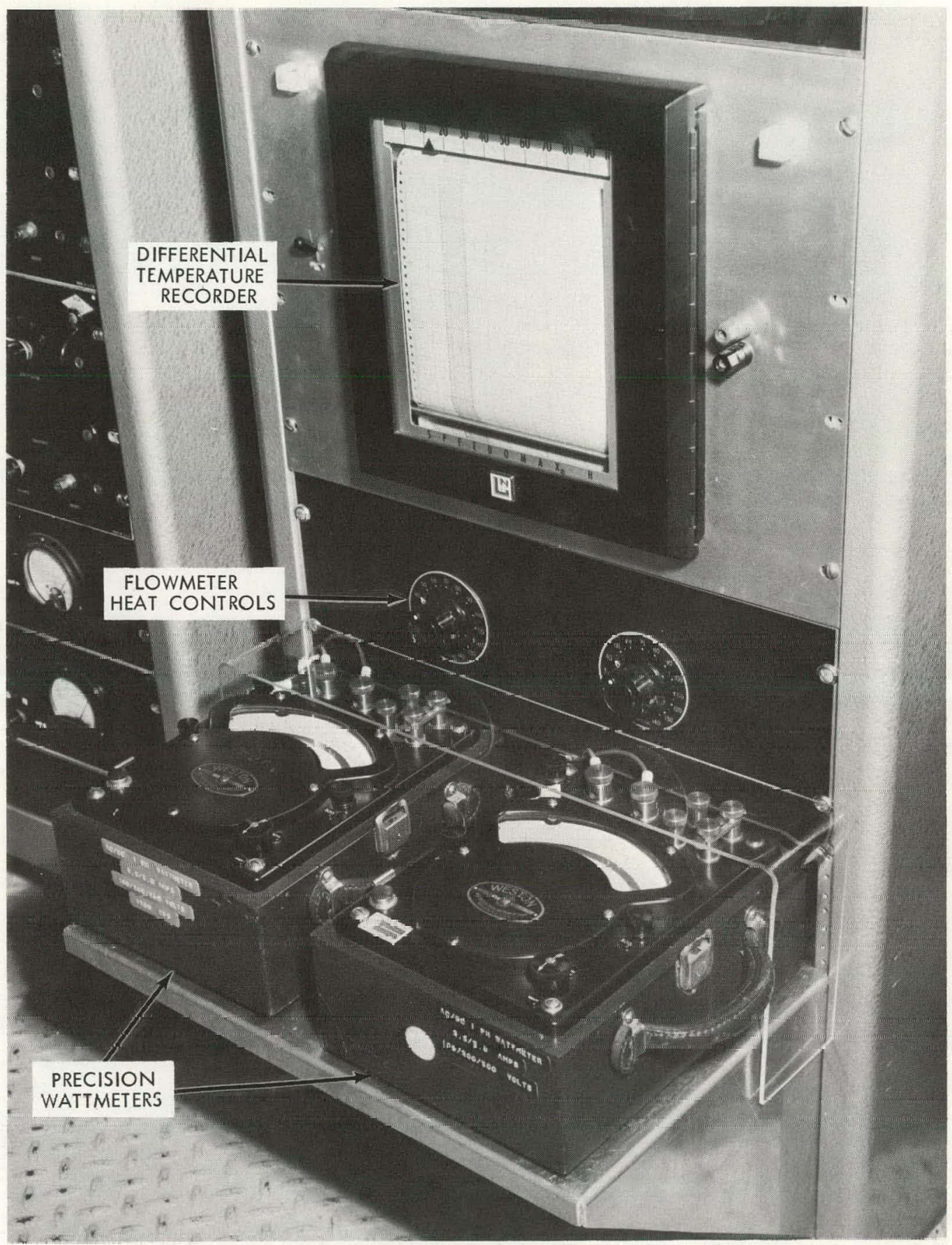

Figure 17

THERMAL FLOWMETER CONTROLS 
PHOTO NO. PH-65-1063

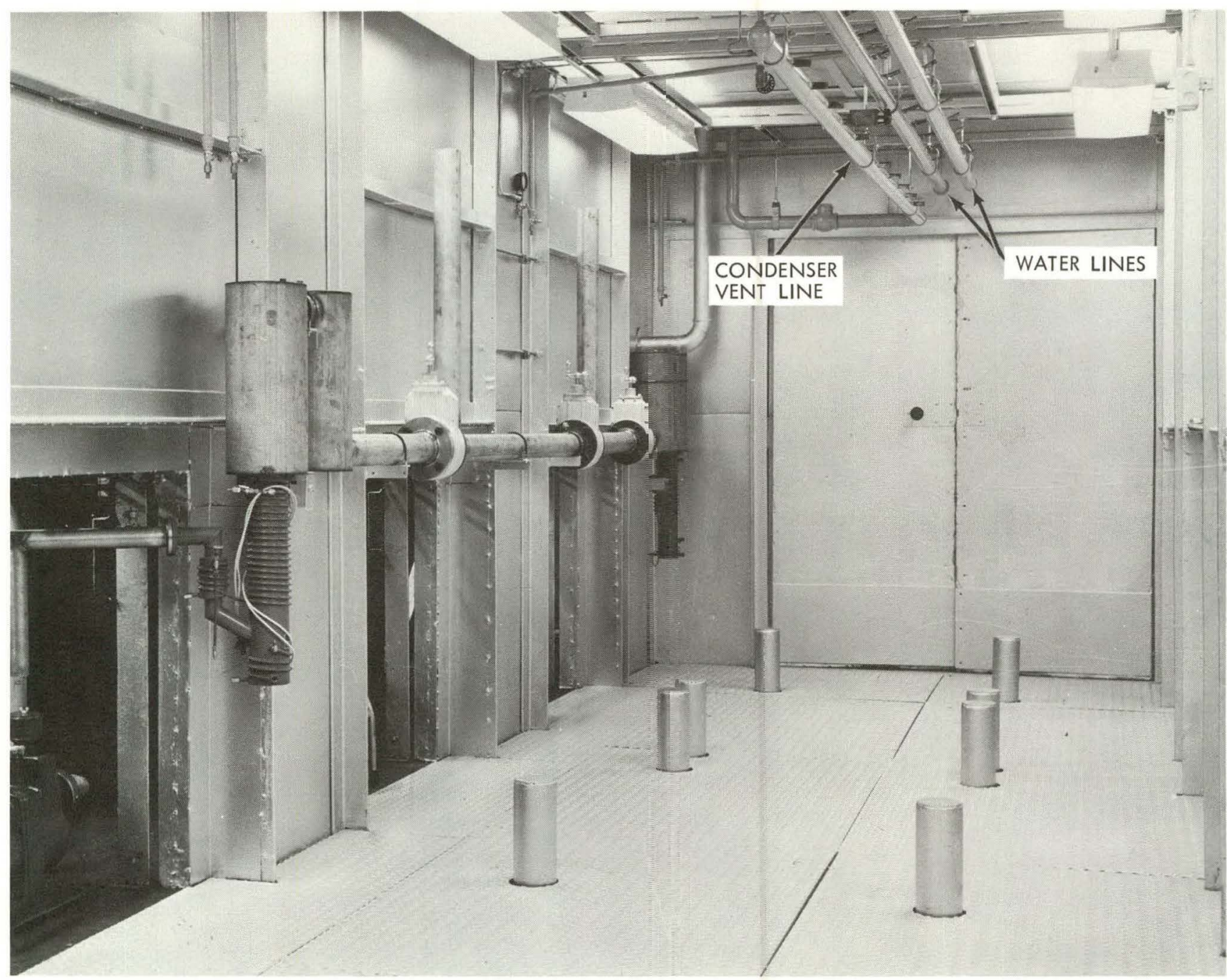

Figure 18

MODEX INSTALLATION SITE 
The two trays after installation are shown in figure 19 without insulation. The triangular Chromalox heating elements, rated at 1600 watts $277 \mathrm{v}$. each, are visible beneath each stage. The expansion joint-vacuum header has been connected to the high vacuum system by overhead loops. Two vacuum locks for sample probes are shown in this view, one penetrating the expansion joint. The xylene reflux system can be seen here, with the quickopening gate valves on the liquid return lines. A plastic sight tube can be seen at the extreme right edge of the photograph. This view is from the product end of the still; end loops had not been installed at this time.

Figures 20 and 21 show the product and reject ends of the completed still. Insulation consists of a $1 / 2$-inch thick blanket of Fiberfrax (aluminum silicate fiber) covered with a l-inch thick layer of aluminum-faced fiberglass. The condenser top is covered with Fiberfrax wool and fiberglass. The xylene vapor lines and condensers are also insulated to avoid condensation of xylene vapor before it reaches the reflux measuring system.

The glass diffusion pump using mercury, shown on the cell wall in figure 21 , evacuates the sampling system. One of the sample probes is shown assembled at the corner of the still in figure 20. Details of the probe and removable sampling tip are shown in figure 22. The tip remains retracted in the sheath until it has been inserted through the vacuum lock and is flush with the tray floor. The sheath is then raised for a few minutes to allow the potassium to wet the tip, then closed to trap a sample of about $60 \mathrm{mg}$. It can then be removed without danger of contamination by potassium vapor or condensate on the tray walls. Vacuum lock valves are 0-ring sealed plug valves. Tips containing the various stage samples are weighed in plastic sample bottles and exposed to moist air in a closed container until they are completely hydrolyzed. The tip is rinsed in the sample bottle with distilled water and the solution neutralized with hydriodic acid; this solution of potassium iodide is then assayed for its isotopic abundance ratio. Used tips and sheaths are washed with nitric acid, rinsed with distilled water, and dried before re-use to avoid cross contamination.

The power supply system, partially shown in figure 23, is located in a room adjacent to the still. Sille a wide range of power levels must be covered, and since continuous adjustment of each stage is needed for flow balancing, a double set of transformers was used. Four tap transformers, the larger units in figure 23, were used to cover large reductions in the 480-v. 3- $\varnothing$ line.

These transformers then fed 10 induction regulators (Inductrol), each stage being contrulled by a separate regulator. This combination made it possible to cover the power range from $3 \mathrm{kw}$. to $250 \mathrm{kw}$. continuously. Each rcgulator was equipped will receptacles and switches enabling a precision wattmeter to be attached so that the power supplied to individual stages could be monitored. 
PHOTO NO. PH-65-1067

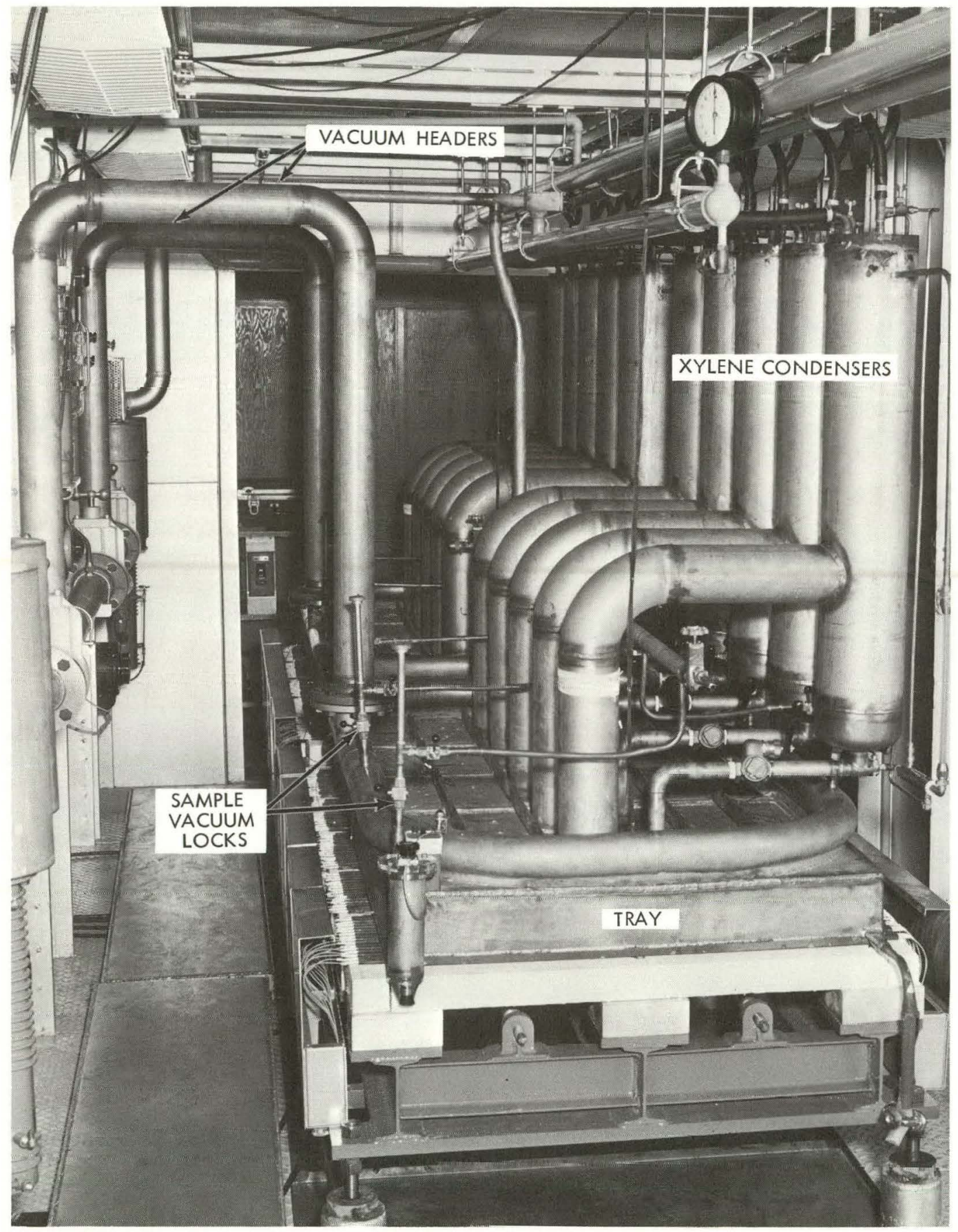

Figure 19

MODEX ASSEMBLY BEFORE INSULATION 
PHOTO NO. PH-64-491

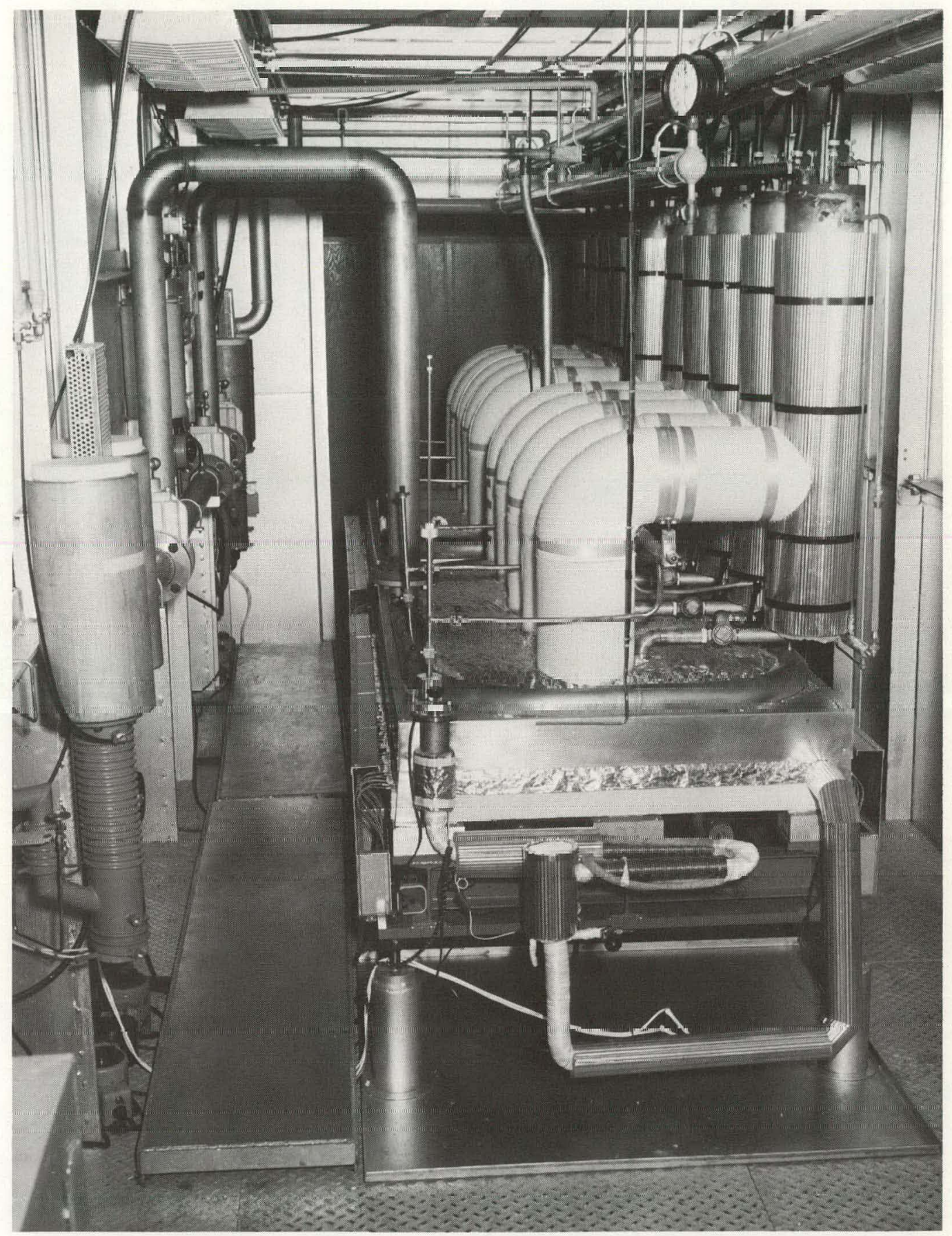

Figure 20

MODEX FACILITY - NORTH VIEW 
PHOTO NO. PH-64-494

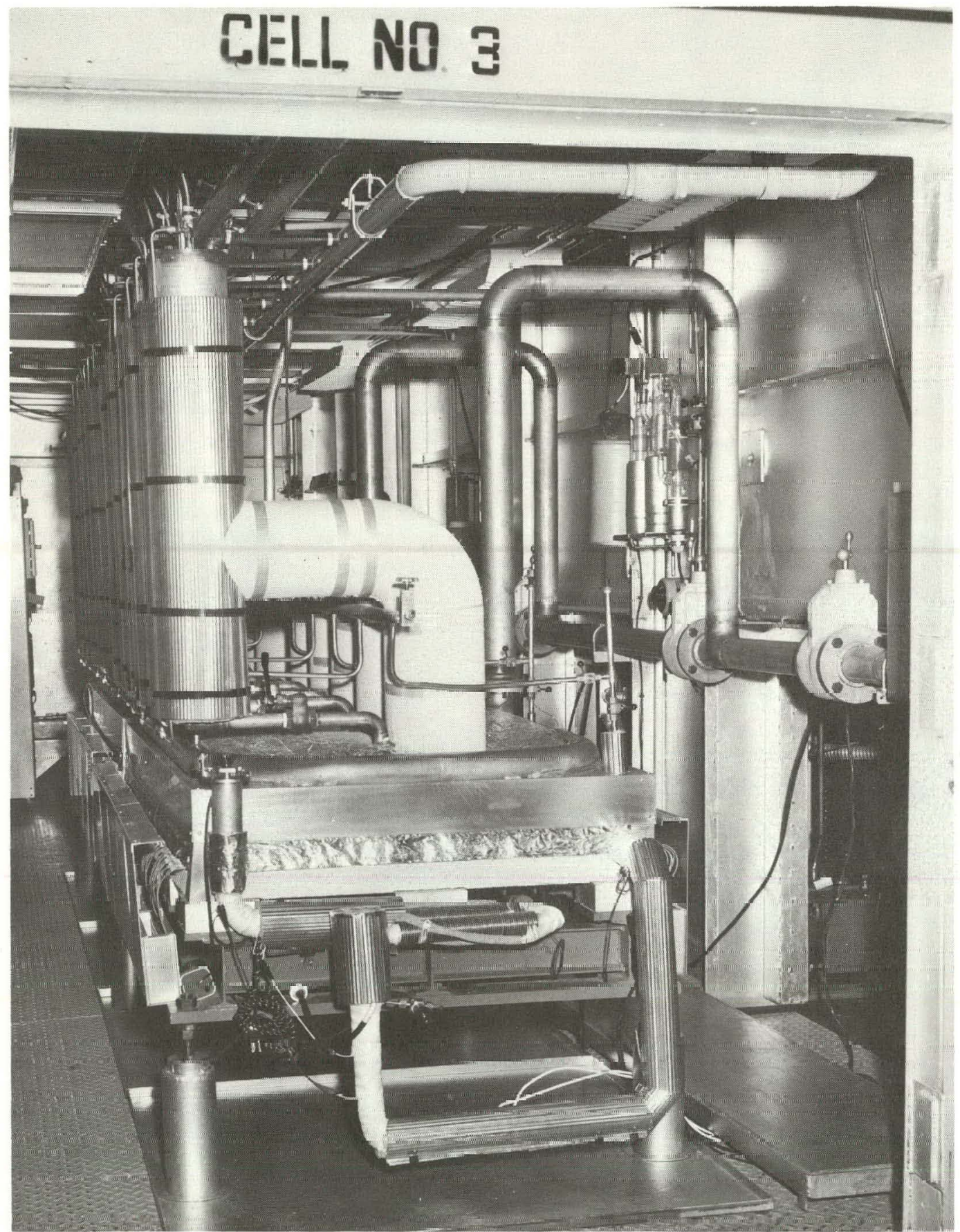

Figure 21

MODEX FACILITY - SOUTH VIEW 
PHOTO NO. PH-64-489 \& -490

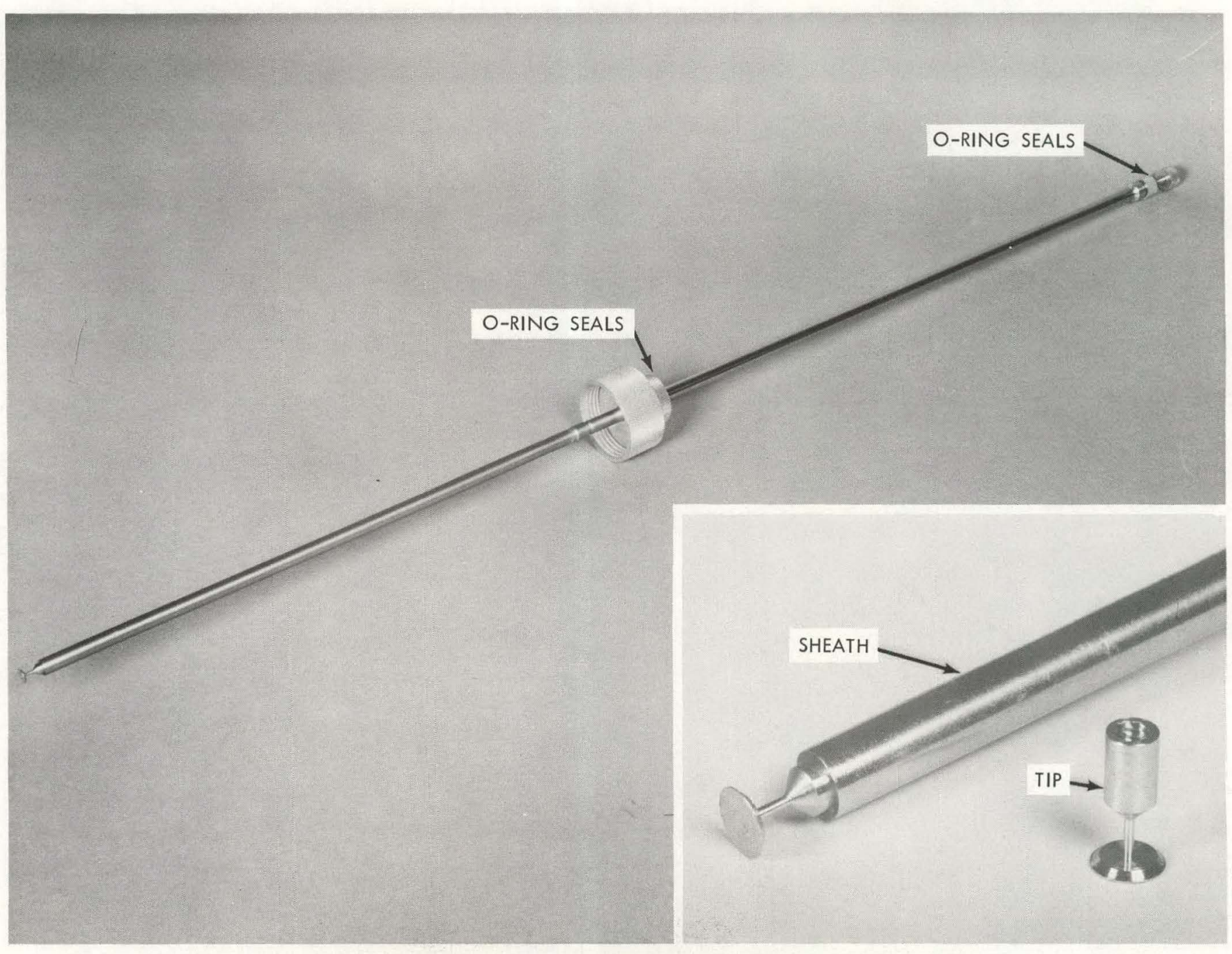

Figure 22

SAMPLE PROBE ASSEMBLY 
PHOTO NO. PH-65-1064

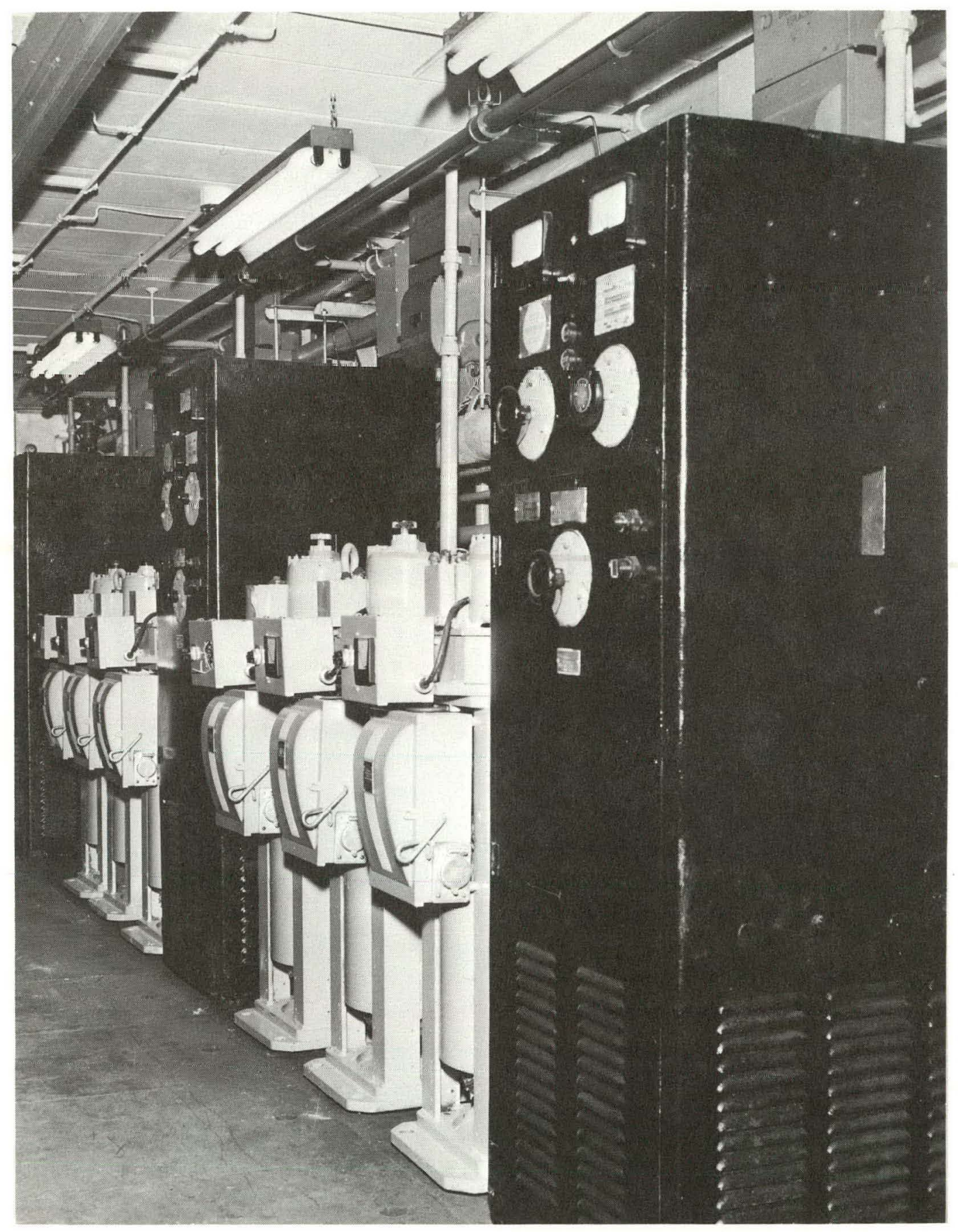

Figure 23

STAGE POWER CONTROL TRANSFORMERS 
A 24-point temperature recorder for iron-constantan thermocouples was used to monitor temperatures in the evaporator pool and the potassium condenser of each stage, and some points in the xylene coolant system. All of these were scanned every 72 seconds. A separate 20-point recorder measured temperatures required for operation of the end loop thermal pumps and intertray connections. Vacuum instrumentation on the trays consisted of VG-IA ion gauges on the high vacuum manifold next to the oil diffusion pump traps; General Electric ion gauge controllers were used. A separate system measured pressures in the sampling vacuum manifold.

Safety Features. Consideration was given to the possible consequences of a number of dangerous conditions which could arise in the Modex system either through leakage or as a result of failure of any of the utility systems, and of the best method of dealing with these conditions. First, the still is installed in a fireproof area with adequate supplies of powdered carbon and special extinguishers for dealing with metal fires. No sprinkler system is used. An alarm panel was installed which signalled dangerous conditions both to the still operators and to the Cascade Pilot Plant control room personnel. This panel was activated by the following conditions:

1. Evaporator pool temperatures more than $5^{\circ} \mathrm{C}$. higher than the selected operating temperature.

2. Pressure conditions in the manifold of either tray in excess of $5 \times 10^{-5}$ torr.

3. Cooling water pressure to the xylene condensers below $30 \mathrm{psig}$.

The high temperature signal from the trays was obtained from a switch on the tray temperature rccorder which surveyed these values every 72 seconds. A second switch set about $10^{\circ} \mathrm{C}$. above the selected operating temperature shut off all power to the trays. Since a pressure increase to several microns in the vacuum system would interfere with the evaporative transfer of process heat to the condenser, this condition would also produce a high evaporator temperature and eventually shut off the power supply.

The philosophy in this design was to inform personnel of an unsatisfactory operating condition before it reached a dangerous level and to permit the operators to select a course of corrective action; the system takes action only if the condition persists or worsens.

\section{EXPERIMENTAL WORK}

Conditioning and Shakedown Run. The Modex still was fully evacuated and baked out at $250^{\circ} \mathrm{C}$. until a pressure of about $2 \times 10^{-6}$ torr was sustained. A 'educlilg atmosphere of $5 \%$ hydrogen in nitrogen was then introduced to clean out any reducible metal oxides on the interior surfaces and the still re-evacuated. It was then charged with approximately 40 pounds of lowsodium low-oxygen potassium metal obtained from MSA Research Corporation. This charge of mctal was allowed to stand in the still for several days to 
condition surfaces of the evaporator and condenser and promote wetting. The potassium condensers were charged with $5.8 \mathrm{~kg}$., about $1.78 \mathrm{gal}$., of pure $p$-xylene; the pure isomer allowed using a definite value of the heat of vaporization rather than an average value for the isomeric mixture.

During a 10-day period, the still evaporator was held at about $247^{\circ} \mathrm{C}$. for preliminary tests of the end loop pump operations, xylene reflux rate measurements, sampling system, and thermal flowmeter operations. All systems functioned satisfactorily after some initial difficulty with a gas bubble trapped in the product loop flowmeter. Operating temperatures in the 10 stages varied by only about $2^{\circ} \mathrm{C}$. Heat losses were largest at the ends of the trays, as would be expected, but the xylene reflux rates could be equalized readily by adjusting the power input to the end stages. The thermal flowmeter in the product end loop showed good agreement with the xylene reflux rate in estimating interstage flows and both were in good agreement with the theoretical evaporation rate of potassium at this temperature. Tray pressures during this test period varied from $2 \times 10-6$ to $3 \times 10^{-7}$ torr.

Metal samples were withdrawn from each of the 11 sampling ports to check their operation and were assayed to determine if proper condenser drainage was taking place. A faulty stage condenser would produce an offset in the isotopic gradient since its efficiency would be impaired. A plot of the values of $\log \mathrm{S}$ vs. stage number for three samplings of the still at $247^{\circ} \mathrm{C}$. is shown in figure 24. While the confidence limits on these analyses have not been firmly established, preliminary tests indicate they are of the order of \pm 0.005 for the $S$ value. Within these limits, the data shown define a straight line; it was concluded, therefore, that all stages were functioning as designed with proper mixing of liquid flows. The line slope in figure 24 indicates that a stage separation factor $\Psi$ of about 0.022 , or about $60 \%$ of the theoretical value, was attained; however, no effort was made to match flows to secure a cut of one-half in stage 1 , and therefore this value must. be considered preliminary.

Following this test, most of the Modex still charge was drained through the reject loop withdrawal valve into a waste storage drum. Of the original 40-1b. charge, $26 \mathrm{lb}$. was drained and replaced with clean metal to reduce the amount of dissolved material washed from the still surfaces. The following experiments were all conducted with this charge of metal.

Variation of $\Psi$ and $\mathrm{L}$ with Temperature: Maximum Separative Capacity. A series of total reflux runs was made at temperatures from $222^{\circ} \mathrm{C}$. to $296^{\circ} \mathrm{C}$. in order to establish simultaneously the variation of the stage separation factor and interstage flow with the temperature. With a single exception, all of these total reflux runs were carried out on the basis of 16 hours operating time per run; during the remaining 8 hours the still was placed in standby condition, operating unattended at about $200^{\circ} \mathrm{C}$. One run was made at $222^{\circ} \mathrm{C}$. and, because of the longer equilibrium time characteristic of this low temperature, the run was continued through a weekend with occasional checks on the operating conditions. Since these runs were largely routine, a general description of a typical run will suffice to 


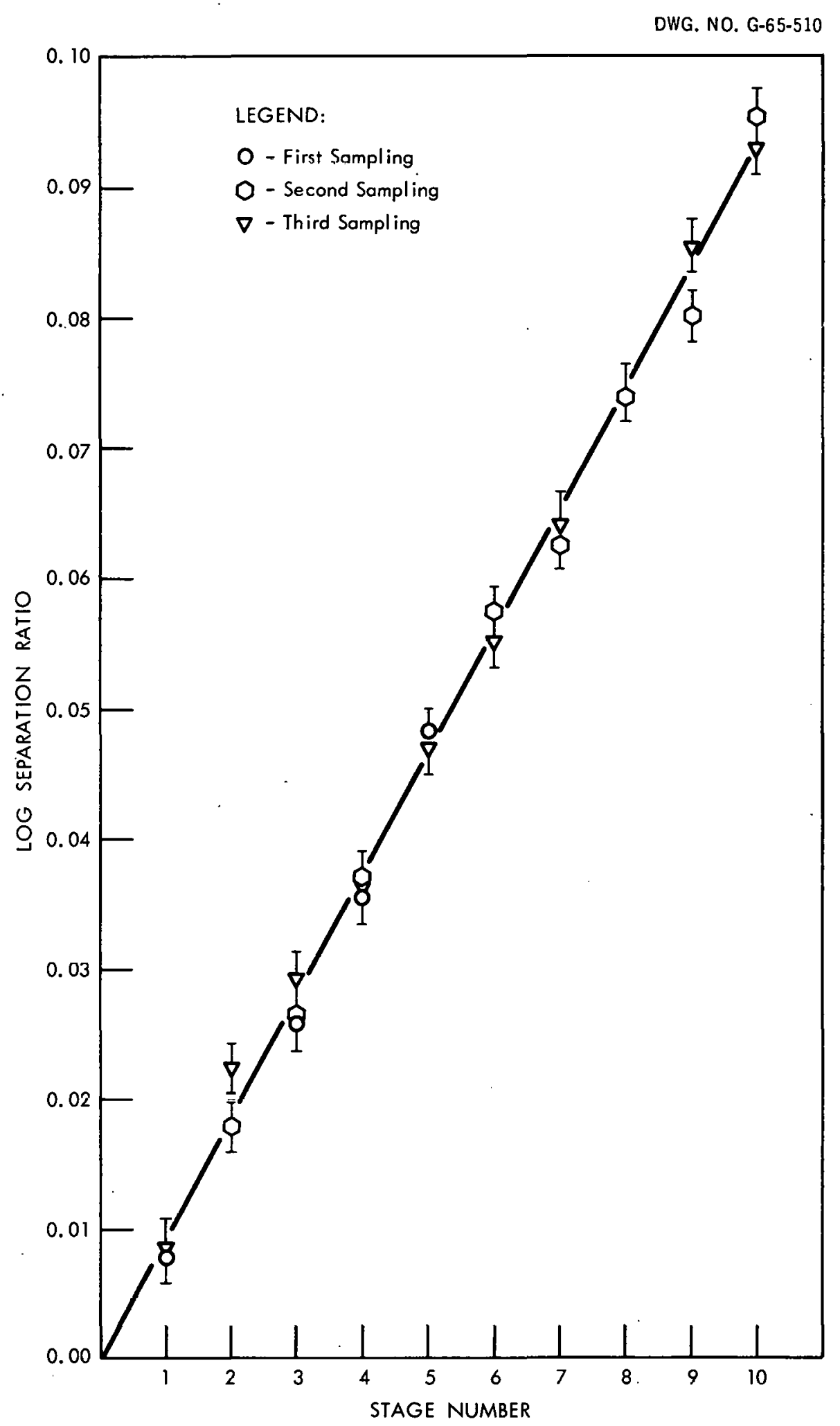

Figure 24 MODEX GRADIENT AT $247^{\circ} \mathrm{C}$. 
illustrate the procedure.

Power was applied to the still to obtain the power density indicated theoretically for the desired operating temperature. When the temperature in the evaporator had equilibrated after 15 to 30 minutes, power adjustments were made to bring the actual temperatures in the interior stages of each tray to the desired value. Xylene coolant reflux rate measurements were then made on all stages by timing the collection of $1 \mathrm{~kg}$. of xylene from each condenser. It was usually found at this point that the rates measured on the interior stages of each tray (stages $2,3,4$, and $7,8,9$ ) were in fairly good agreement, but that the rates on the exterior stages (stages 1, 5, and 6, 10) were lower because of heat losses to the atmosphere. Based on the measured xylene reflux rates, proportional adjustments were made in the power input to various stages to obtain the same xylene reflux rate in all stages. These rates were rechecked frequently during the course of a run and minor power corrections applied if required. The thermal pumps located on the end loops on stages 1 and 10 were started to provide total reflux to the still. Stage 10 pump was adjusted to keep the stage 10 product trough pumped out, while the stage 1 pump was set to circulate metal at the lower end of the still at the same rate indicated by the thermal flowmeter in the stage 10 loop. Under these conditions, interstage flows within the still should have been balanced to provide a cut of one-half in each stage.

These conditions were maintained throughout the remainder of the 16-hour run. Sampling was performed twice during the latter portion of the run, ordinarily with several hours between.samplings. All 11 samples were removed at each sampling, although not all samples were assayed. Inert gas pressures in the trays varied from $2 \times 10^{-7}$ to $2 \times 10^{-6}$ torr during runs, though during sampling pressures sometimes reached $1 \times 10^{-5}$ torr momentarily.

Ratio-of-ratio isotopic measurements, $S$, were obtained on each series of samples: In most cases the reject stream from stage 1 was used as a reference; however, in a few runs the cut actually measured in the first stage was significantly different from one-half and the product from stage 1 was used as a reference. In the latter cases the still was simply treated as a 9-stage unit. All samples were assayed from a few sclected runs at high, intermediate, and low temperatures in order to verify a uniform isotopic gradient in the still; results are shown in figure 25. The normal procedure, however, was to assay only the product from the top three stages, since these results most accurately define the slope of the straight line obtained when the logarithm of the overall separation is plotted as a function of stage number. Least squares analysis was then used to obtain the statistically best slope, which is the logarithm of the stage separation factor for the run.

Figure 26 summarizes the variation of stage separation factor with temperature over the range tested. The line was drawn by inspection, additional weight being given certain points which have higher precision due to repetitive measurement. Pertinent data on operating conditions for these runs are presented in table $I$. Figure 27 shows the flow rate of metal in 


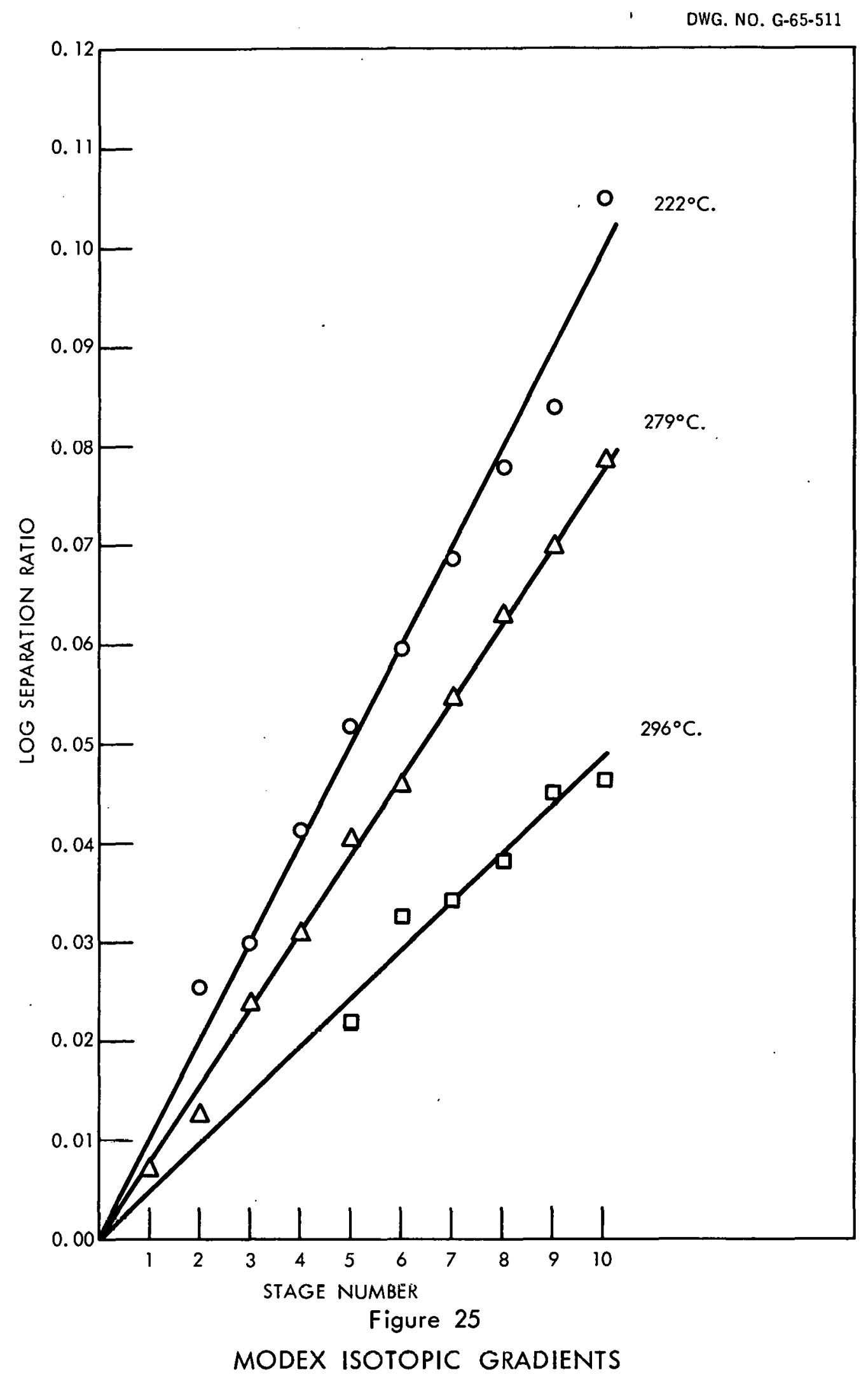




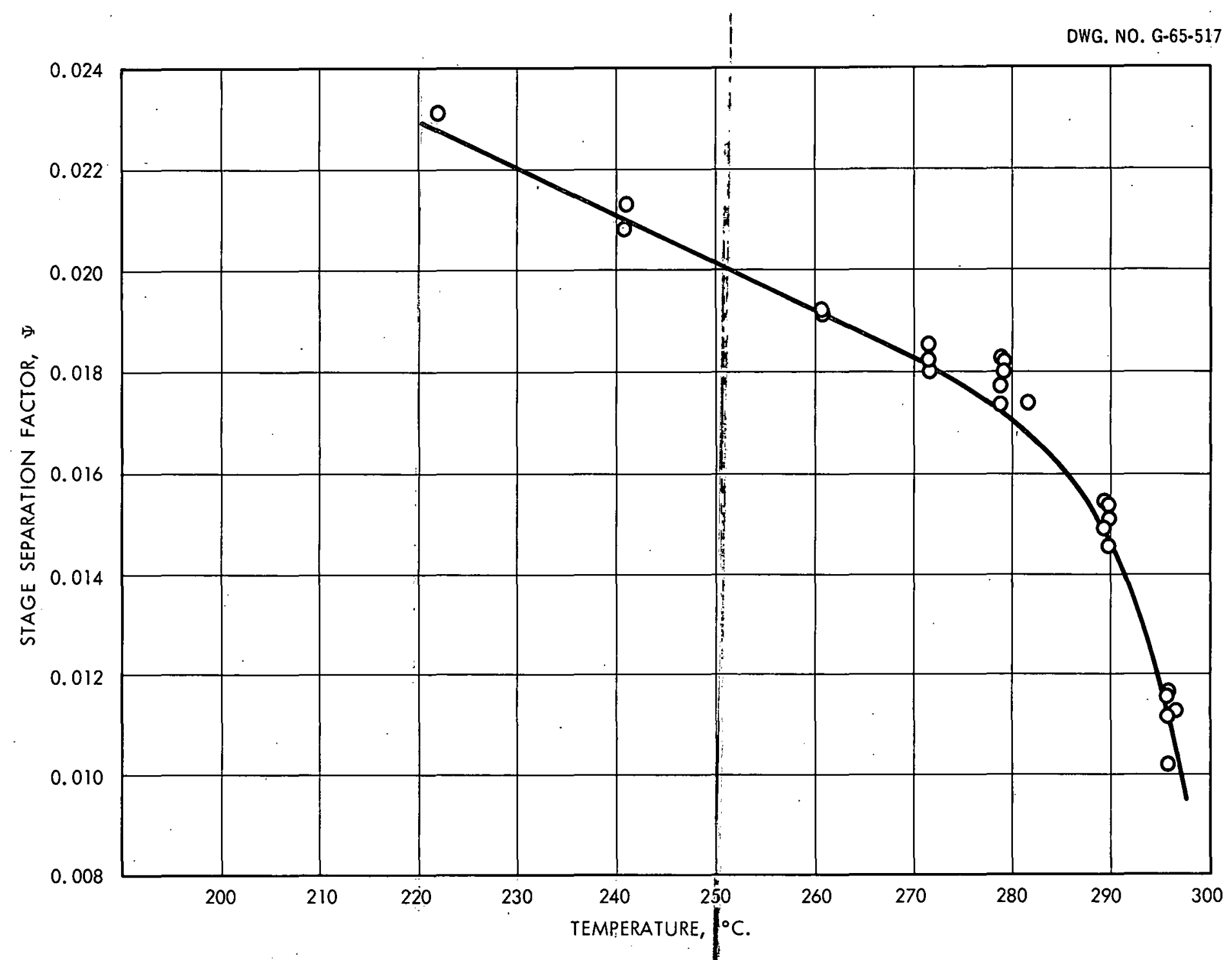

Figure 26

VARIATION OF SEPARATION FACTOR WITH TEMPERATURE 
TABLE I

FLOW AND SEPARATION DATA AT TOTAL REFLUX

\begin{tabular}{|c|c|c|c|c|c|c|c|c|c|c|c|c|}
\hline \multirow[b]{2}{*}{ Run } & \multirow{2}{*}{$\begin{array}{l}\text { Evap. } \\
\text { Temp., } \\
{ }^{\circ} \mathrm{C} . \\
\end{array}$} & \multirow{2}{*}{$\begin{array}{l}\text { Cond. } \\
\text { Temp., } \\
{ }^{\circ} \mathrm{C} \text {. } \\
\end{array}$} & \multirow{2}{*}{$\begin{array}{l}\text { Power } \\
\text { Input, } \\
\text { Iw. } \\
\end{array}$} & \multicolumn{2}{|c|}{ Xylene System } & \multicolumn{2}{|c|}{$\begin{array}{l}\text { End Loop } \\
\text { Thermal } \\
\text { Flow Meters } \\
\end{array}$} & \multicolumn{3}{|c|}{$\begin{array}{l}\text { Separation Ratio, } \\
\text { S }\end{array}$} & \multirow[b]{2}{*}{$\Psi$} & \multirow{2}{*}{$\begin{array}{l}\text { Condenser } \\
\text { Efficiency, } \\
\%_{* *}^{*} \\
\end{array}$} \\
\hline & & & & $\begin{array}{l}\text { Rate, } \\
\text { səc./kg. }\end{array}$ & $\begin{array}{l}\text { Est. Flow, } \\
\text { g.K/min. }\end{array}$ & $\begin{array}{c}\text { Stage } \\
10 \\
\end{array}$ & $\begin{array}{c}\text { Stage } \\
1 \\
\end{array}$ & $\begin{array}{l}\text { Stage } \\
8 \\
\end{array}$ & $\begin{array}{c}\text { Stage } \\
9 \\
\end{array}$ & $\begin{array}{l}\text { Stage } \\
10 \\
\end{array}$ & & \\
\hline 1 & 278.8 & 184.3 & 130.5 & 28.13 & 350 & 315 & 344 & $\begin{array}{l}1.145 \\
1.145\end{array}$ & $\begin{array}{l}1.171 \\
1.166\end{array}$ & $\begin{array}{l}1.195 \\
1.189\end{array}$ & $\begin{array}{l}0.01770 \\
0.01732\end{array}$ & $97 \cdot 7$ \\
\hline 2 & 289.9 & 198.8 & 180.0 & 19.70 & 500 & 435 & 445 & 1.119 & 1.138 & 1.159 & 0.01455 & 95.8 \\
\hline 3 & 295.7 & 210.2 & 217.0 & 16.15 & 609 & 457 & 478 & $\begin{array}{l}1.091 \\
1.086\end{array}$ & $\begin{array}{l}1.113 \\
1.101\end{array}$ & $\begin{array}{l}1.126 \\
1.126\end{array}$ & $\begin{array}{l}0.01170 \\
0.01113\end{array}$ & 95.5 \\
\hline 4 & 279.0 & 190.0 & 130.6 & 27.60 & 366 & 315 & 326 & $\begin{array}{l}1.153 \\
1.156\end{array}$ & $\begin{array}{l}1.174 \\
1.174\end{array}$ & $\begin{array}{l}1.196 \\
1.198\end{array}$ & $\begin{array}{l}0.01803 \\
0.01818\end{array}$ & 97.0 \\
\hline 5 & 289.8 & 201.0 & 133.4 & 19.30 & 510 & 421 & 430 & $\begin{array}{l}1.131 \\
1.129\end{array}$ & $\begin{array}{l}1.145 \\
1.143\end{array}$ & $\begin{array}{l}1.166 \\
1.161\end{array}$ & $\begin{array}{l}0.01539 \\
0.01509\end{array}$ & 95.2 \\
\hline 6 & 271.4 & 182.0 & 100.3 & 35.88 & $27^{\prime}+$ & 271 & 272 & $\begin{array}{l}1.159 \\
1.153\end{array}$ & $\begin{array}{l}1.178 \\
1.177\end{array}$ & $\begin{array}{l}1.202 \\
1.200\end{array}$ & $\begin{array}{l}0.01853 \\
0.01825\end{array}$ & 97.3 \\
\hline 7 & 281.4 & 191.0 & 141.0 & 25.59 & 385 & 336 & 331 & 1.150 & 1.164 & 1.187 & 0.01737 & 97.0 \\
\hline 8 & 278.7 & 189.3 & 129.2 & 28.31 & 348 & $\begin{array}{l}301 \\
307\end{array}$ & $\begin{array}{l}295 \\
312\end{array}$ & $\begin{array}{l}1.145 \\
1.156\end{array}$ & $\begin{array}{l}1.167 \\
1.179\end{array}$ & $\begin{array}{l}1.189 \\
1.197\end{array}$ & $\begin{array}{l}0.01730 \\
0.01830\end{array}$ & 97.1 \\
\hline 9 & 289.2 & 202.8 & 183.5 & 19.59 & 502 & $\begin{array}{l}399 \\
404\end{array}$ & $\begin{array}{l}373 \\
376\end{array}$ & $\begin{array}{l}1.108 \\
1.128\end{array}$ & $\begin{array}{l}1.140 \\
1.145\end{array}$ & $\begin{array}{l}1.163 \\
1.171\end{array}$ & $\begin{array}{l}0.01490 \\
0.01545\end{array}$ & 96.1 \\
\hline
\end{tabular}


TABLE I (CONTINUED):

FLOW AND SEPARATION DATA AT TCTAL REFLUX

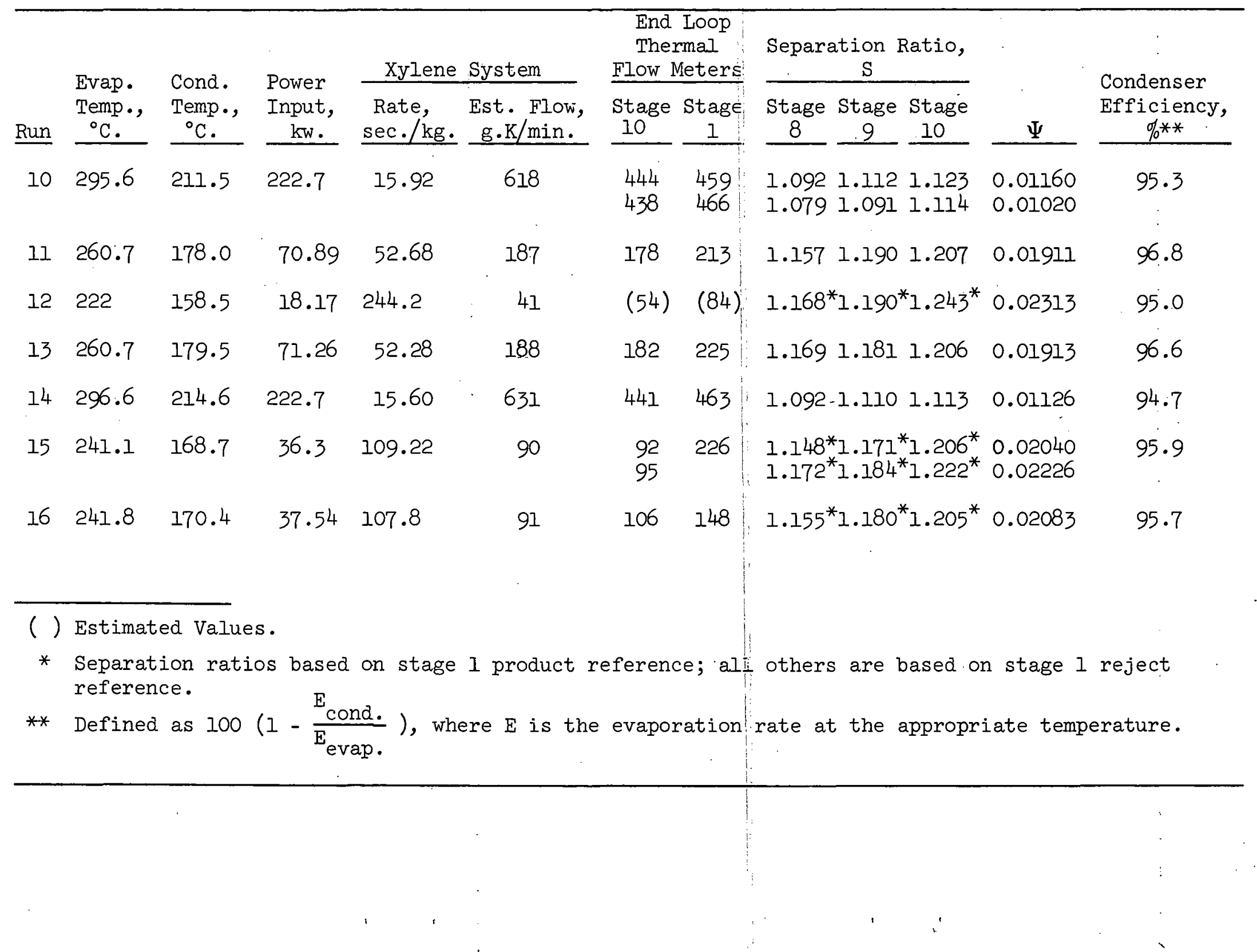


DWG. NO. G-65-513

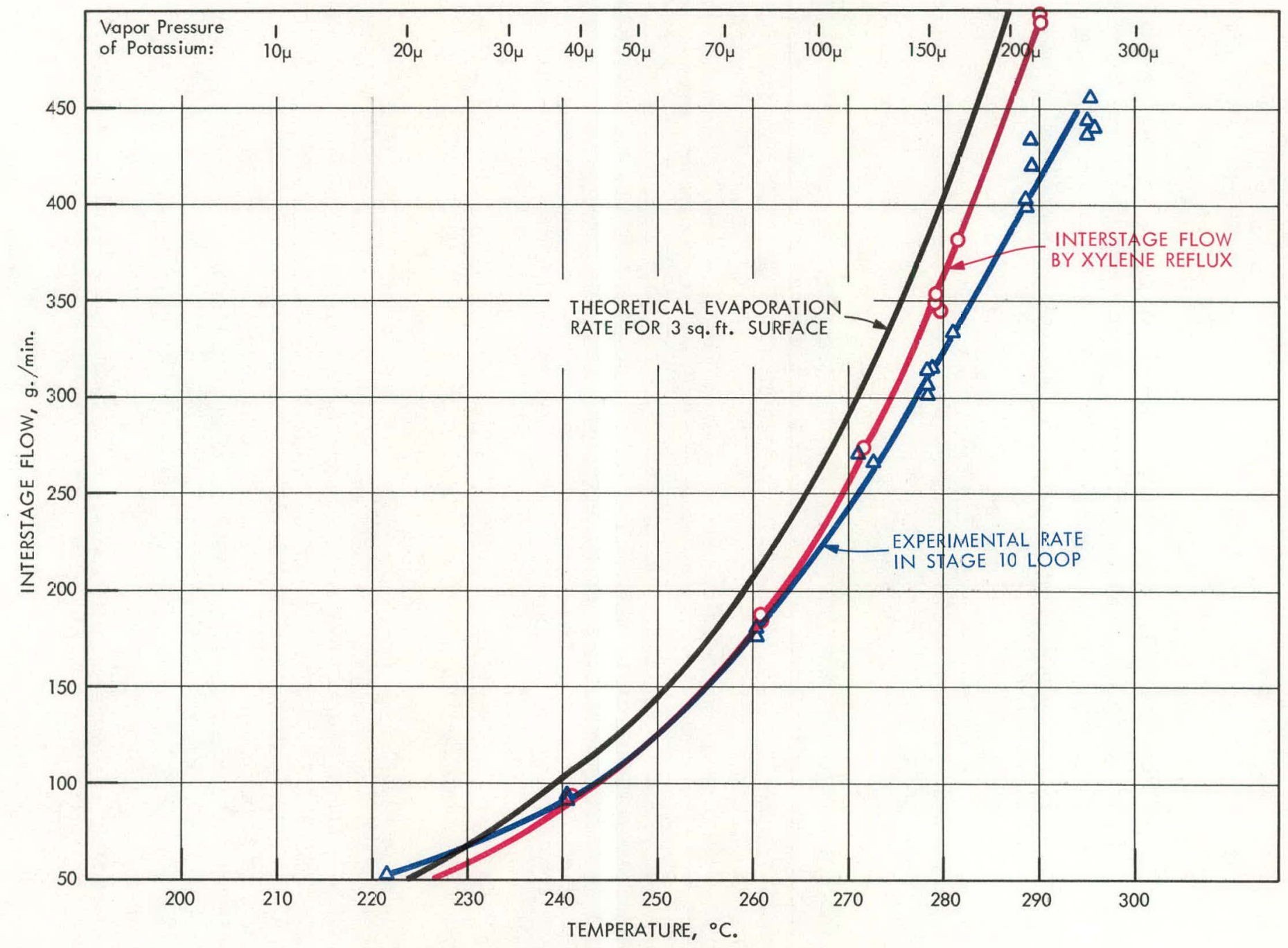

Figure 27

VARIATION OF POTASSIUM FLOWS WITH TEMPERATURE 
the product end loop as measured by the thermal flowmeter; for comparison, the evaporation rate of $3 \mathrm{sq}$.ft. of surface calculated by the Langmuir equation is also shown. Flow estimates can also be made from the xylene reflux rate measurements as shown in table I, the values lying between the theoretical and experimental curves in figure 27. The experimental data in figures 26 and 27 can then be combined to give the variation of the separative capacity function $\Psi^{2} \mathrm{I}$ with temperature as shown in figure 28. It is clear from this curve that the maximum separative capacity is obtained at about $283^{\circ} \mathrm{C}$, although from the shape of the curve as the peak is approached, the minimum cost of product will be achieved at a temperature below $283^{\circ} \mathrm{C}$. This is due to the fact that as the peak is approached, increasingly expensive expenditures of process power are needed to obtain small improvements in separative capacity. Temperatures above the peak in figure 28 are definitely not economical.

Some comment is needed on the discrepancies between the stage 10 product flow rate, the interstage flows estimated from the xylene reflux rates, and the theoretical flow rate shown in figure 27. First, it will be recalled that the theoretical rate applies only if all molecules leaving the surface are trapped before they can be reflected back to the surface. Table I shows that the appropriate condenser temperatures for the various runs result in an average of about $96 \%$ condensation efficiency; vapor which is not trapped on the condenser refluxes on the sides of the tray, interstage dividers, and vacuum header and is not measured as interstage flow. Further, at the higher temperatures shown in figure 27, the appreciable pressure of potassium produces enough intermolecular collisions to reflect some evaporating molecules back into the liquid pool. The Langmuir equation therefore should give a maximum attainable rate; the apparent high point shown at $222^{\circ} \mathrm{C}$. is subject to considerable error due to the sluggishness of the thermal flowmeter at this very low flow rate. The xylene reflux rate data should be more reliable than the theoretical curve since, as was mentioned earlier, condensation of potassium vapor is the predominant mechanism of heat transfer into the xylene evaporator. Actually, the f'low rates estimated from the xylene reflux rates and those measured by the stage 10 thermal flowmeter are in agreement within experimental error up to about $270^{\circ} \mathrm{C}$. At higher temperatures, especially above $290^{\circ} \mathrm{C}$. , a liquid entrainment error biases the xylene measurement high, just as was encountered in the small test stage. Proof that entrainment was occurring was visible during the high temperature runs when a definite discoloration of the refluxing xylene was noted. On completion of the total reflux runs, the xylene coolant in the condensers was found to have been partially degraded to produce some dark colored non-volatile material. Since this material appeared in the xylene condensate, it could only have been transported by liquid entrainment. The condensers have identical structures, therefore the entrainment bias should not have affected the balancing of interstage flows by measurement of the reflux rates. The xylene was later distilled to remove the colored material and the residue fractionated in a Podielniack column. A small amount of benzyl alcohol and a crystalline solid tentatively identified as benzyl benzoate were recovered, indicating that some oxidation of the xylene had occurred. 
DWG. NO. G-65-512

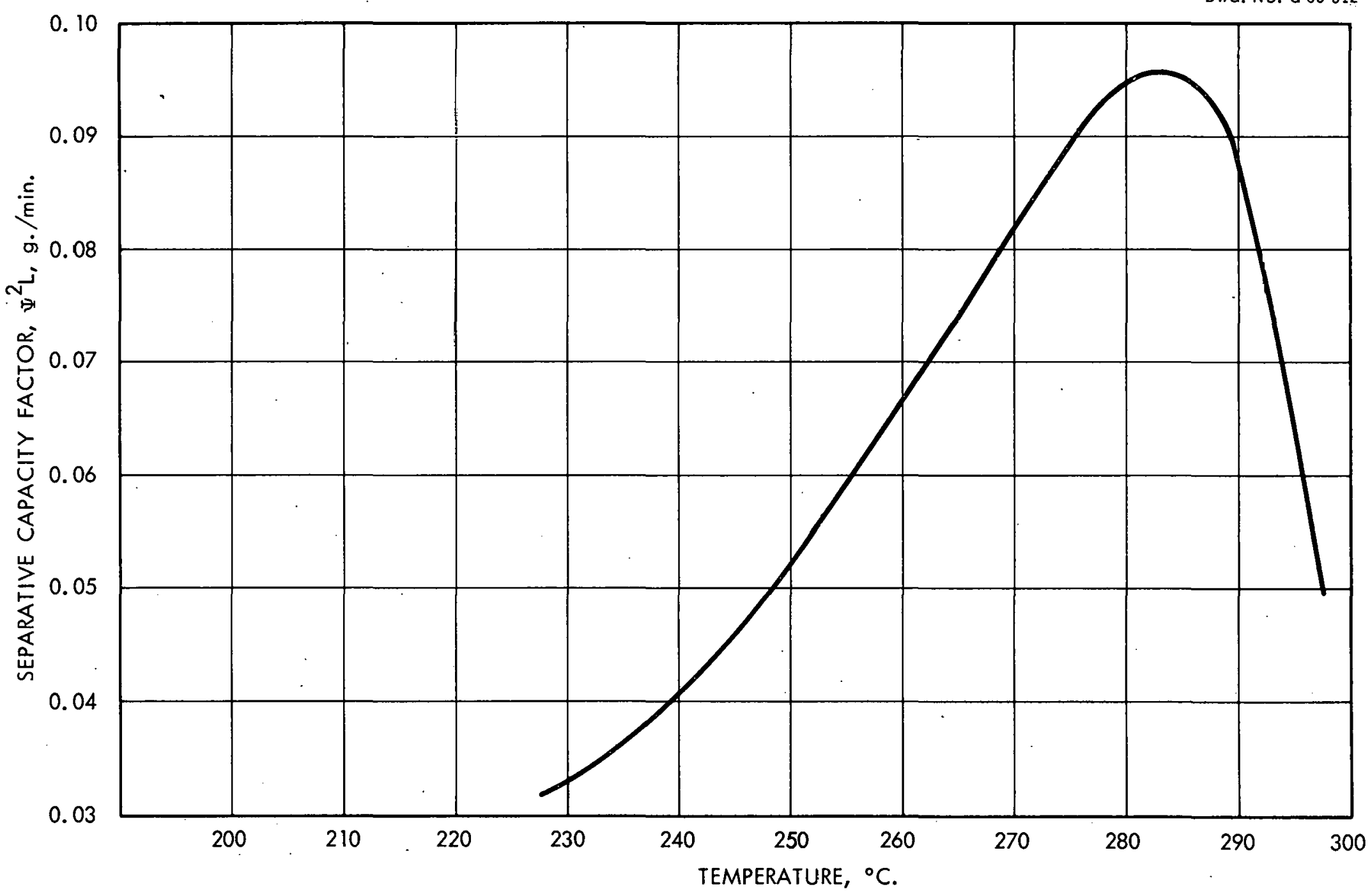

Figure 28

OPTIMIZATION OF SEPARATIVE CAPACITY 
It should be noted that even if the maximum theoretical interstage flow is used to calculate the product $\Psi^{-}$, the function will still maximize at $283^{\circ} \pm 1^{\circ} \mathrm{C}$. ; this is due to the strong influence of the $\Psi$ factor and its rapid decrease above $280^{\circ} \mathrm{C}$.

For correct operation of the still at temperatures of $280^{\circ} \mathrm{C}$. and above, it was found necessary to introduce a small tilt to the trays, the reject end (stage 1) being lower than the product end (stage 10). Unless this tilt was used, the depth of metal at the reject end became too low to sustain proper operation of the end loop thermal pump. The minimum amount of tilt necessary was used and increased with operating temperature. About 7 mils per stage was needed at $280^{\circ} \mathrm{C}$., increasing to about $28 \mathrm{mils}$ per stage at $296^{\circ} \mathrm{C}$. At no time did the introduction of tilt make any detectable change in the interstage or product end loop flow rates. It will be recalled that the potassium condensing surfaces were constructed with a slope of 62.5 mils per stage toward the product end of the tray; therefore, the tray tilt should not have caused the potassium collection efficiency to be badly affected.

The data show in figure 26, combined with economic considerations to be presented later, fix the economic optimum operating temperature near $270^{\circ} \mathrm{C}$. ; this operating temperature results in the minimum unit cost of enriched $\mathrm{K}-39$. Having established this temperature, the remaining experiments with the Modex still were all conducted near this point.

Interstage Flow Imbalance. In the total reflux runs carried out to locate the temperature for maximum separative work, considerable care was taken to assure the equality of interstage potassium flows in order to obtain a cut of one-hälf' in each stage and avoid any separation losses due to mixing streams of unequal concentrations. This balance was obtained by adjusting the power input to individual stages until equal xylene reflux rates were measured. Individual stage heat control and reflux measurements are not practical for a distillation cascade, therefore such balance will not be attainable on large trays and it is considered necessary to evaluate the effect on separative efficiency of various degrees of imbalance. One way in which measurable imbalance can arise is by heat losses to the atmosphere at stages bordering a tray; another way is by burn-out of one or more heating elements serving a stage or stages.

The Modex still was brought to equilibrium at total reflux at $273^{\circ} \mathrm{C}$. evaporator temperature with a power input of $103 \mathrm{kw}$. Stage xylene reflux rates were balanced to within $\pm 0.4 \mathrm{sec}$. for a collection time of 34.8 $\mathrm{sec} . / \mathrm{kg}$. xylene. Stage isotopic samples were taken twice in 24 hours to obtain the isotopic gradient under balanced conditions. Then the power input to stages 3 and 8 , the center stages of each tray, was reduced by $7 \%$ to simulate burn-out of one of the 15 heating elements under each of these stages. Two samplings for the isotopic gradient were again taken during the next 24 hours and the power to stages 3 and 8 again reduced to simulate the loss of a second heating element. Stage sampling was repeated under these conditions and power then restored to bring these stages back to a balanced condition. Final sampling of the gradient completed this 
experiment. Table II summarizes the performance of the still during this test, with the isotopic gradients illustrated in figure 29.

Although the power reductions are definitely detectable in both stage temperature and xylene reflux rate, figure 29 shows that no significant deviation of the isotopic gradient from the balanced condition results for either test, indicating that interstage flow imbalance of this order of magnitude in $20 \%$ of the stages would produce no appreciable loss of separation at total reflux. Calculations based on the data in figure 28 also show that if comparable degrees of imbalance occur in a producing cascade, with equal numbers of stages operating slightly above and below the average $270^{\circ}-\mathrm{C}$. operating point, no significant loss of separative capacity should result.

TABLE II

EFFECT OF STAGE POWER IMBALANCE ON TRAY PERFORMANCE

\begin{tabular}{|c|c|c|c|c|}
\hline \multirow[b]{2}{*}{ Condition } & \multicolumn{2}{|c|}{$\begin{array}{c}\text { Average Evaporator } \\
\text { Temp., }{ }^{\circ} \mathrm{C} \text {. }\end{array}$} & \multicolumn{2}{|c|}{$\begin{array}{l}\text { Average Xylene Reflux } \\
\text { Rate, sec./kg. }\end{array}$} \\
\hline & $\begin{array}{c}\text { Balanced } \\
\text { Stages } \\
\end{array}$ & $\begin{array}{c}\text { Unbalanced } \\
\text { Stages } \\
\end{array}$ & $\begin{array}{c}\text { Balanced } \\
\text { Stages }\end{array}$ & $\begin{array}{c}\text { Unbalanced } \\
\text { Stages }\end{array}$ \\
\hline 1. Balanced & 273.4 & - & 34.8 & - \\
\hline $\begin{array}{l}\text { 2. } 7 \% \text { Reduction, Stages } \\
3 \text { and } 8\end{array}$ & 273.3 & 270.5 & 35.0 & 37.5 \\
\hline $\begin{array}{l}\text { 34. Reduction, } \\
\text { Stages } 3 \text { and } 8\end{array}$ & $273 . ?$ & 269.0 & 35.1 & 40.5 \\
\hline 4. Balanced & 273.4 & - & 34.8 & - \\
\hline
\end{tabular}

Condenser Temperature Reduction. In all separation tests previously described, the potassium condenser was cooled by $p$-xylene refluxing at its atmospheric boiling point of $138^{\circ} \mathrm{C}$. The actual temperature of the condensing potassium is higher, however, due to the temperature gradient through the stainless steel condenser bottom required to effect the transfer of heat. From a theoretical standpoint it is desirable to maintain the condensing potassium at the lowest possible temperature in order to avoid re-evaporation from the condenser and a consequent lower separation factor: Generally, a $100^{\circ}-\mathrm{C}$. temperature difference between the evaporating and condensing surfaces is considered adequate for molecular distillation of most substances. In the runs previously described, this value varied from about $81^{\circ}$ to about $95^{\circ} \mathrm{C}$, as shown in table $\mathrm{I}$, depending on the operating temperature and the corresponding heat load. A test was desired to determine if reduction of the potassium condenser temperature would produce a useful improvement in separation factor. 
74

DWG. NO. G-65-522

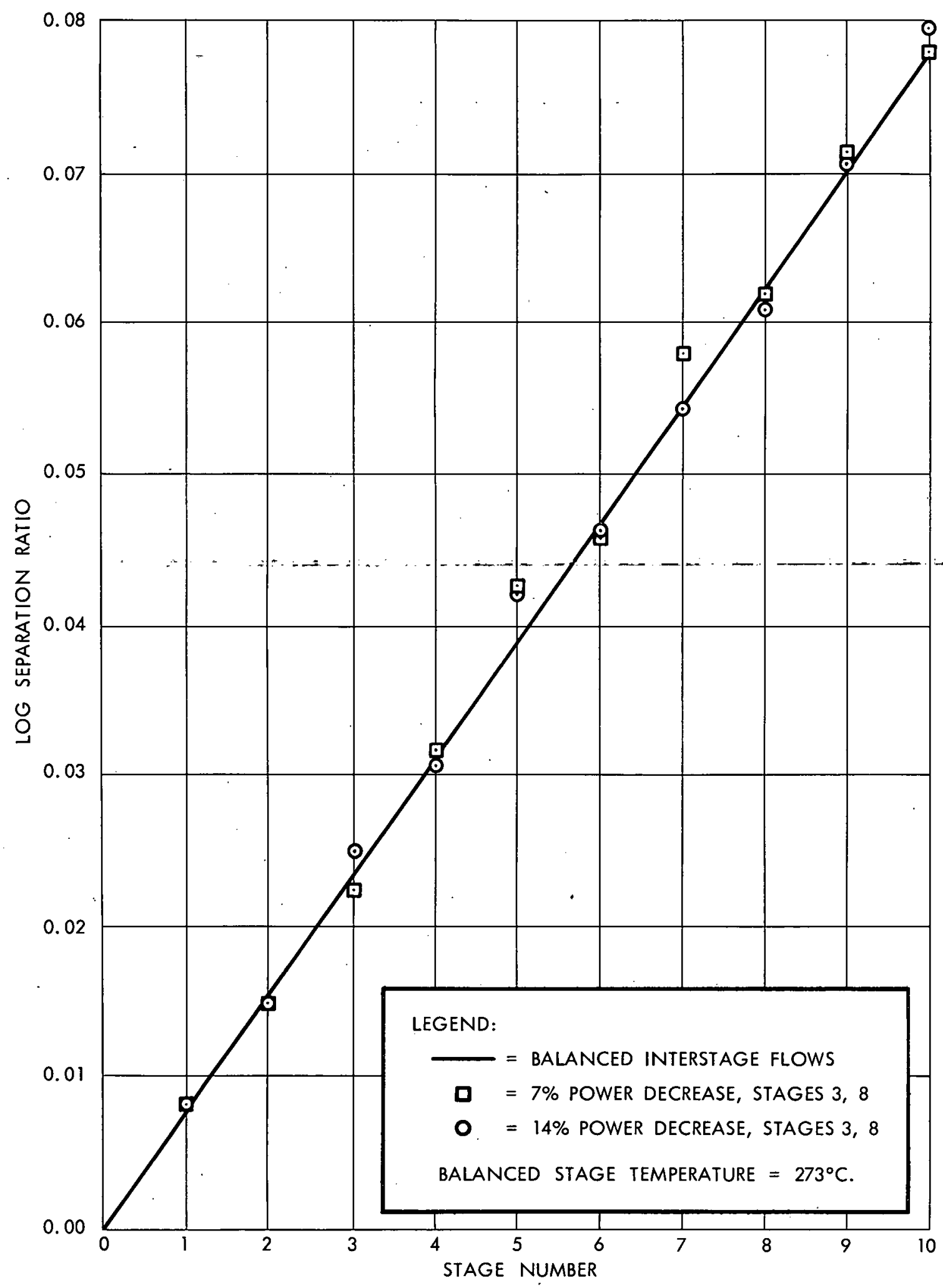

Figure 29

EFFECT OF INTERSTAGE FLOW IMBALANCE 
This test was begun under the same conditions just described for the flow balance test: total reflux, power input $103 \mathrm{kw}$. , evaporator temperature $273.1^{\circ} \mathrm{C}$. Under these conditions the potassium condenser was operating at an average temperature of $189.5^{\circ} \mathrm{C}$., for a temperature differential of $83.6^{\circ} \mathrm{C}$. After equilibrating the still and withdrawing samples, the pressure over the refluxing xylene coolant was reduced from atmospheric pressure to 8.5 psia. by a pressure control system on the xylene vent header. The xylene boiling point was reduced from $138^{\circ} \mathrm{C}$. to $118^{\circ} \mathrm{C}$. and the potassium condenser reduced to $175.3^{\circ} \mathrm{C}$. for a temperature differential of $97.3^{\circ} \mathrm{C}$. The still was held at these conditions for 24 hours, then returned to the original conditions as a check. Stage separation data for the two conditions are presented in figure 30. While the points do not differ significantly from the line, the fact that they lie primarily above it suggests that an improvement might be detectable if more separative stages were available to reduce the effect of analytical error.

Inert Gas Pressure. Ideally, the molecular distillation process should be carried out with nothing other than the vapor of the distilling substance present, since extraneous gas molecules only increase the number of detrimental collisions occurring during passage to the condensing surface. Some measurements of the extent to which inert gas pressure does interfere with the separation process were made by bleeding argon into the high vacuum system during operation and/or throttling the pumps to attain a series of inert gas pressures up to $53 \mu$. The still was allowed to equilibrate at each pressure condition for 24 hours or longer with two samplings being made to determine the isotopic gradient. Gas pressures of $5 \times 10^{-5}$ torr and higher were verified with a calibrated McLeod gauge; lower pressures were simply measured with the ion gauge system.

Figure 31 summarizes the data obtained. The normal operating pressure for all previously described runs was in the range $5 \times 10^{-7}$ to $2 \times 10^{-6}$ torr. With an increase in inert gas pressure to $25 \mu$, the loss in separation factor was not significant over 10 stages, nor could any change in interstage flows be detected. At $53 \mu$ pressure, however, a reduction of interstage flow of about $4.5 \%$ occurred and the evaporator temperature increased, both indicative of interference with the vaporization process. It was necessary to reduce the power input from $103 \mathrm{kw}$. to $88 \mathrm{kw}$. to maintain a $273^{\circ} \mathrm{C}$. operating temperature. From figure 31 , it is clear that the brief pressure excursions to $1 \times 10^{-5}$ torr which occasionally occur during sampling have no effect on the performance of the still, and that temporary loss of diffusion pumping would not even be expected to be detectable over 10 stages of distillation. However, the figure should not be taken to imply that only rough pumping is needed, since contamination of the potassium would become serious at the higher pressures noted unless the gas is truly inert.

Feed and Withdrawal Runs. These runs were made to determine the effect on the isotopic gradient of feeding and withdrawing potassium at flow rates consistent with the production of one ton per year of enriched potassium. This involves a product flow rate of approximately $2 \mathrm{~g} . / \mathrm{min}$. or approximately $0.74 \%$ of the interstage potassium flow at $273^{\circ} \mathrm{C}$. in the Modex still. Normal potassium feed is most easily introduced in this still at the 
DWG. NO. G-65-521

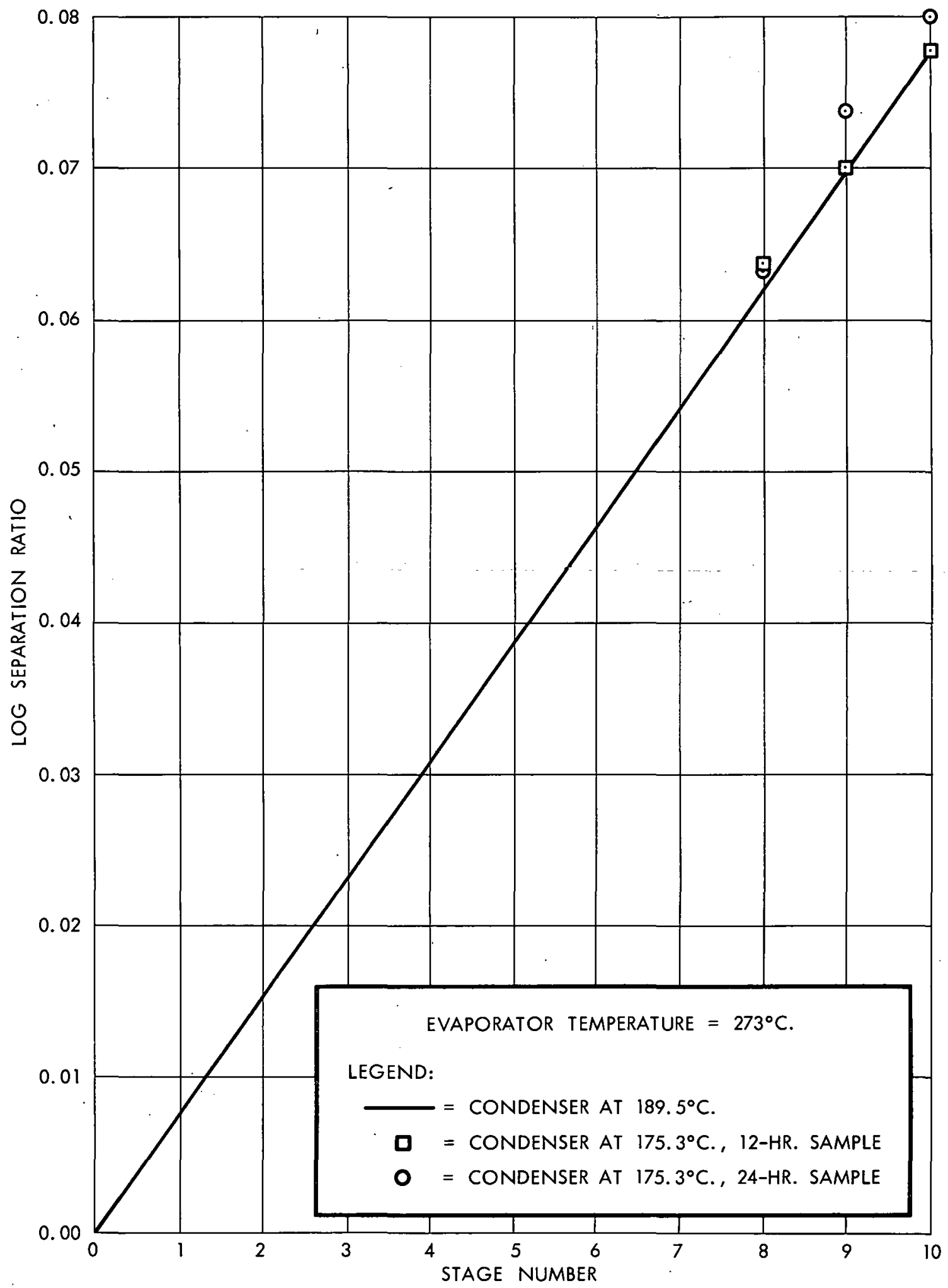

Figure 30

EFFECT OF LOWERING CONDENSER TEMPERATURE 
DWG. NO. G-65-631

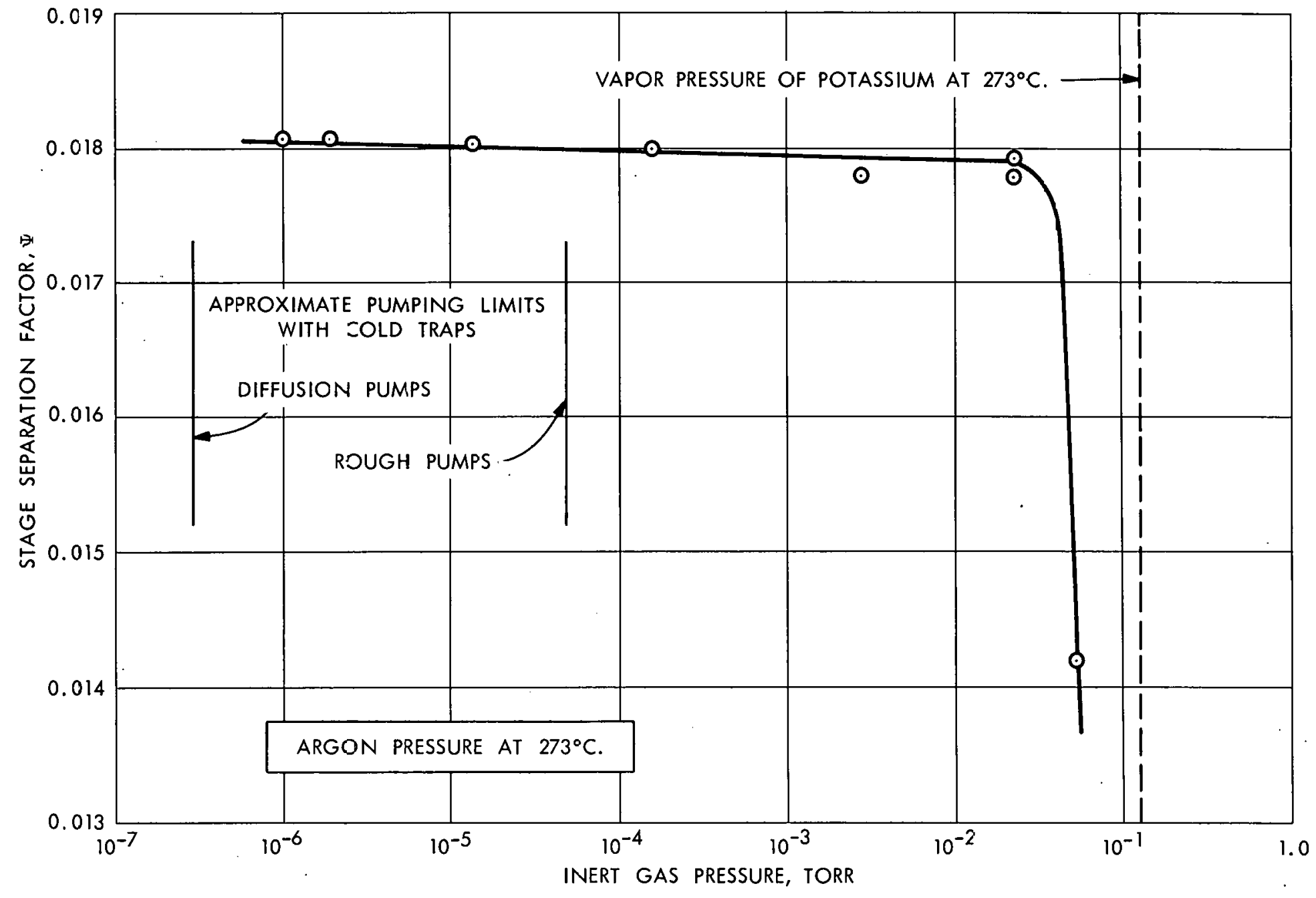

Figure 31

EFFECT OF INERT GAS PRESSURE ON THE SEPARATION OF POTASSIUM ISOTOPES BY MOLECULAR DISTILLATION 
intertray connection between stages 5 and 6 , since the assay of the metal at this point remains normal under total reflux conditions. A feed valve was provided at this location during the construction of the still and valves for the removal of product and reject streams were provided on the end loops of stages 10 and 1 respectively.

Careful metering of the three streams is necessary to avoid any marked changes in the still inventory during the feed and withdrawal runs. Although accurate metering of potassium flows of the required order of magnitude (< $10 \mathrm{~g} \cdot / \mathrm{min}$.$) is difficult, a drop-weight meter was developed$ which proved to be adequate. Drops formed on a special stainless steel metering tip were photoelectrically counted for a period of time to establish a constant flow rate. The tips, $52 \mathrm{mils}$ in diameter at the product and reject stations and 81 mils in diameter at the feed point, were originally calibrated to determine the average drop weight. Collection of product and reject flows was made in stainless steel tanks which were maintained under full vacuum conditions and heated to keep the metal molten; the arrangement used is shown in figure 32. The metal drops on leaving the metering tip fell directly into the tank. Each tank had a capacity of about $12 \mathrm{lb}$. of metal and was equipped with an accurate depth gauge to allow measurement of the actual amount of metal collected at any time. Bellows-sealed sensitive needle valves were used to regulate the flows. The feed system used an identical drop-weight meter feeding directly into the intertray connection. A heated drum of pure potassium metal mounted on scales was slightly pressurized with argon to provide feed.

During the feed and withdrawal runs, it was found that after a few hours the size of metal drops on the metering tips had increased, probably due to better wetting of the tip surtace. Flow measurements were thereafter made by monitoring metal depth in the product and reject tanks at 15-minute intervals and using the drop rate as an indication of steady flow conditions. The feed drum was continuously weighed during runs.

In the first run the still was brought to equilibrium at $273^{\circ} \mathrm{C}$. at total reflux and sampled to establish the isotopic gradient. Feed of normal potassium was then started at $4 \mathrm{~g} \cdot / \mathrm{min}$. with simultaneous withdrawal of product and reject streams at $2 \mathrm{~g} . / \mathrm{min}$. each. These flows were continued for 35.6 hours, three samplings being made during this time to check the isotopic gradient. The still was then returned to total reflux at the conclusion of the run as a check. Actual feed, reject, and product flows averaged over the 35.6-hour period were $3.985,2.001$, and $2.007 \mathrm{~g} . / \mathrm{min}$.; the discrepancy of $23 \mathrm{mg} . / \mathrm{min}$. caused a loss of $0.108 \mathrm{lb}$. of metal in the still, which is not a significant fraction of the 4l.25-1b. inventory.

The second run was carried out in identical fashion except that target flow rates of 8,4 , and $4 \mathrm{~g} \cdot / \mathrm{min}$. were set for the feed, reject, and product flows. This run continued for only 23 hours due to the limited capacities of the withdrawal tanks. Two samplings of the isotopic gradient were made. The actual average flow rates of feed, reject, and product in this run were $8.00,3.98$, and $4.02 \mathrm{~g} . / \mathrm{min}$. No net change in inventory occurred. 
PHOTO NO. PH-65-454

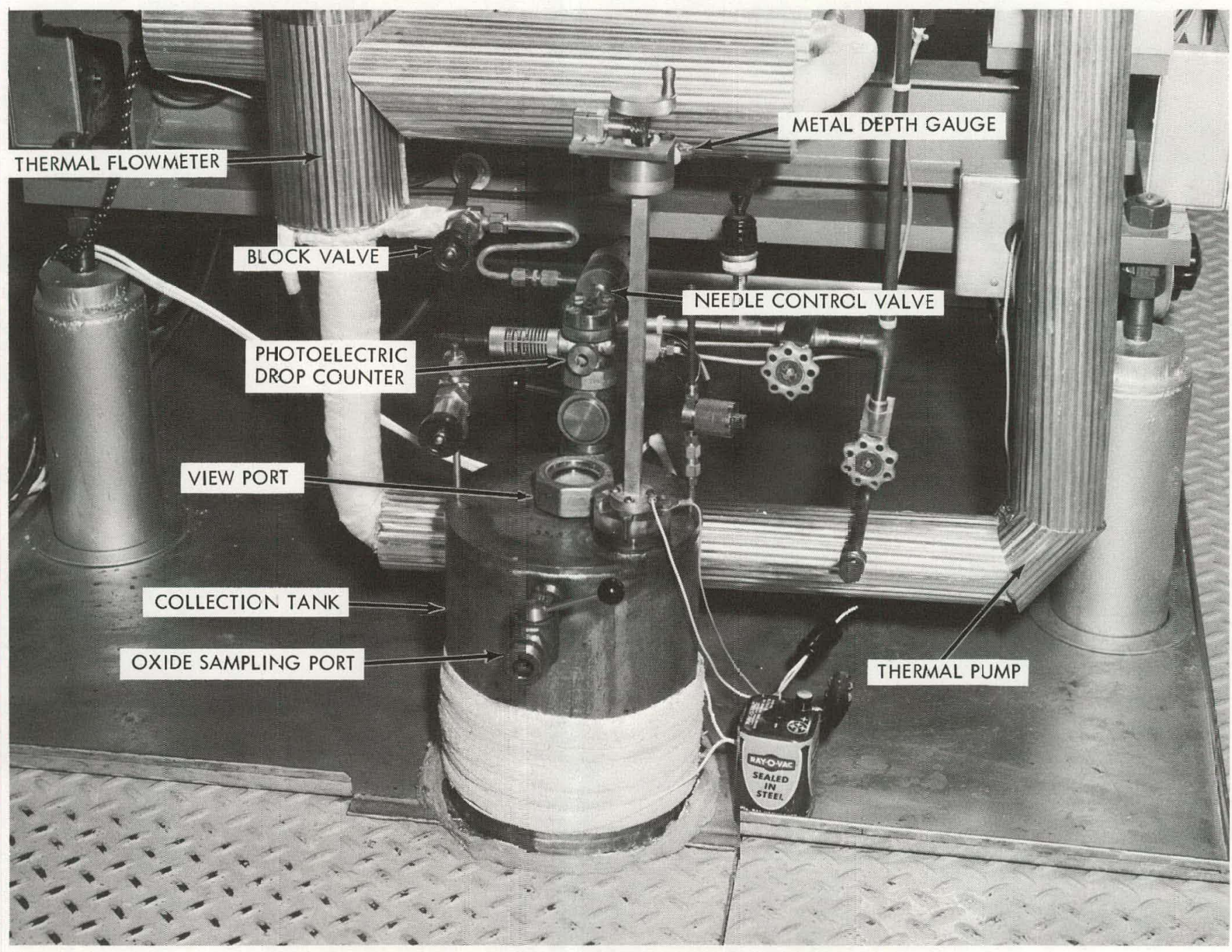

Figure 32

MODEX REFLUX ENDLOOP AND PRODUCT WITHDRAWAL STATION 
Assays of product from stages 8, 9, and 10 during these runs are plotted in figure 33 to show their relationship to the gradient at total reflux represented by the solid line. In the first run there was definitely no significant change in the isotopic gradient detectable over the 10 stages. In the second run the points shown are just at the limit of being significantly lower than the total reflux line. Productivity calculations for these two sets of feed and withdrawal conditions verified that the loss of gradient would be expected to be within the limits of analytical accuracy.

Inventory. The startup of any isotope separation cascade always encounters the equilibrium time - that period after the separation process begins during which the cascade gradient is being established at total reflux. Normal cascade operating costs other than feed are incurred during this period, but no product of the required assay can be withdrawn, making it desirable to keep this period as brief as possible. In the case of a distillation cascade, the length of the equilibrium period at a given temperature is almost directly proportional to the cascade inventory, illustrating the value of minimizing the inventory. A portion of the cascade inventory is held in intertray piping and pumps which can be minimized by proper cascade arrangement, but the largest part of the inventory is in the trays themselves and can only be reduced by lowering the depth of metal in the evaporating pool, since the evaporating area must be fixed.

The Modex trays were designed for operation with a 250-mil pool depth and the experimental work just described verified that this was adequate for the operating temperature range used. Tray tilt was introduced at the higher operating temperatures, but for the purpose of maintaining proper operation of the reject end loop thermal pump, not because stage 1 was in danger of running dry. Experiments were therefore performed at temperatures near $270^{\circ} \mathrm{C}$. to provide answers to the following questions:

1. With the trays level, what is the minimum metal inventory which can be used without stage I running dry? Operation of the reject end loop thermal pump could be suspended for this test, since stage separation data were not required.

2. How much can this level minimum inventory be further reduced if various amount of tilt are introduced toward the reject end?

At temperatures below about $200^{\circ} \mathrm{C}$., the evaporation rates are so low that no differences can be detected in liquid metal depths in various stages; micrometer probes inserted through the sample point vacuum locks are used for these measurements. As evaporation temperatures are increased and interstage flows increase, more metal is moved into the upstream stages from the condensers and must flow back to the downstream stages by virtue of the small liquid head developed. If the evaporation temperature is high enough to move the metal upstream faster than it can flow back through the baffled liquid pool, the lowest stage will dry up and its temperature increase abruptly. 
DWG. NO. G-65-520

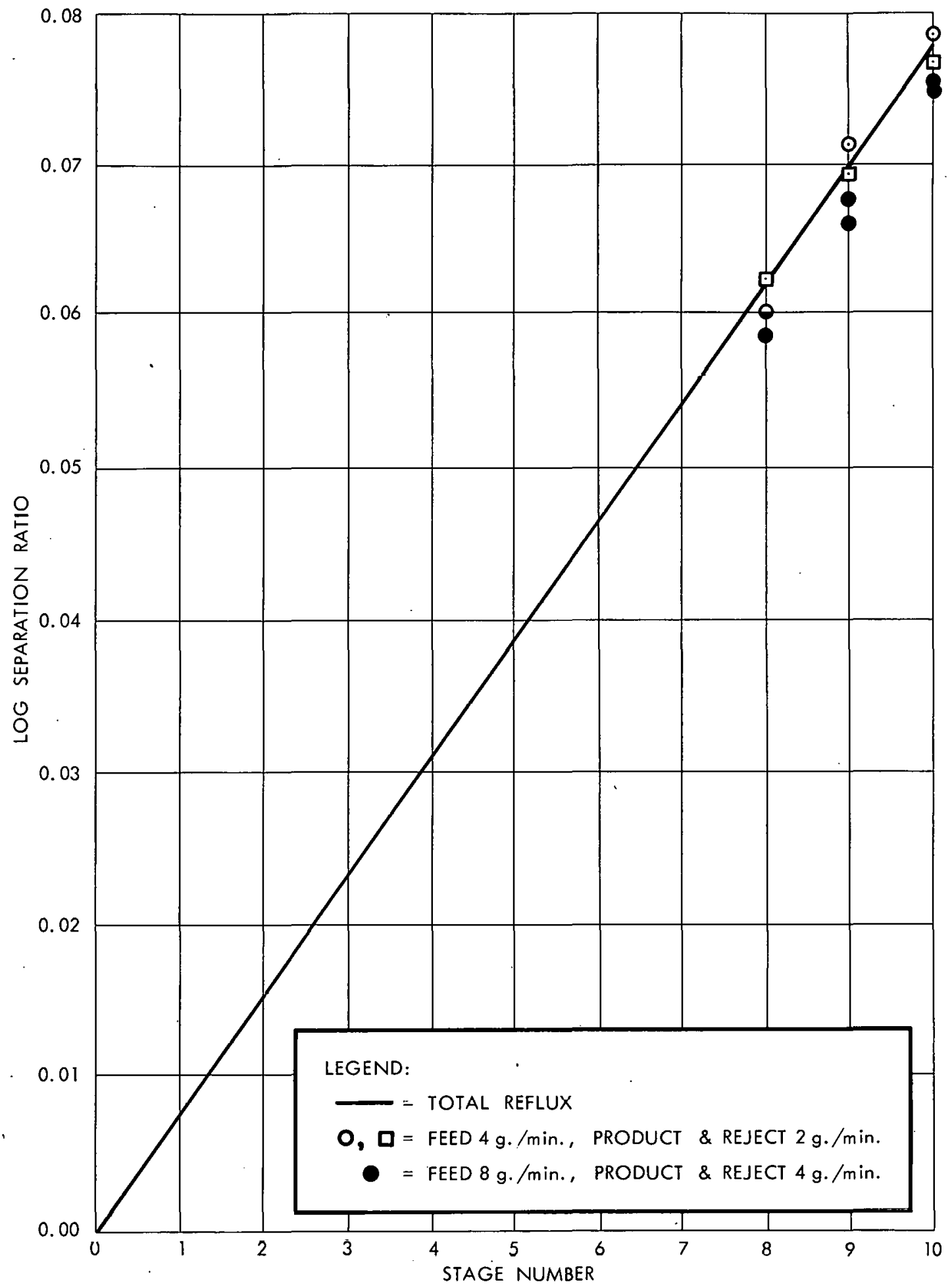

Figure 33

EFFECT OF FEED AND WITHDRAWAL FLOWS ON ISOTOPIC GRADIENT AT $273^{\circ} \mathrm{C}$. 
It was readily determined that an average liquid metal depth of 230 mils was the minimum charge on which the Modex trays could be operated in the level condition at $273^{\circ} \mathrm{C}$; attempts either to decrease the inventory or to increase the operating temperature caused stage 1 temperature to rise sharply. This 230-mil average depth corresponds to a total tray inventory of $31.4 \mathrm{lb}$. of potassium, exclusive of the metal retained in the intertray connections and end loop assemblies.

The introduction of tilt to the trays toward the reject end did allow some reduction of the level tray minimum inventory as shown in table III.

TABLE III

EFFECT OF TRAY TILT IN ALLOWING INVENTORY REDUCTION AT $273^{\circ} \mathrm{C}$.

\begin{tabular}{|c|c|c|}
\hline $\begin{array}{l}\text { Tilt Per Tray, } \\
\text { mils } \\
\end{array}$ & $\begin{array}{c}\text { Minimum Operable Depth, } \\
\text { mils }\end{array}$ & $\begin{array}{l}\text { Equivalent Tray } \\
\text { Inventory, lb. }\end{array}$ \\
\hline 0 & 230 & 31.4 \\
\hline 87 & 198 & 27.0 \\
\hline 140 & 184 & 25.0 \\
\hline
\end{tabular}

While the table shows that the 140-mil tilt allowed approximately a $30 \%$ reduction in level tray inventory, examination of the data also shows that further increase in tilt would not be expected to allow a proportionate decrease in inventory. It is therefore apparent that tilting trays of this particular design is not a very effective method of minimizing tray inventory.

It is interesting to examine actual measured metal depths at various points along the trays in comparison with the calculated depth profile based on the known interstage flows and evaporation rates and the flow resistance encountered in the various flow channels. Such a calculated profile for an operating temperature of $260^{\circ} \mathrm{C}$. is shown in figure 34 , the dotted line representing the average metal depth in the level trays when no significant distillation is occurring. Circles indicate actual measured metal depths at the stage positions plotted. The agreement between the calculated and measured depth profiles suggests that this method of calculation may serve as a valid means of estimating the minimum operable tray inventory. The method is treated in more detail in Appendix D.

Oxygen Contamination. In view of the high reactivity of potassium toward oxygen, some contamination of the metal in a large cascade is to be expected over a period of time, both by reaction with inleaking air and with any oxidized metal surfaces. The extent of contamination in a cascade cannot be readily estimated since it is highly dependent on the degree of 
DWG. NO. G-65-422

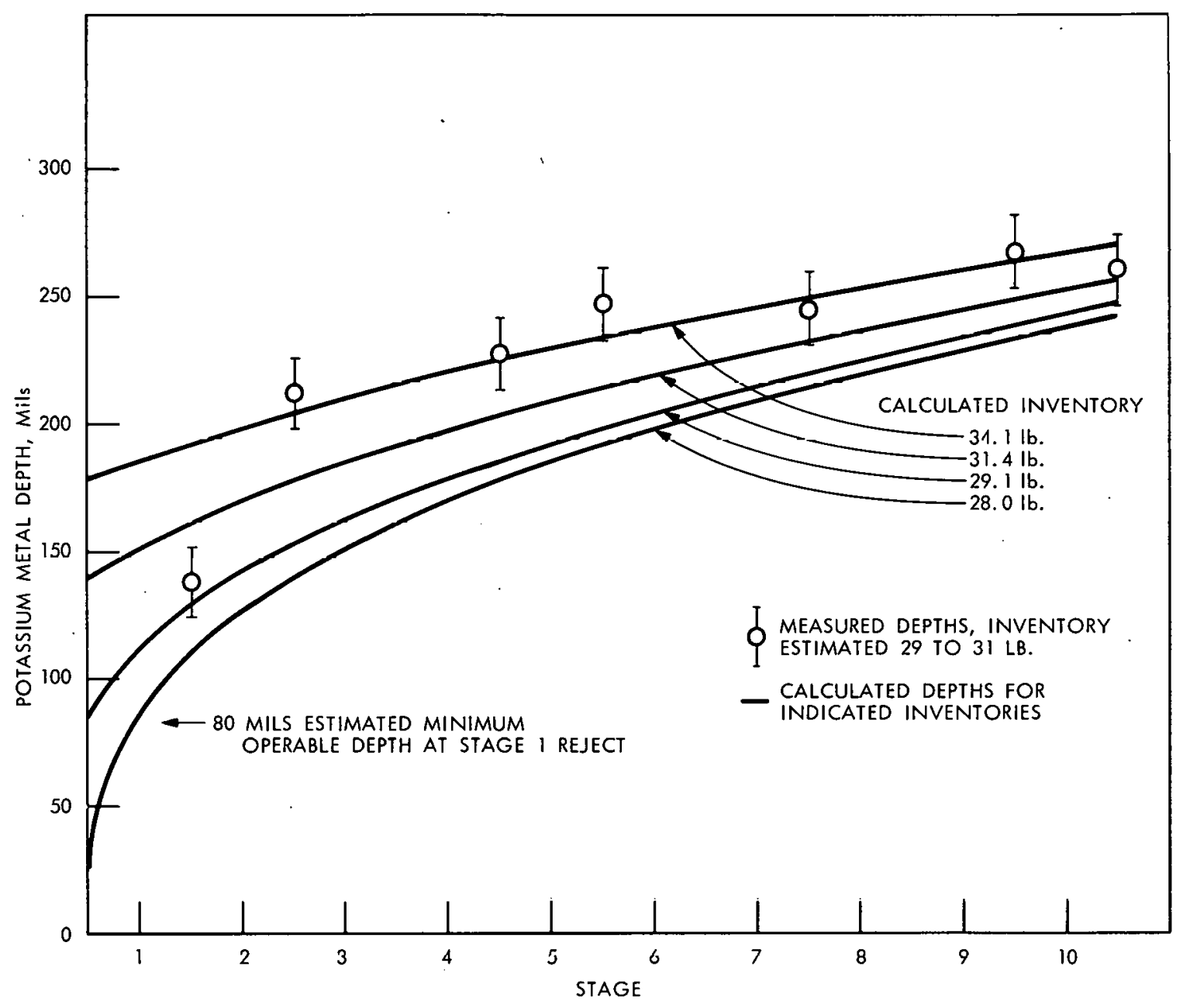

Figure 34

MODEX TRAY METAL DEPTH

GRADIENT AT $260^{\circ} \mathrm{C}$. 
leak tightness which can be maintained. It can be anticipated, however, that the enriched K-39 product will have a low oxygen content, since potassium oxide is not volatile and a simple distillation suffices to give good separation of metal from oxide (10). Therefore, unless an air leak occurs at the product withdrawal point in the cascade, the product will have undergone very many distillations and its oxygen content should be low. The separated oxide fortunately will remain in solution in the remaining undistilled metal and will be flushed toward the lowest stages of the cascade in the downflowing reject stream. It is possible in the event of large air leaks that the oxide content in the lower stages could exceed the high solubility in the metal (see Appendix A) and crystallize to obstruct interstage flow. Therefore, provisions should be made in such a cascade to reduce the oxide content of the interstage flow at points by cold trapping and filtration. Evidence was obtained in some preliminary experiments that the presence of dissolved oxide had no effect on the isotopic separation factor achieved in molecular distillation and that the rate of isotopic exchange between potassium metal and its dissolved oxide was rapid.

The feed and withdrawal runc dcccribcd above provided an opportunity to remove the large samples of metal from the Modex still required to obtain oxide analyses. These samples were removed using a horizontal probe through vacuum locks on the sides of the product and reject collection tanks. Samples of about $3.6 \mathrm{~g}$. were collected in a small bucket positioned directly under the flow metering tip. The samples were analyzed for oxygen by G. Goldberg at ORNL, using the amalgamation method.

Samples which have been completed at this time indicate oxygen concentrations of $39 \mathrm{ppm}$. at the reject end of the still and concentrations of $22,27,25$, and $23 \mathrm{ppm}$. at the product end. For comparison, the manufacturer's analysis of the feed material showed $40 \mathrm{ppm}$. oxygen. Although these samples were removed during the feed and withdrawal runs, when some flushing of oxide-laden metal was occurring, some of the still inventory which had been refluxed about 6 months was still present.

Metal Purity. Spectrographic analyses have been made on three samples of potassium removed from the product and reject collection points after the feed and withdrawal runs described above. These analyses are summarized in table IV along with the ORGDP analysis of the feed material; the manufacturer's analysis of the feed material is confused by considerable contamination of graphite and methanol used in preparing the analytical samples.

With the exception of sodium, all of the metals listed in table IV would be nonvolatile at the evaporator temperature of $273^{\circ} \mathrm{C}$. and should be lower in concentration in the product if they are present in solution. It is possible for them to move upstream in a distillation, however, if they are present as suspended particulate matter which can be transferred to the condensing surface by bombardment by potassium vapor. Filtration of the product might be effective in removing such material, but facilities are. not yet available to carry out this operation. The high silicon content of the product and reject samples could have resulted from the collection 
PURITY OF POTASSIUM FEED AND WITHDRAWAL STREAMS

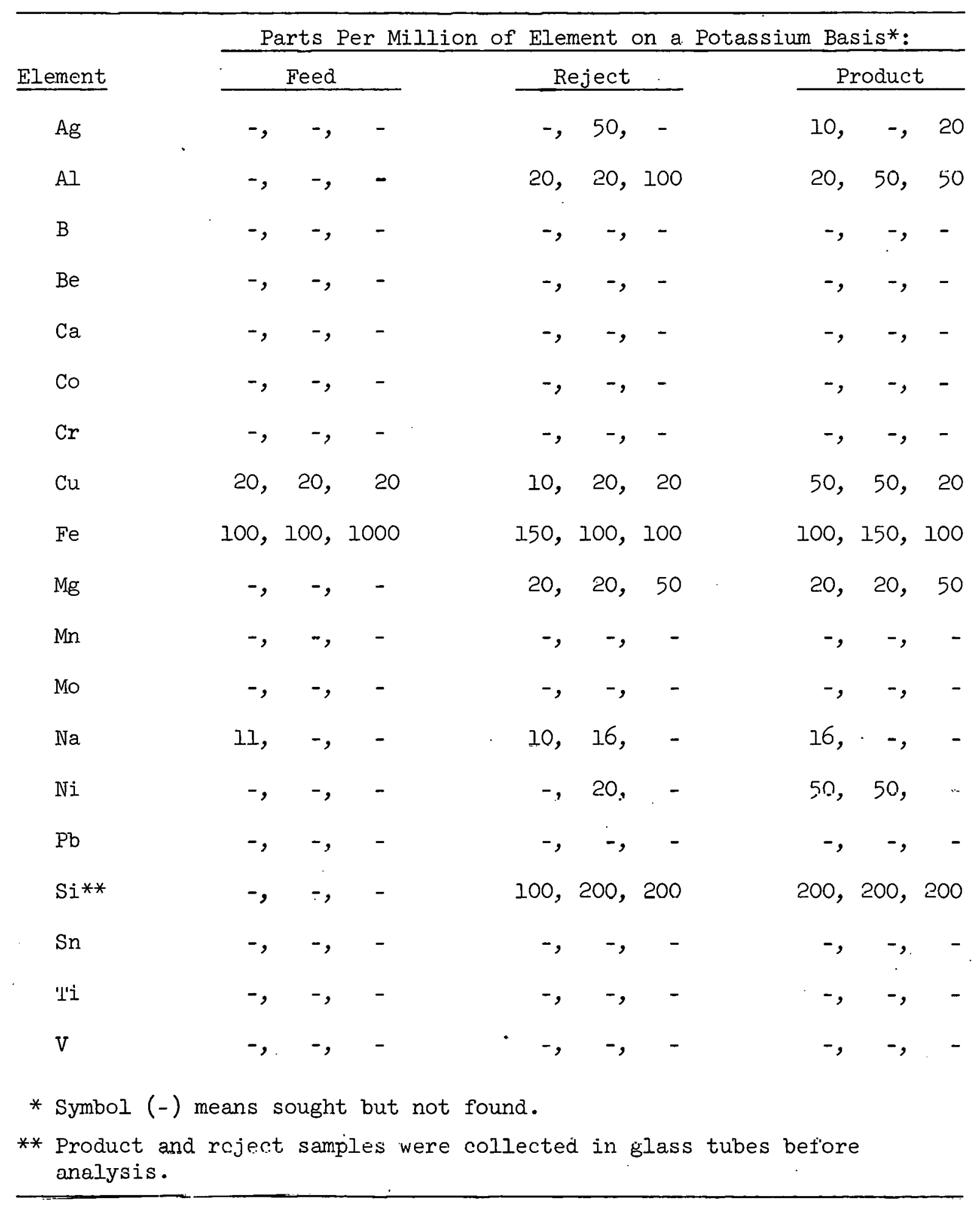


of these samples in glass tubes.

\section{CONCLUSIONS}

The construction and successful operation of the Modex trays definitely demonstrate the feasibility of conducting the molecular distillation of potassium on a scale commensurate with the production of ton-per-year quantities of enriched K-39. The fabrication of multistage trays presented some unusual problems in machining and assembly, but satisfactory solutions were found and experience was gained which will be valuable in further tray construction. In particular, the functioning of the tubular expansion joint vacuum header was most gratifying since this was a critical part of the assembly and one which was a source of some trouble in the Mevac lithium distillations.

The Modex experiments demonstrate the following features of the process:

1. Multistage molecular distillation can be conducted in flat trays with all interstage transfer of material by gravity. By eliminating interstage pumping within trays, considerable economy of tray construction and of control systems curi-be realized and by limiting mechanical seals to the sampling system a reliably leak-tight assembly can be achieved.

2. The process as conducted in the Modex equipment yields an acceptable fraction of the theoretical maximum available separation factor at the temperature of maximum separative capacity.

3. The process is readily amenable to control, i.e., the separation factor is not extremely sensitive to small variations in process parameters such as residual inert gas pressure, balance of interstage flows, and the operating temperatures of the evaporator and condenser.

4. Contamination of the enriched $\mathrm{K}-39$ product by oxygen from inleaking air does not appear to be a problem. First, it has been shown that it is possible to operate the trays so that air inleakage during a 6 -month period causes no significant increase in the oxygen content of the original feed material. Any oxide which may form is nonvolatile and therefore is washed continuously to the lower stages of the cascade where it can be removed. This should be equally true of any other nonvolatile contaminating metals which enter the system in the feed stream. Because of this purifying effect of distillation, the enriched K-39 product should be of as high or higher purity than the feed material. Volatile metal contaminants, such as sodium, can also be reduced in concentration in the product provided sufficient difference exists between their vapor pressure and that of potassium at the distilling temperature. 
5. The process can be conducted safely, in spite of the high reacitivty of potassium and the flammability of the evaporative coolant xylene. With care, considerable maintenance can be performed on trays containing molten potassium.

It must be noted that these experiments have established the temperatureseparation factor relationship which applies to trays or stages having the same or comparable spacing between the evaporating and condensing surfaces as the Modex stages. This spacing was originally established at 0.75 inch as a workable dimension. With experience gained in tray construction, the possibility may be considered of constructing stages with smaller spacings, which should increase the separation attainable at a given evaporating temperature. Further development work along this line may prove productive; smaller spacings, however, will demand some improved precision in machining and assembling the tray components.

Degradation of the xylene coolant, probably caused by air in the coolant vent system, was not anticipated. No discoloration of the coolant in the test stage occurred, though it was only operated a relatively short time. It should be possible to control this degradation by closer control of oxygen in the coolant condensation system, or by selection of another more stable hydrocarbon coolant. 
THIS PAGE

\section{WAS INTENTIONALLY}

LEFT BLANK 
PART 2 
THIS PAGE

\section{WAS INTENTIONALLY LEFT BLANK}




\section{SPECIFICATION OF THE SEPARATION TASK}

Natural potassium is a mixture of three isotopic species, atoms with a mass of 40 occurring in addition to those of 39 and 41 which have already been mentioned. The natural abundance of $\mathrm{K}-40$ is only $0.01 \%$ (see Appendix A) and it can, in consequence, be ignored with negligible error for the isotope separation job at hand. The cascade design calculations are therefore based on a binary isotopic feed mixture composed of $93.08 \% \mathrm{~K}-39$ and $6.92 \% \mathrm{~K}-41$.

The separation goal has been given as one ton per year of potassium containing no more than $0.07 \% \mathrm{~K}-41$ (no less than $99.93 \% \mathrm{~K}-39$ ). If only the target product rate and product concentration are given, the separation job is not completely specified, since the feed and waste stream rates and the waste concentration are then indeterminate. The customary way of completing the job specification is to determine the fraction of the desired component in the feed material to be recovered in the product. The feed. rate to a cascade is inversely proportional and the length of the stripping section is directly proportional to the fraction of desired component to be recovered. A preliminary economic balance between feed rate and stripper length led to a design target of $50 \%$ recovery of the $\mathrm{K}-39$ fed as enriched product. With this additional specif'ication, the flow rates and isotopic concentrations of all the cascade streams are established on the basis of material balance considerations.

\section{MAGNITUDE OF THE SEPARATION TASK}

The magnitude of a specj.fic isotope separation task is measured in terms of a quantity called separative work, which is a function of the cascade stream rates and concentrations. The theoretical separative work required for a binary separation is given by

where

$$
U=P V\left(x_{P}\right)+W V\left(x_{W}\right)-F V\left(x_{F}\right),
$$

$$
\begin{aligned}
& \mathrm{V}(\mathrm{x}) \quad=(2 \mathrm{x}-1) \ln \frac{\mathrm{x}}{1-\mathrm{x}} . \\
& \mathrm{U}=\text { the separative work, in moles/unit time. } \\
& \mathrm{P}, \mathrm{W} \text {, and } \mathrm{F} \quad=\text { the product, reject, and feed stream flow } \\
& \text { rates respectively, in moles/unit time. } \\
& \mathrm{x}_{\mathrm{P}}, \mathrm{x}_{\mathrm{W}} \text {, and } \mathrm{x}_{\mathrm{F}}=\text { the mole fraction of the desired component } \\
& \text { in the product, reject, and feed streams, } \\
& \text { respectively. }
\end{aligned}
$$

The maximum separative work which can be obtained from a cascade can be expressed in terms of the process separation parameters by 
where

$$
U=\frac{1}{4} \Psi^{2} \int_{0}^{N} L d n
$$

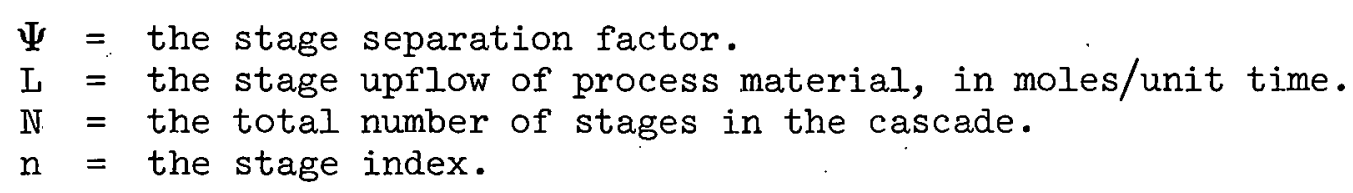

For an ideal cascade, which is defined as one in which there are no mixing losses, $\overline{\mathrm{L} \text { is }}$ a function of the stage isotopic concentration and is therefore continuously varying. The ideal stage upflow is given by

$$
L=\frac{2 P\left(x_{p}-x\right)}{\Psi x(1-x)},
$$

where $\mathrm{x}=$ the local isotopic concentration. The separative work calculated from equation 16 for an ideal cascade is equal to that given by equation 15. The variation of the ideal $L$ with stage number for this separation job is presented in figure 35 for the stated value of $\Psi$. It may be noted that the area bounded by such a curve, which is the measure of cascade size, is inversely proportional to $\Psi$ ?

\section{CASCADE DESIGN}

An ideal cascade can only be approximated in practice. A practical design is usually a step function of $\mathrm{I}$ vs. $\mathrm{n}$ approximating the ideal cascade curve. The departure of a real cascade from ideality shows up as an inefficiency in that the separative work computed by equation 15 using the actual values of the cascade stream rates and concentrations will be less than the ideal separative work computed from equation 16 .

The ideal cascade curve for the potassium isotope separation task presented in figure 35 is of such a shape that a cascade with constant interstage flow, a square cascade, fits it satisfactorily. The rectangle in figure 35 represents the square cascade selected to do the separation job. The number of stages and the stage evaporation rate required are thus specified. With the operating temperature implied by the $\Psi$ value assumed in the calculation of the ideal curve, one can then compute the metal surface area required per stage. The cascade size is thus specified.

\section{OPTIMUM OPERATING TEMPERATURE}

Selection of the operating temperature such that the quantity $\Psi_{L}^{2}$ for the process is a maximum.results in the smallest cascade and therefore the lowest capital investment. However, the quantity that should be minimized is the unit cost of product. The temperature at which this is a minimum should be somewhat lower than that at which separative work is a maximum since the cost of power increases essentially exponentially with increasing temperature. Thus, to determine the optimum operating temperature, the cascade size and power needed to yield a ton per year of potassium with a 


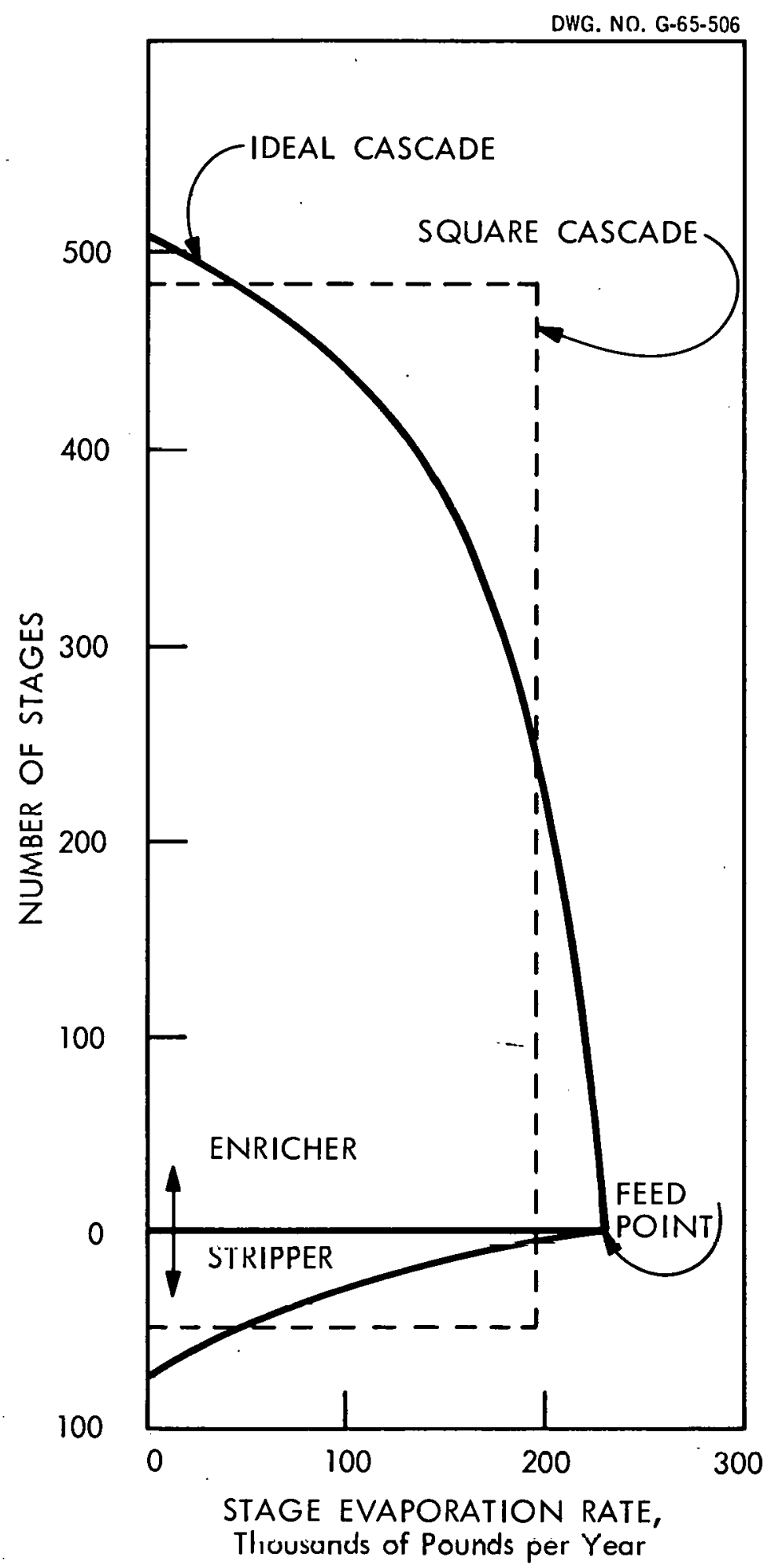

Figure 35

IDEAL CASCADE TAPER AND AN

EQUIVALENT SQUARE CASCADE APPROXIMATION $\Psi=0.0183$ 
K-39 content of $99.93 \%$ were computed for several different temperatures over the range of $240^{\circ}$ to $300^{\circ} \mathrm{C}$. Stage separation factors and potassium evaporation rates were based on the correlations of the data from'the Modex still. Estimates of the capital and operating costs were made for each cascade, and unit product costs were computed assuming a 10-year amortization of capital costs. The results are summarized by the curve in figure 36. The unit product cost is estimated to be a minimum at $270^{\circ} \mathrm{C}$.

The cost bases used in making the above analysis differ somewhat from the later bases used in obtaining the more detailed cost estimate reported in the section below, which describes the prototype molecular distillation. tray designed for this separation and the conceptual cascade layout. The differences in the two bases do not appear to be of such a nature or magnitude as to shift the locus of the optimum operating temperature significantly, though the estimated unit costs at the optimum will differ somewhat.

\section{CHARACTERISTICS OF THE DESIGN CASCADE}

The characteristics of a cascade designed to operate at $270^{\circ} \mathrm{C}$. to produce about one ton per year of potassium with $99.93 \% \mathrm{~K}-39$ are presented in table $v$. This cascade is about half the size and roughly the same in power demand as the preliminary design mentioned in the Introduction, which had been based on operation at $250^{\circ} \mathrm{C}$. and theoretical or assumed separation parameters.

An estimate of the maximum length of time after start-up required for the cascade to reach steady state operating conditions is 4.6 months. To make this estimate it was assumed that the liquid metal depth will be 250 mils. Liquid metal inventories external to the stage and all vapor holdups were neglected.

Productivity calculations for the design cascade indicate the expected yield at a product concentration of $99.93 \% \mathrm{~K}-39$ to be 1960 pounds per year of potassium. Figure 37 shows the predicted variation of product concentration, expressed in terms of the K-4I depletion factor, as a function of the product withdrawal rate.

A ternary productivity calculation for the cascade confirmed that the error introduced by the assumption of a binary isotopic separation is negligible. 


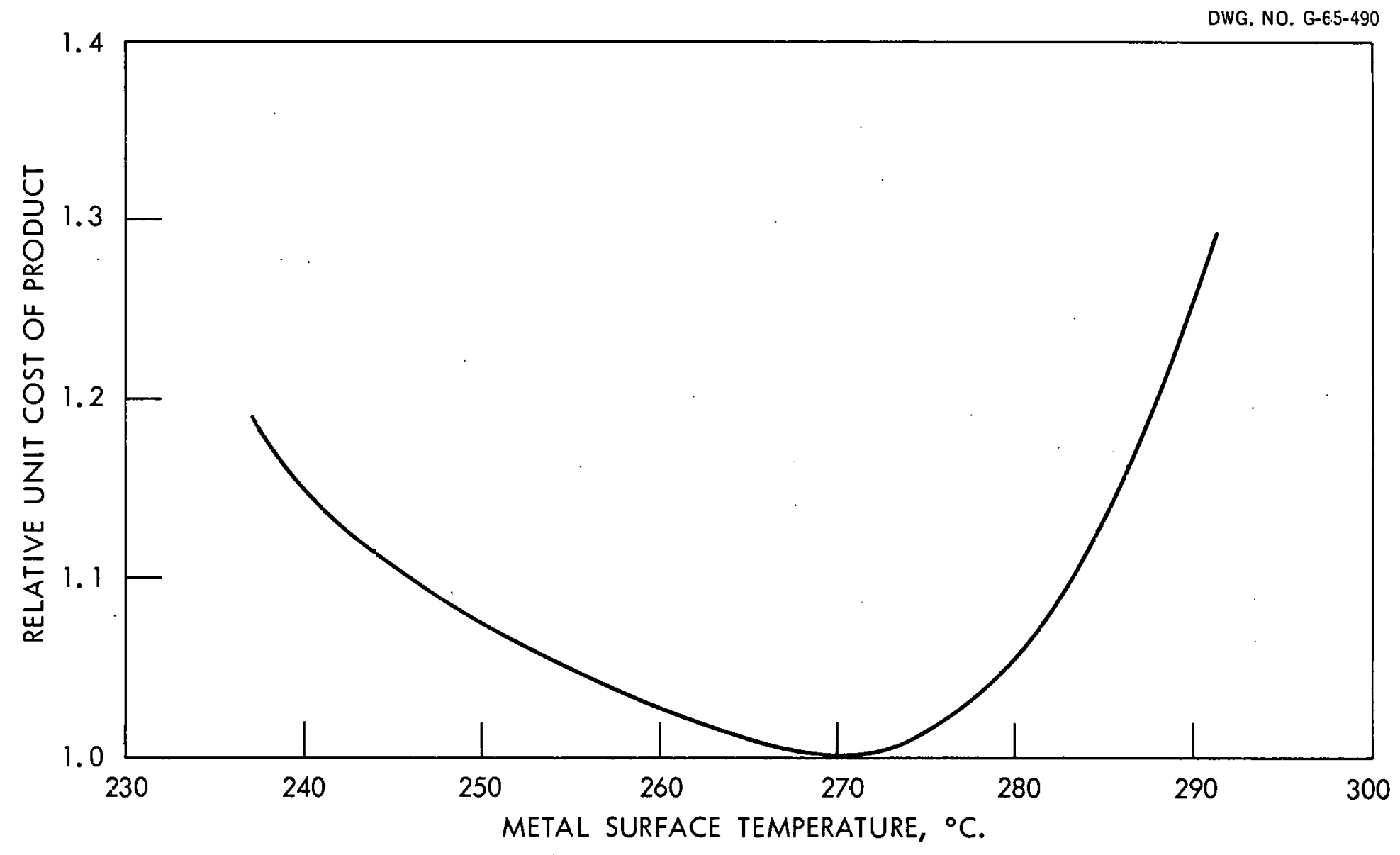

Figure 36

EFFECT OF OPERATING TEMPERATURE ON COST OF PRODUCT 
TABLE V

CHARACTERISTICS OF THE DESIGN CASCADE

Operating Conditions, ${ }^{\circ} \mathrm{C}$.

Liquid metal temperature

270

Condenser temperature

180

Separation Parameters

Stage separation factor, $\Psi_{n}$

0.0183

Evaporation rate, Ibs./sq.ft.-hr.

10.7

Cascade Dimensions and Requirements

Totai number of' stages

$-525$

Number of stripping :stages

48

Stage area, sq.ft.

2.1

Total cascade metal surface area, sq.ft.

1100

Stage evaporation rate, Ibs./yr. 194,000

Power consumption, MW. 3.63

Iiquid metal depth, in. 0.25

Potassium inventory, Ibs. 1490

Equilibrium time, months

$$
4.6
$$

\section{Cascade Productivity}

Product concentration, K-41 atom \%

0.07

Product rate, Ibs./yr.

1960

Feed rate, Ibs./yr. 4290

Recovery of $\mathrm{K}-39$ in the product stream, \% of $\mathrm{K}-39$ Fed

49.1 
DWG. NO. G-65-505

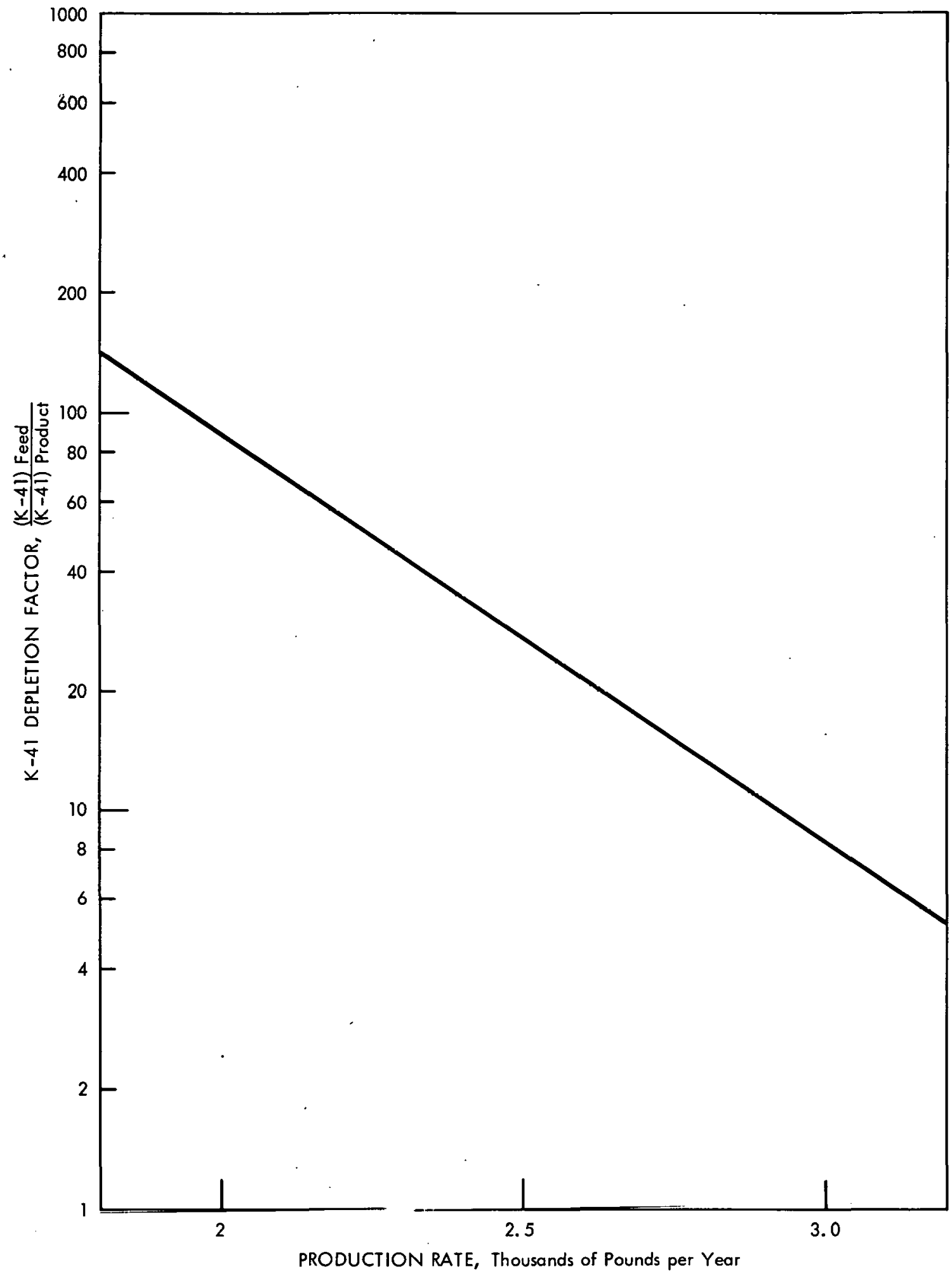

Figure 37 


\section{PROTOTYPE CASCADE TRAY}

The previous section has presented a description of the methods by which the experimental Modex still data were treated in order to specify the molecular distillation cascade required to perform the desired separative work. Two important tray design factors are fixed by this cascade design, viz., an optimum evaporator temperature of $270^{\circ} \mathrm{C}$. and a stage evaporating area of about $2.1 \mathrm{sq.ft}$. The establishment of these two factors allowed making an improved tray design for cascade use; it will be recalled that the experimental Modex trays necessarily had to be designed for operation over a wide range of temperatures and with a compromise stage area selected to assure that the required flow and separation data could be obtained.

The smaller stage area, combined with the successful operation of the tubular expansion joint, suggested the feasibility of a prototype tray containing more stages than the Modex trays. By thus decreasing the number of trays required for any given cascade, the capital costs can also be reduced. Two modifications of the stage itself were also indicated. First, a square configuration was to be used rather than the rectangular Modex stage. This feature reduces the stage perimeter tor a tixed stage area and thereby decreases parasitic condensation of potassium vapor on the stage dividers; such condensation would reflux some of the potassium to the evaporating pool without accomplishing useful separation. Second, triangular filler blocks were to be installed in the square corners of the stage flow paths to decrease the possibility of having stagnant metal collected in these areas which could reduce the stage separation factor.

Figure 38 shows the stage arrangement and flow pattern adopted for the Prototype tray. Fifteen of the square stages were arranged in a 3-by-5 array, each stage measuring about $18 \mathrm{in.} \mathrm{square} \mathrm{plus} \mathrm{a} 1$-in. wide distillate collection channel at one edge. By arranging the flow between stages as shown in figure 38 , it is possible to locate all of these collection channels in continuous rows down the length of the tray, which allows placement of the tray heating elements to avoid these channels as in the Modex design. Tray heating elements are of the tubular type, running the length of the tray and arranged into three groups under the three rows of five stages. Each of these three rows of five stages is also furnished with a common xylene coolant system and.coolant condenser. Clearly, this arrangement does not allow adjusting or monitoring the interstage flow from individual stages; the Modex experiments showed that very close control of these flows was not necessary and this modified arrangement permits considerable simplification of the coolant system. Power control for the tray consists of three sets of silicon controlled rectifiers operating from Vectrol gating circuits. The gating circuits supply D.C. pulses of adjustable length which bias the rectifiers conducting during the pulse period. A range of average power levels is attained by regulating the ratio of conducting/nonconducting time. By,using three such control circuits for the tray heating elements, it is possible to apply extra heat to the edges of the tray to compensate for heat losses. An arrangement is made for checking the heat balance between the three 
DWG. NO. G-65-487

FEED FROM

FEED FROM

REJECT TO

TRAY BELOW

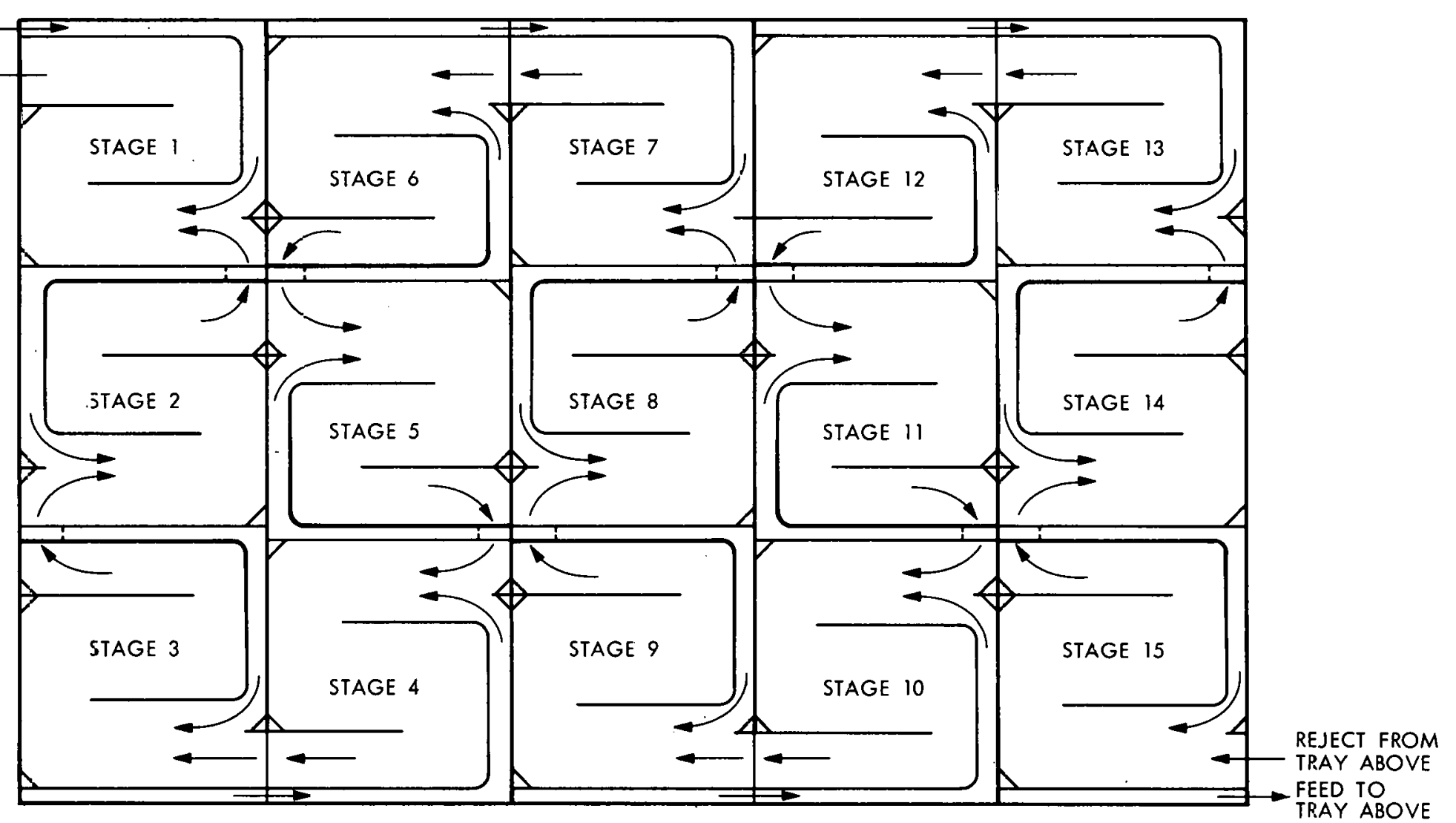

Figure 38

PLAN OF PROTOTYPE TRAY 
rows by metering cooling water to the xylene condensers and measuring its. temperature increase.

The Prototype tray differs in one feature from a cascade tray; six sampling points are provided instead of the single point per cell which should suffice for a cascade. These extra sample points, located at the end of each pass of three stages, allow determining the isotopic gradient within the tray and therefore aid in localizing any defective stages. Construction of the tray support frame and tubular expansion joint follows the Modex design.

Photographs shown in figures 39 and 40 show the Prototype evaporator and potassium condensing surfaces respectively, while figure 41 shows the top surface of the condenser section. Note the openings for attaching the three xylene condensers.

The Prototype tray is interconnected with the Modex trays so that either system may be operated separately at total reflux or they may be joined to form a 25-stage facility. This latter operation requires a flow splitting arrangement, since the Modex stage area is about $50 \%$ larger than the Prototype stage area, and, if both trays are operated at the same temperature, the stage 10 product flow from the Modcx trays is about 50\% larger than the Prototype interstage flow. This excess flow is simply refluxed to stage 10 .

Figure 42 shows one of the silicon controlled rectifier assemblies and its associated Vectrol control circuit; three of these assemblies supply controlled power to the Prototype tray. Note that these units are far more compact than the Modex transformers shown in figure 23, but that individual stage power control is not possible in this arrangement.

At the present time the installation and testing of the Prototype is being completed; performance data on this unit will be covered in a subsequent report. 
PHOTO NO. PH-65-10乞6

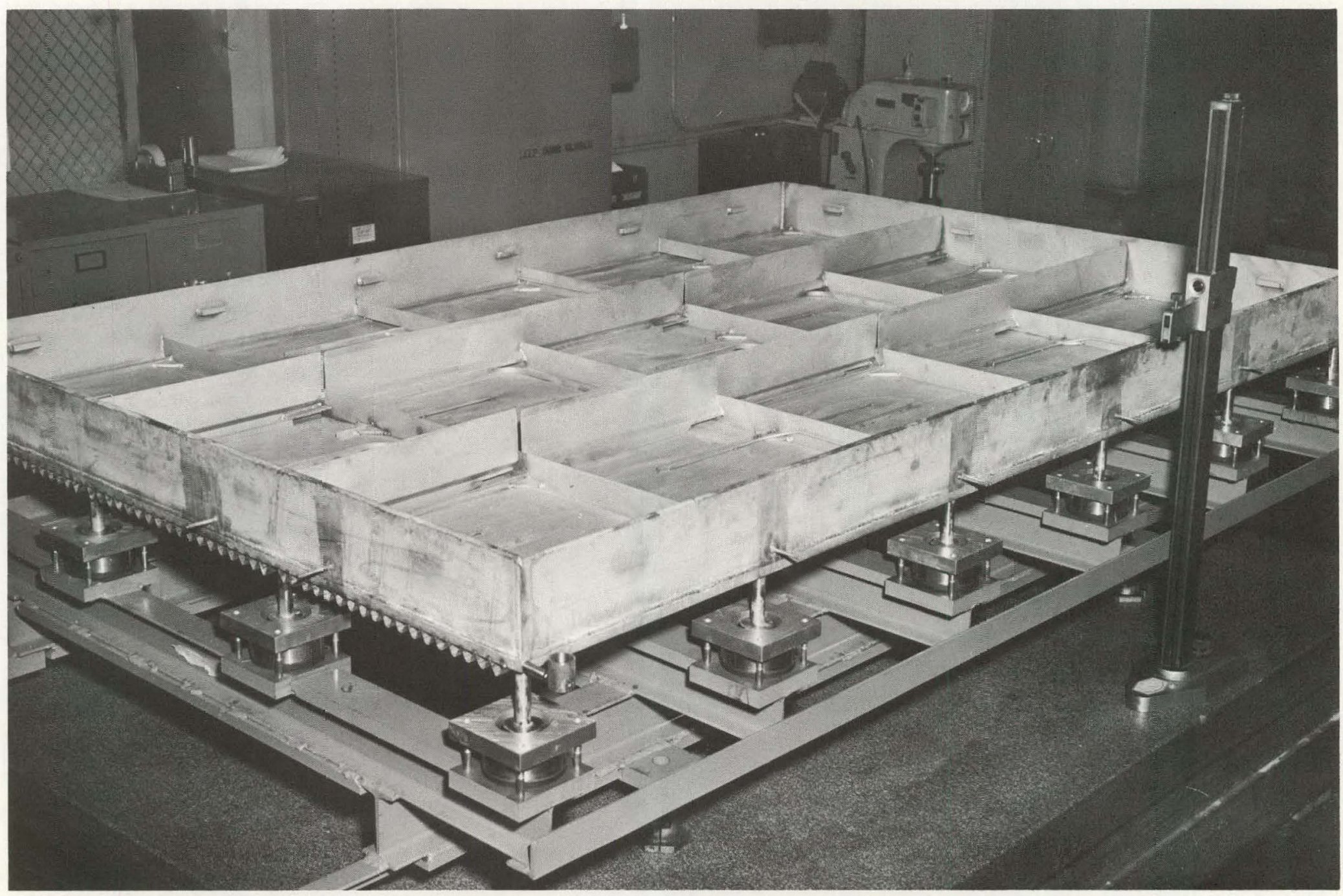

Figure 39

PROTOTYPE TRAY EVAPORATOR SECTION 


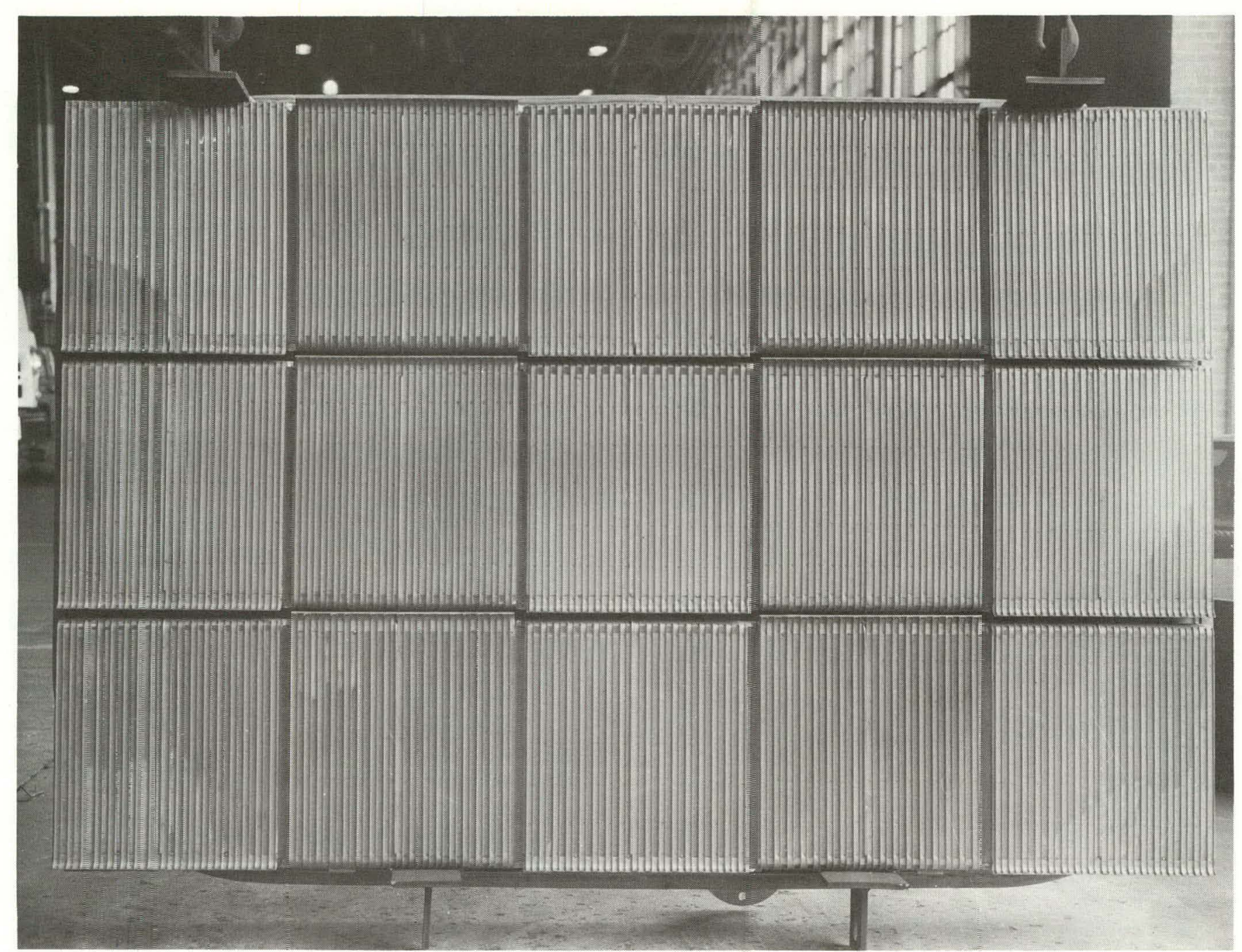

Figure 40

PROTOTYPE TRAY CONDENSER SECTION 


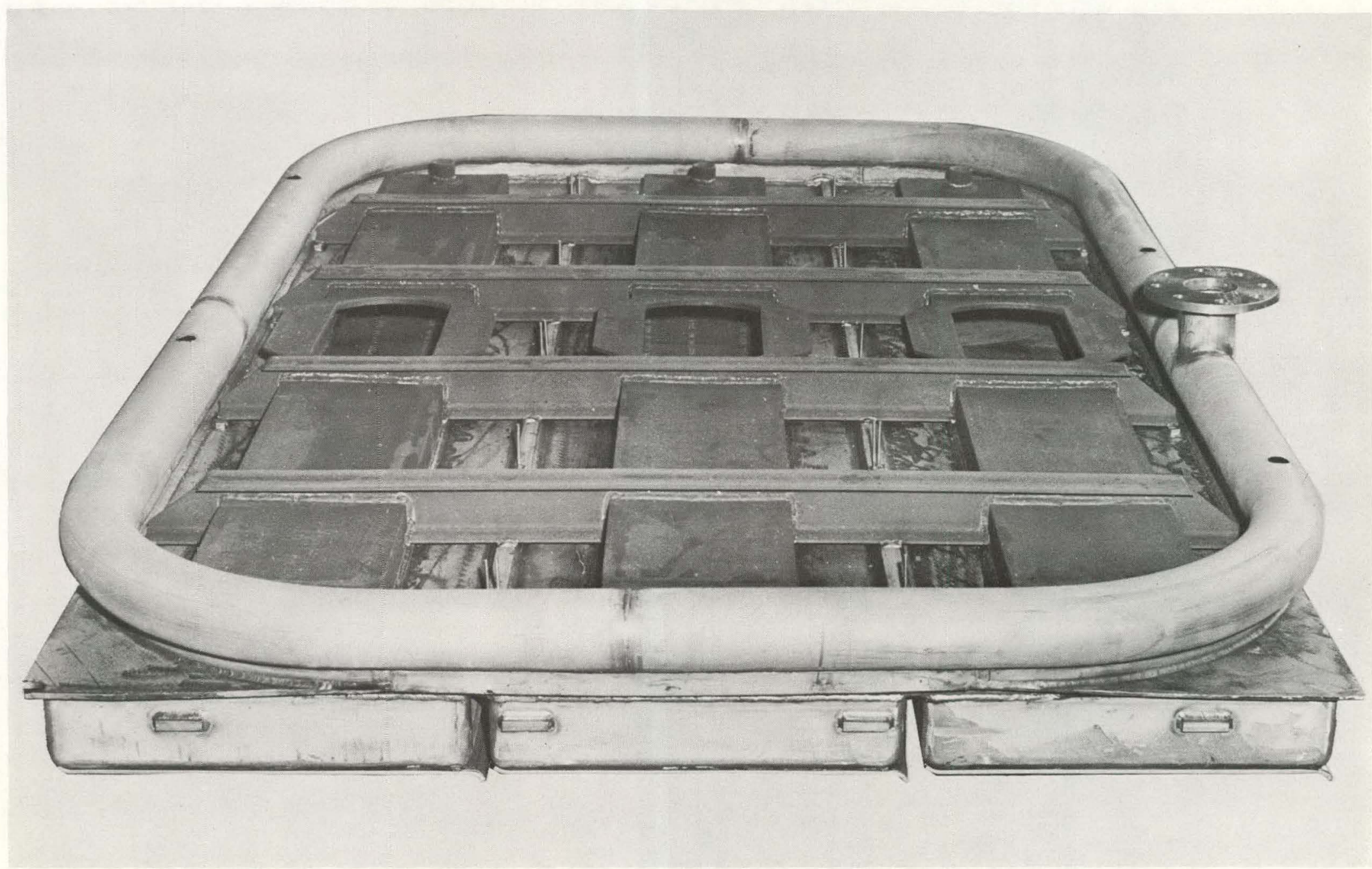

Figure 41

PROTOTYPE TRAY CONDENSER SECTION - TOP VIEW 


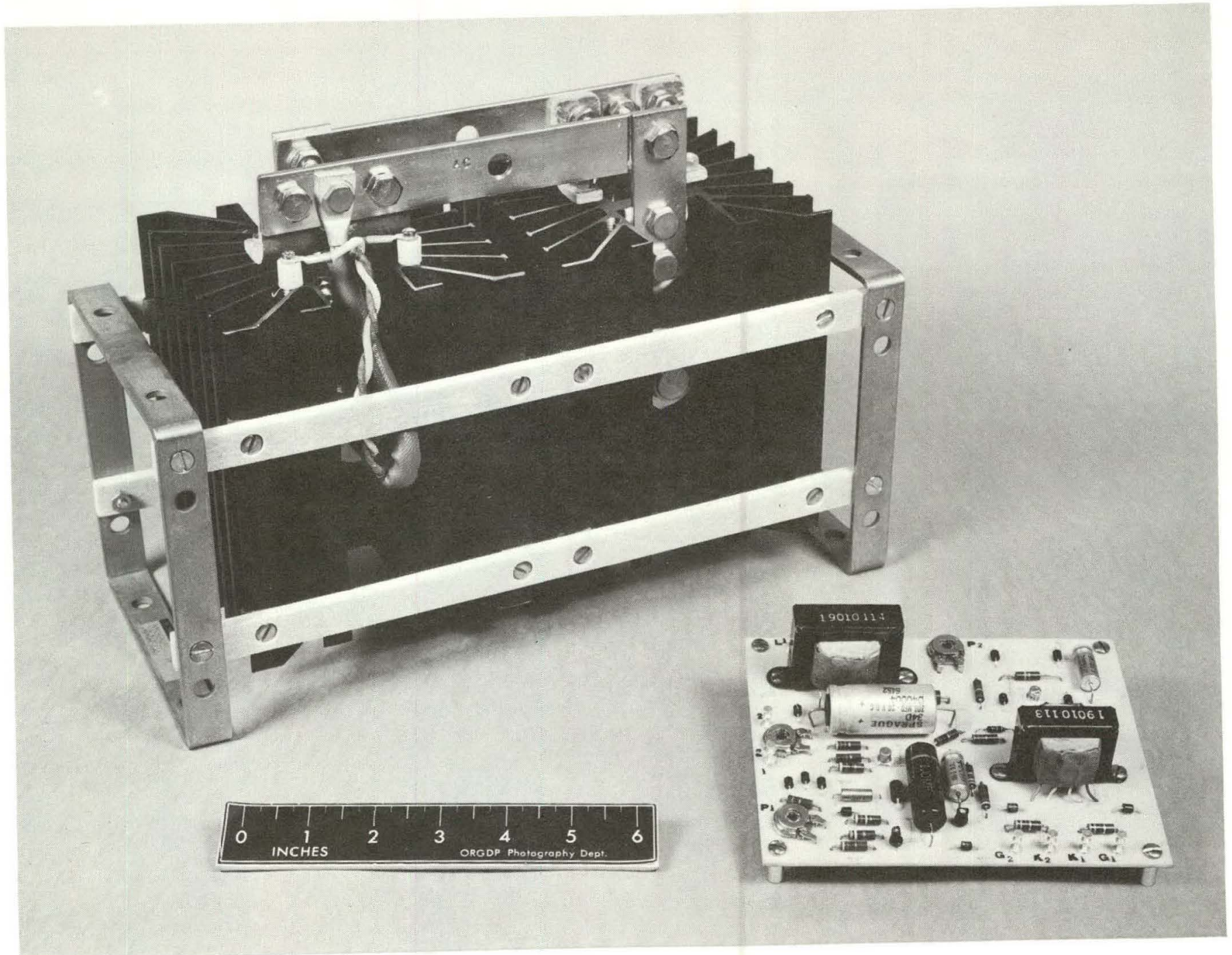

Figure 42

SILICON CONTROLLED RECTIFIER AND GATING CIRCUIT 
The analysis of the Modex performance data and the design of the 15-stage Prototype tray for operation at the optimum conditions were used in the conceptual design of a production molecular distillation cascade. This conceptual design involves giving detailed consideration to all of the process and auxiliary equipment required, utilities, housing, staff (both operating and maintenance), various operating and maintenance procedures and the manner in which these may affect the production rate, and safety features. Estimations of the construction and operating costs of the cascade can be made much more accurately after the conceptual dcsign is completed. Furthermore, the design serves to point out areas in which further experimental work or testing of components or procedures might be desirable to improve the reliability or safety of the cascade operations.

The present design was based on the following criteria:

1. The cascade is to include 525 stages, each stagc having 2.1 square feet of evaporative surface, to provide a production rate of approximately one ton per year of potassium enriched to $99.93 \% \mathrm{~K}-39$.

2. Each stage is to have a nominal evaporating/condensing capacity corresponding to an operating temperature of $270^{\circ} \mathrm{C}$. and a maximum capacity corresponding to a $280^{\circ} \mathrm{C}$. operating temperature.

3. Potassium purity control is based on the use of high quality feed material, high vacuum stage operation, and two oxide removal stations performing in series with the cascade.

4. Auxiliary services include nitrogen, air, steam, cooling water, and electrical power - locally available and of high reliability.

5. Facility staffing is based on continuous operation, utilizing, where possible, personnel associated with adjacent operations; laboratory analytical services and operational analysis services are also assumed locally available.

In this cascade concept, two 15-stage trays form an operating unit or cell. Thirty stages is then the smallest number that may be isolated from the remainder of the cascade. This size unit cell is a convenient and economical arrangement with regard to interstage valving and support equipment. Offstream losses and cascade split effects are minimal, the former having been estimated at 0.3 pounds per cell-day production loss. A typical cell tray and piping arrangement is illustrated in figure 43. Referring to the cascade layout depicted in figure 44, the feed point is between tray 3 and tray 4. Trays 4 through 35 are the enriching stages, with product being withdrawn from the last stage of tray 35 . 
106

DWG. NO. E-P-32023C

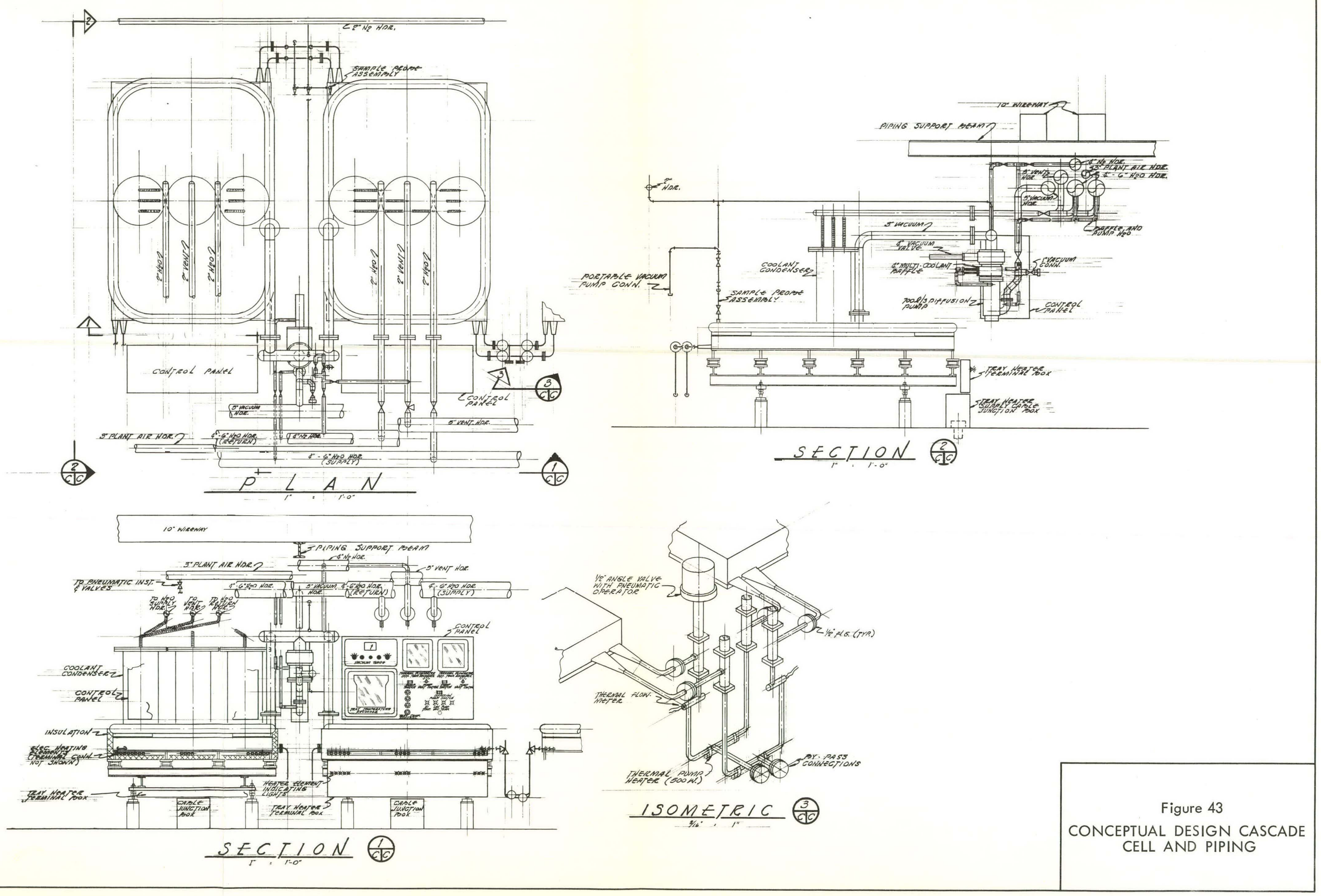




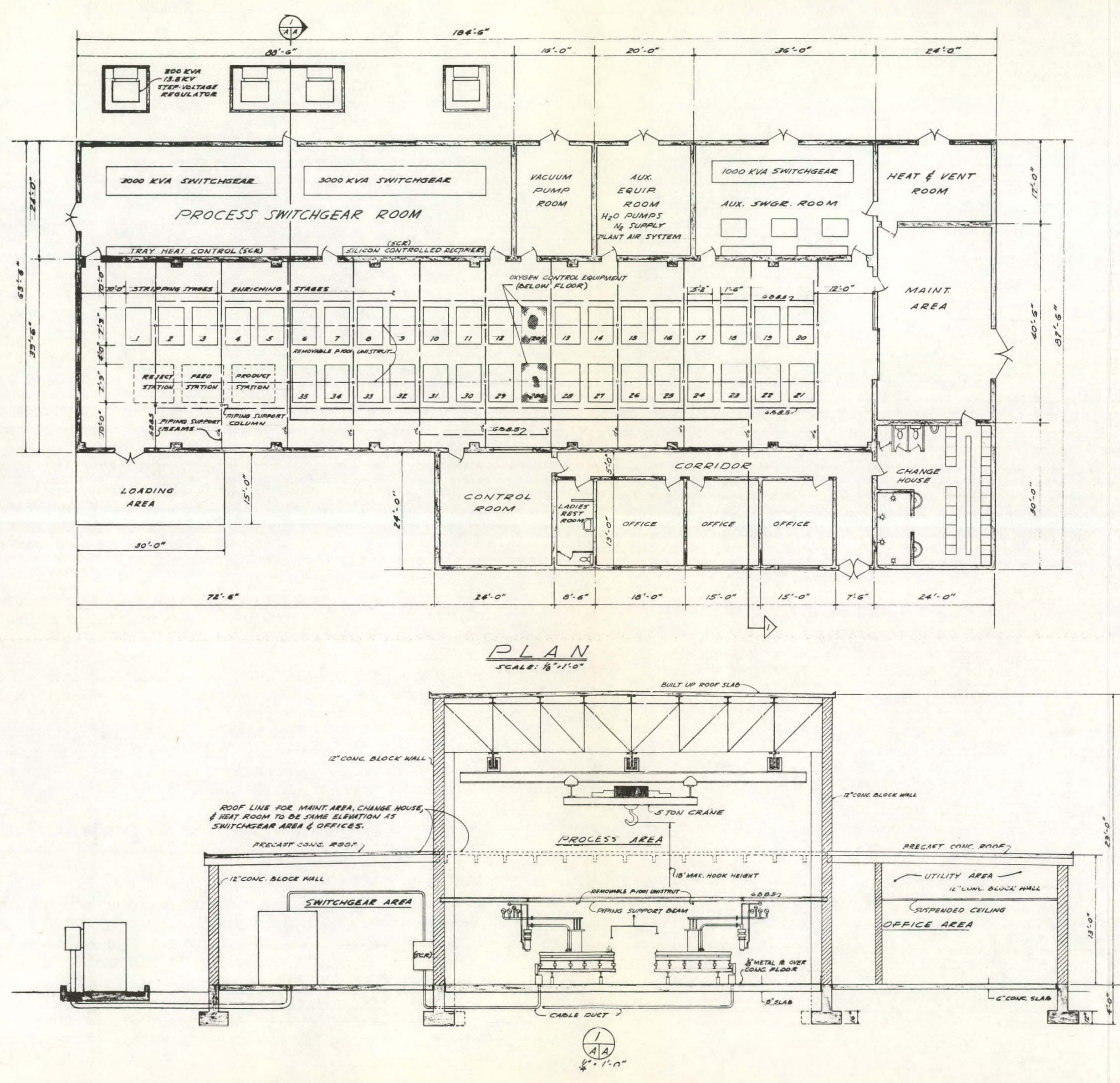


The oxide control stations located in approximately each third of the cascade are installed below operating floor level to allow for a traffic aisle and piping crossover midway of the building. These control stations consist essentially of a potassium pump, a wire-mesh-packed cold trap to reduce the potassium to oxide-saturation temperature for oxide precipitation, a heat exchanger to return the potassium stream to normal distillation temperature, and the necessary instrumentation and control.

The piping and wiring support structures are arranged such that the trays may be readily removed by the overhead crane for transport to the maintenance area. This minimizes floor space and facilitates auxiliary equipment installation.

Although existing structures could be used to house the cascade, a new building is shown in figure 44 to illustrate the cascade layout. This figure depicts a single story, concrete block structure covering 14, 409 sq.ft. and enclosing 276,917 cu.ft.

Fire water sprinkler system protection is provided in the service rooms only; this includes all areas outside the process area with the exception of the two switchgear rooms. Process area fire protection is by means of hand-operated devices including portable extinguishers and/or powered graphite to contain potassium fires and $\mathrm{CO}_{2}$ extinguishers for xylene fire protection. The process area floor is covered with sheet metal to prevent potassium spills reacting with the concrete floor and to facilitate clean-up. The floor covering is diked to minimize spread of potassium spills and resulting heat energy release.

Electrical power is supplied to the main substations at 13,800 volts from four feeder cables through voltage regulators. The double-ended process switchgear substations are provided with a bus-tie as indicated on the flow sheet, figure 45, to assure a high degree of reliability. With this arrangement one of the four power sources, either high-voltage cable or transformer, may be removed from service without affecting the process load. Process power supply reliability is a basic requirement, since interruption of distillation tray heating can result in a major cascade disturbance. On the other hand, total cascade power failure will not create hazards to personnel or equipment. Therefore, no provisions are included to circumvent this possibility.

The process power system is sized to supply sufficient power to maintain the liquid potassium pool in the distillation trays at a temperature of at least $280^{\circ} \mathrm{C}$. This temperature corresponds to a heating power requirement of approximately 5,600 kw. including tray heat loss and control requirements. Switchgear is designed using standard size equipment, for example, $1500 / 2000 \mathrm{kva}$ transformers, to provide ample capacity economically. Tray heat control is obtained by the use of silicon controlled rectifiers (SCR), which are particularly suitable for this application, being lightweight and compact. The control circuits for the SCR are also lightweight and small, requiring little power. Power loss from source to tray heaters is negligible when using this type control; the application of saturable reactor control, the only other practical means, would involve a significant 


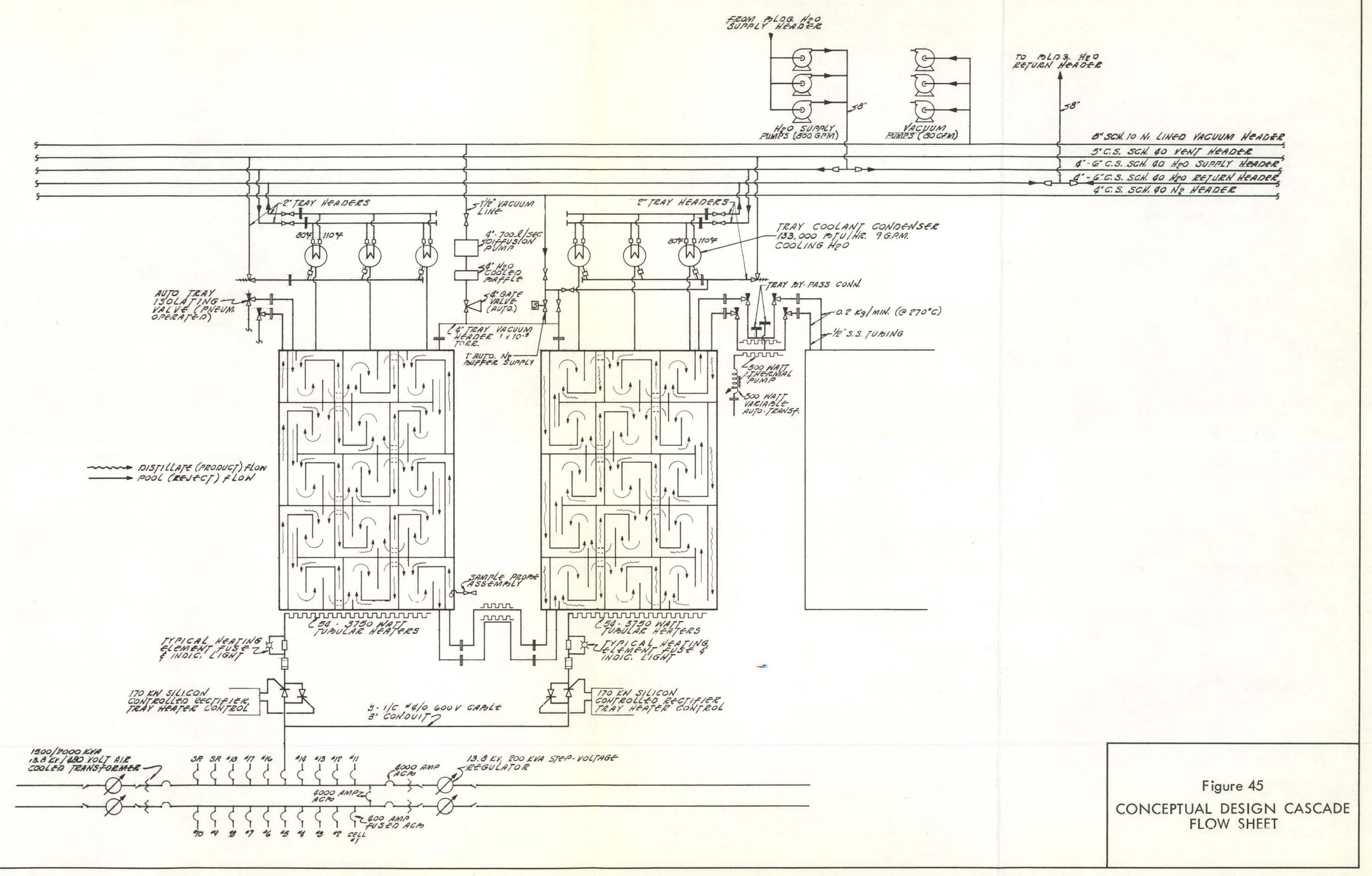


power loss in addition to higher installation cost.

Power supply for required electrical auxiliaries is again by means of a double-ended substation for reliability. Critical equipment, for example, vacuum pumps, cooling water pumps, and process thermal pumps, is arranged for alternate operation or alternate supply. Total power failure, however, not only results in loss of potassium vaporizing heat but also results in loss of vacuum pumping and coolant condenser cooling water. The entire distillation process stops; the vacuum pumping system is automatically isolated; and nitrogen is automatically admitted to the cascade. In this manner, the vacuum pumping system is protected; and air inleakage to the cascade, with consequent contamination of potassium, is avoided. The evaporative coolant system is protected from loss of heat removal capability (water failure) by means of relief valves to the coolant vent headers.

The vacuum pumping system consists of a 700 liter/sec. oil diffusion pump for each cell, two 5-inch roughing headers terminating in an 8-inch pump station header, and three 80-cfm. mechanical vacuum pumps. The system is capable of pumping the entire cascade to a pressure of $10^{-4}$ torr in about 4 hours. Evacuation of individual cells is accomplished by a small portable rough pump connected to the cell diffusion pump at the l-inch stiuh nn the diffusinn pump nut.let; this pronesure is user, for example, after tray maintenance and/or replacement. The oil diffusion pumps are protected against high system pressure directly and pump heater loss indirectly. Pump protection is primarily afforded as a secondary feature of tray over-pressure protection in that, when cell pressure rises to approximately one micron (10-3 torr), the diffusion pump inlet valve automatically closes in addition to other automatic operations to protect the potassium trays. The cell high pressure trip may result from loss of diffusion pump heater or cooling water. It is anticipated that, with essentially no tray air inleakage, diffusion pump maintenance can be performed without detrimental effects to the process. Unintentional loss of pump water or heat, however, results in automatic cell isolation from cell over-pressure.

Because the diffusion pump is at a relatively long distance from the distillation trays, a cold trap in the vacuum system may not be needed. This assumes that there is baffling of the chevron type in the vacuum connection at each tray to retard potassium vapor diffusion into the vacuum system. In addition, a water-cooled chevron baffle is incorporated at the diffusion pump to prohibit back-streaming of pump oil vapors.

The evaporative cooling system to condense the potassium vapors includes a coolant condenser for each of five distillation stages and a cooling water system. Xylene is used as the coolant medium because of its desirable operating characteristics in this application. At approximately $140^{\circ} \mathrm{C}$. the vapor pressure of xylene is zero psig, which provides the desired $90^{\circ}$ to $100^{\circ} \mathrm{C}$. minimum temperature differential between the potassium evaporating pool and potassium condensing surface. This allows the coolant system to operate at atmospheric pressure, simplifying design considerably. The coolant condenser is of the shell and tube type directly attached to the distillation tray. The 70 feet of $1-1 / 8$ inch condenser tubing is in the 
form of a double helical coil. Since there is to be no control or metering of the coolant vapor or liquid return, the condenser shell can serve as both the vapor connection and the liquid return line to the tray.

The condenser cooling water has a design flow of $9 \mathrm{gpm}$. for a $30^{\circ} \mathrm{F}$. water temperature rise to a maximum of $110^{\circ} \mathrm{F}$. total water discharge temperature. This flow corresponds to a 54-gpm. flow per cell or about $1000 \mathrm{gpm}$. for the cascade. A 4-inch supply and a 4-inch return line connected to the respective 2-inch cell headers are routed along each of the two cell rows to accommodate these flow requirements. Process cooling water is supplied at .150 psig. from three 800-gpm. centrifugal pumps, which have as their source either nearby river water or a cooling tower. The supply system design allows for moderate increase in water flow, although control of water temperature rise has little effect on condenser operation because of the high water/coolant temperature differential. Depending upon operating procedure, one or two of the cooling water pumps may be removed from service with no change required in the process operation. Total cooling water failure, occasioned by loss of water from the source or by power failure, will ultimately result in high cell temperature and pressure followed by automatic cell isolation and nitrogen blanketing, as described before.

Process control and monitoring is primarily from potassium temperature and tray pressure sensing elements. The distillation rate is dependent upon heat energy input which can be observed either as potassium evaporation temperature or as electrical power to the tray heating elements. Because the silicon controlled rectifier power supply circuits function as static switches, turning heater power off and on, power measurement is feasible only with relatively elaborate equipment. On the other hand, temperature monitoring is inexpensive but somewhat insensitive; that is, a significant heat energy change is reflected by only a small temperature change.

In view of the above and because of the inherent stability of the distillation process it is possible to achieve steady and reliable operation by providing a manually controlled, fixed voltage power source. This can be accomplished as indicated on the flow sheet, figure 45, through the use of voltage regulators equipped to control source voltage to within 5/8\%, which means that at the nominal operating level of $270^{\circ} \mathrm{C}$. power input may vary by about $1 \%$ or, as reflected by temperature, about $0.5^{\circ} \mathrm{C}$. This allows the operating temperature level to be set by the manipulation of the silicon controlled rectifier gating circuit control at each tray control panel. The gating control circuit is preset for repetitive control cycle periods of from 0.1 second to 2 seconds during which period heater power will flow the required fraction of time to achieve the average tray temperature desired. The four tray temperature controls on the tray control panel, as shown in figure 43, provide tor individual temperature control of each of three 5-stage sections of a tray plus an overall tray control. Tray heat energy determines potassium vaporization rate, and a stage cut of one-half is dependent upon obtaining the same vaporization rate in each stage. 
Cell over-temperature backup protection is initiated from contacts on the temperature recording instrument which monitors the fifteen pool thermocouples and several condensing surface thermocouples. One contact on the recorder initiates an alarm and the second contact, set at some higher temperature, will trip open the cell heating power circuit breaker. In addition, tray pressure in excess of $10^{-3}$ torr will open the SCR gating circuit, making the SCR nonconductive.

Control of the interstage flow external to the trays is by means of thermal syphon pumps. These pumps develop head by virtue of differential density of liquid potassium columns. Density difference is established and controlled by cooling of potassium in one column and heating potassium in the other column; this is illustrated in figure 43. A 16-inch column with a $50^{\circ}$-C. temperature differential can develop up to 0.25 inch potassium head for the flow application specified in the cascade. Under the design criteria for this cascade, intercell pumping requirements are less than 0.125 inch of potassium head and 0.25 inch of potassium head for normal operation and cell bypass operation, respectively.

The thermal pumps are manually controlled by means of a 500 -watt variable auto-transformer. The pump is protected by a high temperature thermostat which operates to open the power source and by a cell high pressure trip to shut off the pump on high pressure with attendant cell isolation. Intertray potassium flow is monitored by a thermal flowmeter, the operating principle of which is the same as the pump, but at a much lower energy level. Measured constant low level heating is applied to the flowing potassium and the temperature differential which is developed is measured. The differential is calibrated in terms of flow from the known thermal properties of potassium. For more rapid response in flow measurements, particularly during start-up and following tray outages, provisions are made for the application of a portable magnetic flow meter.

Potassium distillation tray vacuum is monitored by a hot filament ion gauge. Continued operation of the cell is ineffective at pressures much above $10^{-3}$ torr; therefore, the built-in gauge tube filament protection circuit can also be used to control external circuitry. Should the tube filament cut-off pressure of approximately $10^{-3}$ torr be reached, as a result of air inleakage or vacuum pump failure, the protective circuit will trip:

1. diffusion pump suction valve closed,

2. diffusion pump heater off,

3. tray heaters off,

4. cell isolation valves closed,

5. cell thermal pumps off, and

6. cell nitrogen blanketing valve open.

This action isolates the cell or cells affected and splits the cascade. In the event of an extensive cell outage, it may be necessary to connect portable bypass lines at the flanged connections between cells. The cas. cade flow can then be re-established. To perform this operation, it is necessary to freeze the potassium in the process lines at the flange 
connections, install the portable lines, evacuate and vacuum test the connections, and fill the lines with potassium. While the affected cell is isolated, in-place maintenance may be performed or the individual trays may be removed by means of the overhead crane to the maintenance area for cleaning and repair.

All process control is performed locally from the cell. In addition to the alarms at the local cell, all alarms, process and auxiliary, are annuciated in the control room. Since no provision is made for remote operation from the control room, annuciation requires that the operator go to the indicated trouble area to take action.

Process analytical control is initiated by the sampling of the potassium product streams at the sampling probes. Sampling devices are also located at the feed and withdrawal stations. The sample probes are designed for the insertion of a sampling rod in a way that will avoid the entrance of air. When it is desired to take a sample, the sample probe assembly is evacuated with a portable rotary pump, and through the cell diffusion pump if necessary, then sealed off. The isolation valve between the assembly and the tray is opened, and the sample rod pushed down into the potassium pool. Upon removal of the rod, the isolation valve is clo'sed and the sample probe assembly filled with nitrogen. The sample may then be removed and sent to the laboratory for isotopic analysis.

Control and monitoring of other auxiliaries not described follow accepted industrial practice. 
THIS PAGE

\section{WAS INTENTIONALLY LEFT BLANK}


PART 3 
THIS PAGE

\section{WAS INTENTIONALLY \\ LEFT BLANK}




\section{CONSTRUCTION}

It is estimated that about $\$ 2,511,000$ would be required to construct the cascade described in the conceptual design presented above. A breakdown of these costs is given in table VI. The assumption has been made that a facility of this size could readily be located within an existing building in a large industrial site, such as at the Oak Ridge Gaseous Diffusion Plant. For this reason, no cost has been included for a building to house the cascade and its auxiliaries, although a charge is added for building remodeling and reworking of existing utility systems other than power. A new power supply has been provided, sized to yield up to $5.6 \mathrm{Mw}$. at the tray heaters. Indirect construction costs are included for the items in the table, where applicable, at the rate of $32 \%$ of the equipment purchase and installation costs. The costs presented here are an improvement over previous estimates in that the distillation tray cost is now based on the prototype tray specifically designed for this particular separation job. In the judgment of the authors, the uncertainty in the plant equipment costs is of the order of $15 \%$.

An estimate of the construction time schedule for this cascade has been prepared and is shown in figure 46.

TABLE VI

CASCADE CONSTRUCTTON COST ESTIMATE

$\underline{\text { Item }}$

Thou sands

of Dollars

Distillation trays

560

Process piping, valves, pumps, and installation of trays

304

Process instrumentation

256

Power supply and controls

591

Feed and withdrawal and oxygen purification systems

Bu.i.ting and utilities remodeling

51

Engineering and inspection

182

Contingency (25\% of items listed above)

499

Potassium inventory cost

Total

2511 
Engineering Title $\dot{I}$

Title II

Title III

Equipment Fabrication

Equipment Installation

Vacuum Testing

Start-Up

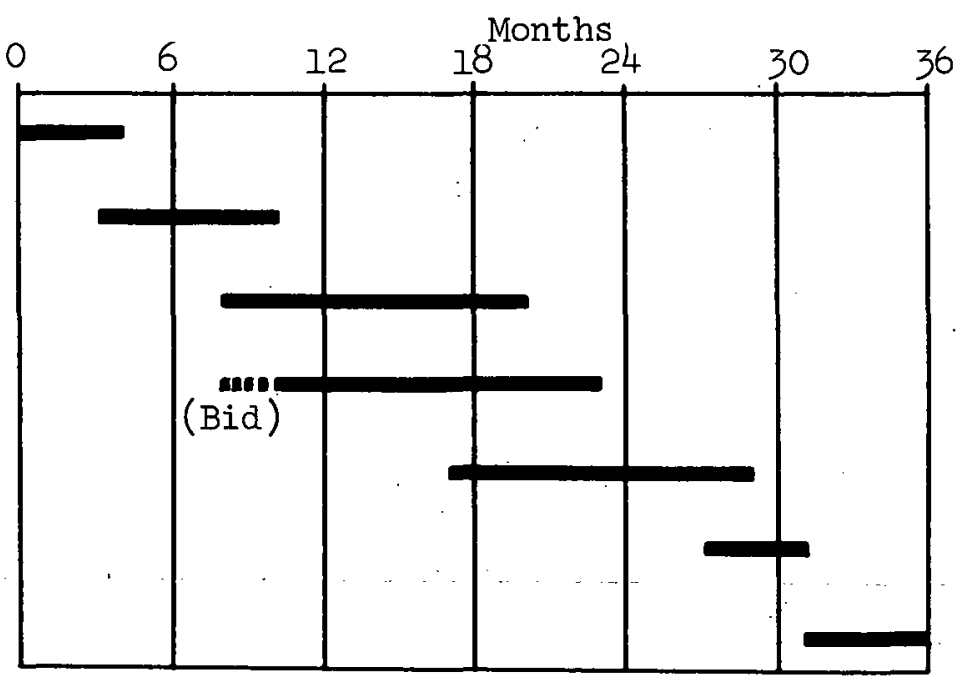

\section{OPERATION}

The annual cost of operation of this facility is estimated to be $\$ 550,000$. A breakdown of this cost is presented in table VII. The assumption that the cascade will be an adjunct of a large plant leads to some economy in operating labor costs in that it permits some personnel to be utilized on a part-time basis. An adequate laboratory fecility is assumed to exist at the site, so that laboratory services would be charged only on a per-sample basis. Plant overhead expenses are charged at $115 \%$ of the estimated direct labor costs. Power consumption is charged at $4.5 \mathrm{mills} / \mathrm{kwh}$. The cost of potassium feed at $\$ 10$ per pound, including the original inventory, is charged off in entirety, the assumption being that the potassium reject from the cascade will not be resaleable. Though there is a large uncertainty in the estimate of the maintenance costs, it is believed that the overall uncertainty in the operating costs is of the order of $10 \%$.

\section{UNIT PRODUCT COST}

The cost per pound of potassium depleted in $\mathrm{K}-41$ by a factor of 100 is expected to be about $\$ 420$. To arrive at this value, the cost of operation of the cascade during the 4.6 months expected to elapse between cascade start-up and attainment of steady state production is included in the total capital investment, which is amortized over a period of 10 years from the date equilibrium conditions are reached. No charge for loss of interest on the capital investment is included. Table. VIII summarizes the computation of the unit product cost. 
TABLE VII

ANINUAL CASCADE OPERATING COSTS

Item

Operating labor

Maintenance labor

Supervisory, technical and clerical

All labor

Plant overhead expense at $115 \%$

Power usage

Maintenance materials and supplies

Laboratory services

Feed costs

Total

\section{Thousands of Dollars}

90

25

12

TABLE VIII

COST SUMMARY

Cascade construction cost

Operating cost during unsteady state period ( 4.6 months)

Total capital cost

Annual operating cost

Unit product costs

Attributable to capital costs

Attributable to operating costs

'l'otal

$\therefore$
127

141

143

71

25

43

550 
ECONOMICS OF VARYING THE TARGET PRODUCT

CONCENTRATIONS AND PRODUCTION RATES

\section{VARIATION IN TARGET PRODUCT CONCENTRATION}

In consideration of the ultimate use of potassium depleted in $\mathrm{K}-41$ as a reactor coolant, the cost of isotope separation needs to be balanced against the incremental cost of shielding and maintenance to determine the extent to which it is advantageous to deplete K-41. For this purpose, design calculations and cost estimates have been made for cascades designed to have a ton of potassium per year production rate with lesser K-4I depletion factors. Figure 47 presents the results for depletion factors from 5 to 100, with unit product costs given relative to the estimated cost for depletion by a factor of 100 .

The cascade designed particularly for depletion by a factor of 100 (K-4I product concentration $0.07 \%$ ), which has been described in detail above, cari also be operated to yield product with a higher $K-4 I$ content. The cascade product yield would increase as the $K-41$ content in it is increased (see figure 37) and unit product costs would decrease. This relationship is also presented in figure 47. It is also evident that operating a cascade to yield its design target product concentration leads to a lower unit cost than obtaining this product from a cascade which was designed to yield a different product concentration.

\section{VARIATION IN PRODUCTION RATE}

Unit product costs are a function of plant capacity. Since the base production rate of one ton per year is a preliminary target, estimates of costs have been made for production rates up to 50 tons per year. The results are presented in figure 48, in terms of the fraction of unit product costs relative to that for production at the rate of one ton per year. Product concentration for all cases is $0.07 \% \mathrm{~K}-41$, i.e., a depletion factor of' 100 . 'Ihe results here are conservative, in that capital costs are assumed to be directly proportional to plant capacity. In actual practice, the cost of process equipment per unit of separative work would decrease to some extent as the equipment size or the number of pieces required is increased.

Curves have been presented in figures 47 and 48 relating the unit cost of product in the conceptual design cascade to the unit cost of product at K-4I depletion factors less than 100 and at production rates larger than one ton per year. For the purpose of estimating the unit cost of product from a cascade in which both production rate and product concentration differ from the conceptual design cascade targets, the product of the appropriate ratios taken from figures 47 and 48 may be applied to the $\$ 420 / 1 b$. base estimate. The resulting cost should represent a first approximation to the unit cost in a cascade specifically designed for the required separative task. 
DWG. NO. G-65-504

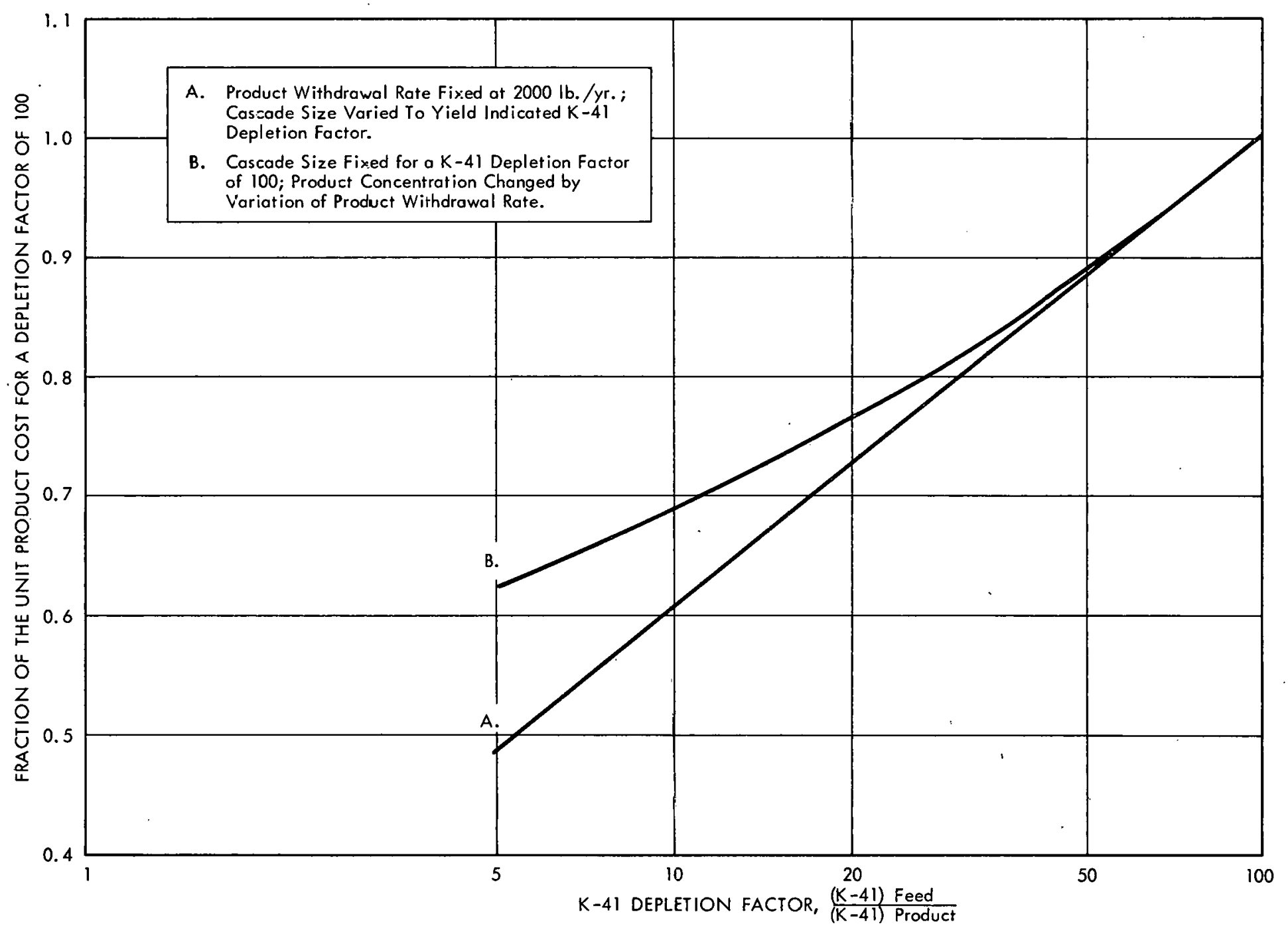

EFFECT OF THE EXTENT OF K-41 DEPLETION ON THE COST OF DEPLETION 
DWG. NO. G-65-500

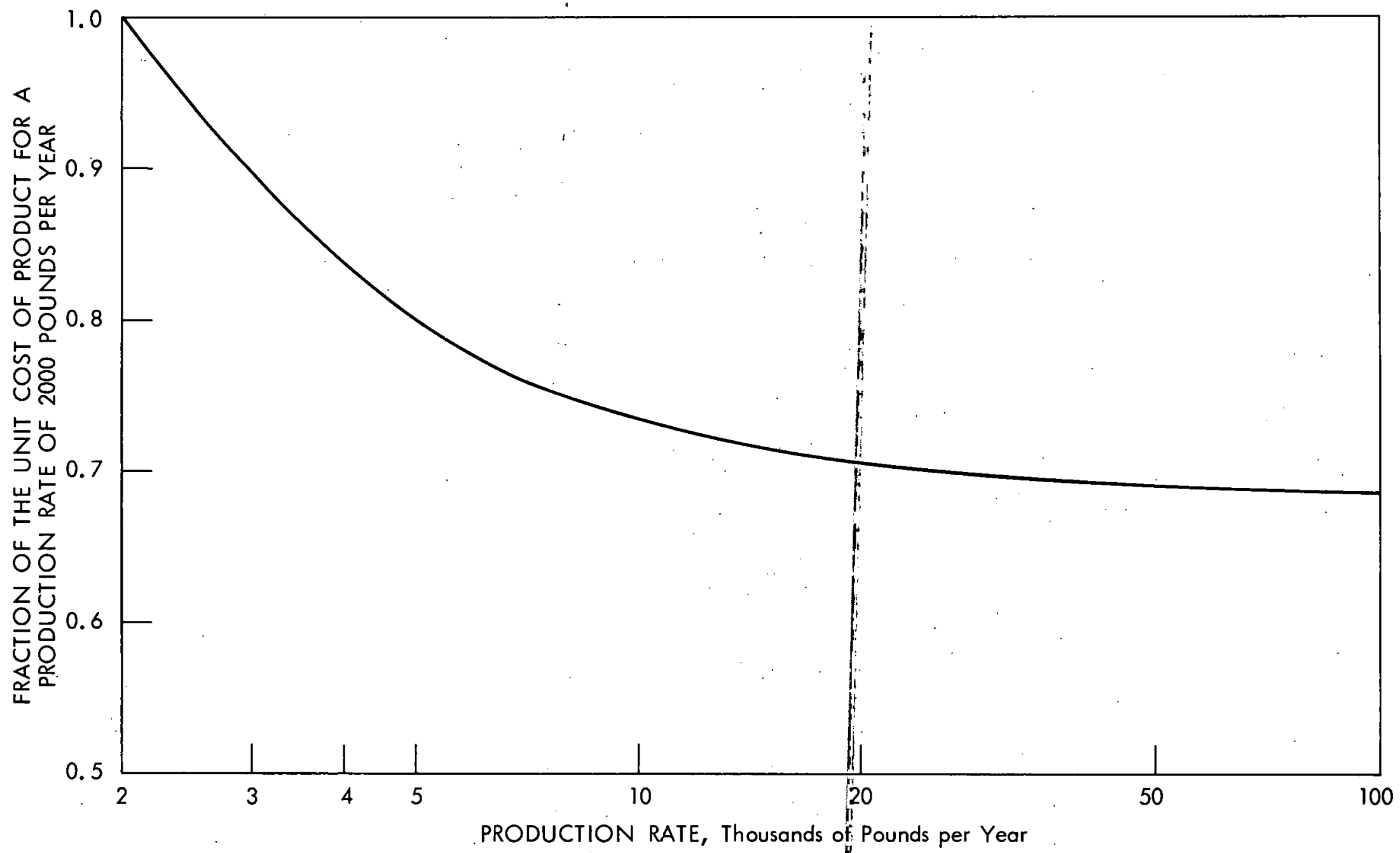

Figure 48

ESTIMATED COST OF PRODUCT AS A FUNCTION CF THE PRODUCTION RATE 


\section{ACKNNOWLEDGMENTS}

The authors wish to express their appreciation for the invaluable assistance rendered by G. S. Samuel, A. V. Faloon, and J. R. Hall in the operation of the Modex equipment and to personnel of the Cascade Pilot Plant for their aid during shift coverage. The success of this project was strongly dependent upon the excellent isotopic analytical services provided by L. A. Smith, J. C. Horton, and O. H. Howard of the Works Laboratory. A. Langdon and personnel of the Instrumentation Section collaborated on the design and construction of the improved mass spectrometer, while $S$. J. Wheatley of the Mechanical Development Department aided in testing experimental expansion joints. G. Goldberg of ORNL provided the oxygen analyses. Finally, the many machinists, sheet metal workers, welders, electricians, instrument mechanics, and their supervisors in the Maintenance Division are recognized for the outstanding job they performed on tray construction. 


\section{BIBLIOGRAPHY}

1. Burrows, G., "Some Aspects of Molecular Distillation," Trans. Inst. Chem. Engr., 32, 23-34. (1954).

2. Cohen, K., The Theory of Isotope Separation, First Edition, McGraw-Hill, New York; 1951 (NNES III-1B).

3. Hart, W. G., and Langdon, A., A Sensitive Ratio Recorder for Mass Spectrometers, Union Carbide Corporation, Nuclear Division, Oak Ridge Gaseous Diffusion Plant, March 18, 1959. (K-1292).

4. Jackson, C. B., Editor-in-Chief, Iiquid Metals Handbook-Sodium (NaK) Supplement, Atomic Energy Commission and the Bureau of Ships, Department of the Navy, Washington, D. C., Third Edition, June, 1955.

5. Kelley, K. K., Contributions to the Data on Theoretical Metallurgy. III. The Free Energies of Vaporization and Vapor Pressures or Inorganic Substances, U. S. Department of the Interior, Bureau of Mines Bulletin 383.

6. Keyes, J. J., Jr., Kuipers, G. A., and Trauger, D. B., Separation of Lithium Isotopes by Molecular Distillation: Second Mevac Pilot Plant, Union Carbide Corporation, Nuclear Division, Oak Ridge Gaseous Diffusion Plant, June 1, 1955 (K-1220).

7. Kuipers, G. A., and Trauger, D. B., First Mevac Pilot Plant, Union Carbide Corporation, Nuclear Division, Oak Ridge Gaseous Diffusion $\mathrm{Plant}$, June 1,1954 (K-1112).

8. Langmuir, I., "The Vapor Pressure of Metallic Tungsten," Phys. Rev., 2, 329-342, (1913).

9. Moore, W. J., Physical Chemistry, Third Edition, Prentice-Hall, Englewood Cliffs, N. J., (1962).

10. Williams, D. D., Grand, J.A., and Miller, R. R., "Determination of the Solubility of Oxygen Bearing Impurities in Sodium, Potassium and Their Alloys," J. Phys. Chem., 63, 68-71, (1959). 
125

APPENDIXES 
APPENDIX A

PHYSICAL PROPERTIES OF POTASSIUM AND XYLENE

This appendix summarizes some of the important properties of potassium metal and the xylene coolant which enter the molecular distillation calculations. It is not intended to be an exhaustive survey of either material and no attempt is made to assess the relative precision of various data sources, since, in general, very high precision is not required.

\section{POTASSIUM}

Isotopic Composition. Normal potassium has the following isotopic composition and isotopic weights based on the C-12 system.

$\begin{array}{ccc}\text { Isotope } & \frac{\text { Mass }(\mathrm{C}-12=12.0000)}{39} & \text { Atom \% } \\ 40 & 38.96371 & 93.08 \\ 41 & 39.96406 & 0.0118 \\ 40.96184 & 6.91\end{array}$

For the purposes of the present study, the low concentration of $\mathrm{K}-40$ can be neglected and the potassium system treated as a binary isotopic mixture.

Melting Point, Heat of Fusion. Potassium melts at $63.2^{\circ} \mathrm{C}$. with a heat of fusion of 574 cal./g-mole.

Vapor Pressure. Kelley (5) gives the following vapor pressure equation for liquid potassium, based on concordant data from several investigators:

or$$
\log \mathrm{P}(\mathrm{atm} .)=-\frac{4769}{\mathrm{~T}}-1.375 \log \mathrm{T}+8.708 \text {, }
$$

where $\mathrm{T}={ }^{\circ} \mathrm{K}$.

$$
\log P(\text { torr })=-\frac{4769}{\mathrm{~T}}-1.375 \log \mathrm{T}+11.588 \text {, }
$$

Heat of Vaporization. The heat of vaporization varies with temperature according to the equation:

$$
\Delta \mathrm{H}_{\mathrm{V}}=21,788-2.73 \mathrm{~T} \text { cal } \cdot / \mathrm{g} \cdot \text {-mole, }
$$

where $\mathrm{T}={ }^{\circ} \mathrm{K}$.

Over the temperature range $200^{\circ}$ to $300^{\circ} \mathrm{C}$. a mean value of $20,300 \mathrm{cal} . / \mathrm{g} .-$ mole has been adopted. 
Heat Capacity. The heat capacity of liquid potassium is interpolated from values given by the Liquid Metal Handbook:

$\begin{array}{ll}t,{ }^{\circ} \mathrm{C} . & \mathrm{C}_{\mathrm{p}, \mathrm{cal} . / \mathrm{g} \cdot{ }^{\circ} \mathrm{C} .} \\ 100 & 0.1942 \\ 150 & 0.1914 \\ 200 & 0.1887 \\ 250 & 0.1862 \\ 300 & 0.1843\end{array}$

Density. The density of liquid potassium is interpolated from values given by the Liquid Metal Handbook:

$\begin{array}{cc}\mathrm{t},{ }^{\circ} \mathrm{C} . & \text { Density, g./cc. } \\ 100 & 0.819 \\ 150 & 0.807 \\ 200 & 0.795 \\ 250 & 0.783 \\ 300 & 0.770\end{array}$

Oxide Solubility: The solubility of potassium monoxide in molten potassium is given by the equation (10):

$$
\text { wt. \% oxygen }=0.0865-6.09 \times 10^{-4} t+7.71 \times 10^{-6} t^{2} \text {, }
$$

where $t={ }^{\circ} \mathrm{C}$. for the range $75^{\circ}$ to $305^{\circ} \mathrm{C}$. Some representative values given by this equation are:

$\begin{array}{lc}\mathrm{t},{ }^{\circ} \mathrm{C} . & \text { Wt. } \% \mathrm{~K}_{2} \mathrm{O} \text { Oxygen } \\ 100 & 0.103 \\ 150 & 0.169 \\ 200 & 0.273 \\ 250 & 0.416 \\ 300 & 0.598\end{array}$


XYLENE

Commercial xylene is a mixture of the ortho, meta, and para isomers. Since p-xylene was used as the coolant in the Modex still, values are given here for that isomer. Properties of the other pure isomers and mixtures deviate slightly from these values, but the data are representative of the general properties of the xylenes.

Boiling Point, Heat of Vaporization. Pure p-xylene boils at $138.3^{\circ} \mathrm{C}$. with a heat of vaporization of 81.1 cal:/g.

Vapor Pressure. The vapor pressure of p-xylene is given by the equation:

where $t={ }^{\circ} \mathrm{C}$.

$$
\log _{10} P(\text { torr })=6.991-\frac{1453.84}{t+215.367}
$$

Specific Heat. Values of $\mathrm{C}_{\mathrm{P}}$ for $\mathrm{p}$-xylene are given by the equation:

$$
C_{P}=0.3978+0.93 \times 10^{-3} \mathrm{t} \cdot \mathrm{cal} . / \mathrm{g} .{ }^{\circ} \mathrm{C} \text {. }
$$

where $t={ }^{\circ} \mathrm{C}$.

Density. p-xylene is reported to have a density of $0.861 \mathrm{~g} \cdot / \mathrm{cc}$. at $20^{\circ} \mathrm{C}$. and $0.620 \mathrm{~g} \cdot / \mathrm{cc}$. at $190^{\circ} \mathrm{C}$. 
APPENDIX B

\author{
POTASSIUM ISOTOPIC ANALYSIS
}

Surface ionization mass spectrometer methods have been developed for measuring the isotopic abundances of related pairs of potassium samples, with precision adequate for evaluation of the separation efficiency of the molecular distillation process.

METHODS DEVELOPMENT ON A TWELVE-INCH SPECTROMETER

Significant improvements were first made in the reproducibility of potassium isotope analyses using a 12 -inch radius, $60^{\circ}$ sector, singlefocusing spectrometer with a triple-filament surface ionization source and a vacuum-lock cylinder for changing sample or filament assemblies. Because an absolute determination of the $\mathrm{K}-39 / \mathrm{K}-41$ ratio had to be made separately on each sample of a pair required to establish a given separation value, one of the major requirements was to maintain constant focus and geometry characteristics during the analysis of the pair. Suitable electrical focusing and filament positioning procedures were established for this purpose, and dual-collection equipment was installed to make the isotope ratio measurements less subject to ionization instabilities. With the dual-collection system, the $\mathrm{K}-39$ and $\mathrm{K}-40$ ions were collected on one plate at the same time $\mathrm{K}-41$ ions were collected on another. The ion current to each collector was amplified by its own vibrating reed electrometer, and both electrometer outputs were fed to a ratio recorder (3).

Platinum filaments were used to reduce the effect of a potassium impurity from the filament, and an easily ionized sample compound, potassium iodide, was selected. Filament outgassing and progressive heating procedures were dcvclopcd to reduce backsivund erfects further and conserve sample material.

Ratio and ion current stabilities were also improved by inserting a condensing surface cooled by liquid nitrogen into the source region.

Repetitive measurements on ten sample pairs established a $95 \%$ confidence limit of \pm 0.005 for a single ratio-of-ratios measurement, using the 12-inch spectrometer.

SIX-INCH SPECTROMETER MODIFICATIONS

Because of the relatively wide mass dispersion between the potassium isotopes at the spectrometer collector, the resolution of a 6-inch instrument appeared suitable for these analyses. Accordingly, a 6-inch surface ionization spectrometer was constructed, using the magnet, analyzer components, and some of the electronic units and measuring circuitry from a uranium hexafluoride spectrometer. The basic techniques developed for the 
larger instrument were utilized, and new facilities for sample changing and analyzer evaluation were devised.

In the new spectrometer the $\mathrm{K}-39$ and $\mathrm{K}-4 \mathrm{l}$ ratios of two samples are also compared by successive sample introductions through a vacuum lock. Samples are loaded on a platinum filament as potassium iodide, and the filament is electrically heated to vaporize the sample; this vapor contacts a second, hotter platinum filament from which the potassium ions are accelerated with 3000 volts through the 6 -inch radius of the magnetic analyzer where the isotopes are resolved. The $\mathrm{K}-39$ and $\mathrm{K}-4 \mathrm{I}$ isotopes are simultaneously collected on two collectors and the two ion currents are amplified and compared in a ratio recorder whose output is proportional to the $\mathrm{K}-39 / \mathrm{K}-4 \mathrm{I}$ ratio in the sample. The small amount of the $\mathrm{K}-40$ isotope. collected with the $\mathrm{K}-39$ is neglected in calculating the ratios.

Pressures of $10^{-7}$ torr in the source region and $10^{-8}$ torr in the analyzer are maintained by separate electronic pumps. The ionizing filament ( 0.002 inch thick, 0.030 inch wide, 0.5 inch long) is permanently mounted in the source to maintain consistent geometry and good analytical reproducibility. The sample filament. (0.004 inch thick, 0.03 inch wide, 0.5 inch long) is mounted in a cylindrical, ceramic cartridge 0.5 inch in diameter and 3 inches long. Teflon 0-rings on each end of the cartridge provide bearing surfaces for sliding the cartridge through a vacuum lock, and also provide seals between the pumping stages of the lock. The sample filament is spring-loaded so that it is recessed within a depression as the cartridge is being pushed through the lock. After the cartridge is in position for analysis the filament is extended to within $1 / 16$-inch of the ionizer, at the same time making electrical contact to the filament current supply.

The vacuum lock consists of a cylinder, 0.5 inch nominal inside diameter, 6 inches long, leading into the source region, and a second similar cylinder leading out of the spectrometer. Each end of the lock is pumped in three stages. The two outer stages of each cylinder are rough-pumped and the innermost stages are evacuated with an ion pump. During an analysis a small cold trap extending into the source region is filled with liquid nitrogen. A tongue-and-groove arrangement on the cartridges permits rotation of the cartridge train so that the sample filament can be properly positioned with respect to the ionizing filament.

When an analysis has been completed the used cartridge is pushed into the exit end of the lock by inserting another freshly loaded cartridge. The used cartridge is washed in hot water and dried for reuse. During routine operation the entrance end of the lock contains two samples awaiting analysis, the source region contains one being analyzed, and the exit end contains two which have been analyzed.

Except for minor problems related to the durability of insulator sections of the cartridge, this spectrometer appears capable of precision comparable to that of the larger instrument, and analytical effort is reduced considerably through the use of the unique vacuum lock design. 
APPENDIX C

\author{
SPECIAL CALCULATIONS
}

\title{
STAGE 1 CUT CORRECTION
}

At total reflux, when the evaporation rate is the same in all stages of the Modex still, a material balance beginning with the tenth stage shows that the cut in each stage must be one-half, with the exception of stage 1. This stage is non-typical in the sense that its feed and reject flows can be varied over wide ranges by adjusting the thermal pump even when its product rate matches that of the other stages. Stage cut is therefore adjustable in this case and it is desirable that it match that of the other stages, since the reject concentration of this bottom stage is the reference concentration on which the various stage separation ratios are based. If the stage $I$ cut is less than one-half, its reject stream will not be sufficiently depleted in $\mathrm{K}-39$ and all of the stage concentration. ratios referred to it will be biased low; conversely, if the stage 1 cut exceeds one-half, its reject stream is depleted too far in K-39 and the corresponding separation ratios are biased high. By examining figure 3 in the vicinity of a cut of one-half, it can be seen that the system is not extremely sensitive in this respect, in fact the analytical accuracy is not sufficient to distinguish cut values $\pm 5 \%$ from a value of one-half. Therefore, if the reject loop flow on stage 1 is in agreement with the other interstage flows within 10\%, no correction of the various stage separation ratios is justified.

In almost all of the runs made with the Modex still to define the temperature at which maximum separative capacity was obtained, it was possible to adjust the thermal pump on the reject end loop to obtain a flow properly matching the interstage potassium flow. At low temperatures, primarily veluw $260^{\circ} \mathrm{C}$., there was ot'ten dif'ficulty in reducing the loop flow far enough while still maintaining steady operation of the pump and flowmeter. This was a consequence of the large diameter 3/4-inch lines which had to be used in the end loops to handle the metal flow at the $300^{\circ} \mathrm{C}$. operating level; at low flow rates through these large lines adequate heat control could not be maintained. As noted in table $I$, in the low temperature runs in which the stage 1 cut was considerably different from one-half, stage 1 reject was neglected in the data analysis and the product stream from stage 1 cut was just outside the range 0.45 to 0.55 , a correction was applied by the following procedure:

1. The uncorrected data are first treated as described previously to obtain an estimate of the single stage separation factor $(\Psi+1)$.

2. The catimated value of $\Psi$ is multiplled by the ratio of $1.386 /$ cut correction factor for the true cut calculated by equation 8 . This 
corrects the value of $\Psi$ for stage 1 to the value which should have been obtained with a cut of one-half.

3. The value of $\left[\log (\Psi+1)_{\text {corrected }}-\log (\Psi+1)_{\text {uncorrected }}\right]$ is then added to the values of $\mathrm{log} S$ for other stages referred to stage I reject concentration.

4. The analysis in step 1 is repeated using the cut corrected ratios obtained in step 3 .

This procedure was applied in only a few cases and the amount of correction was never large, since in most cases the actual stage 1 cut was quite close to $0.50 \pm 0.05$. It has been applied, however, wherever the stage 1 cut was outside this range.

\section{THERMAL FLOWMETER CALCULATIONS}

The thermal flowmeters used on the Modex still end loops consisted of 4-3/4-inch sections of 1-1/4-inch tubing with a 3/4-inch concentric well. Tho wcll held a 180-watt cartridge heater and iron-constantan thermocouples were attached to the potassium lines at each end of the flowmeter section. The meter was well insulated with Fiberfrax blanket and aluminumfaced fiberglass.

Theoretically, the flow through the meter can be given by:

$$
F=\frac{k W}{c \Delta T}
$$

where $F=$ flow rate in $\mathrm{g} \cdot / \mathrm{min}$.

$\mathrm{W}=$ heat input in watts.

$c$ F heat capacity of potassium in cal./g.- ${ }^{\circ} \mathrm{C}$.

$\Delta \mathrm{T}=$ temperature difference in ${ }^{\circ} \mathrm{C}$.

$\mathrm{k}=\mathrm{a}$ constant for dimensional correction, equal to 14.34 for the units given.

The two thermocouples may be conveniently wired to present the temperature difference in microvolts and since the output of iron-constantan couples changes at the rate of $55 \mu \mathrm{V} /{ }^{\circ} \mathrm{C}$. at the operating temperature level, the value of $\mathrm{k}$ in the equation above becomes 788.72 when the value of $\Delta T$ is given in microvolts.

Equation C-1 assumes, however, that no heat is lost by metal flowing through the meter. Actually, however, if no heat is applied to the meter heating element, a negative value of $\triangle T$ is measured due to cooling of the metal on passing the meter section. This loss, usually amounting to about $I^{\circ}$ to $2^{\circ} \mathrm{C}$. at operating temperatures of $200^{\circ}$ to $250^{\circ} \mathrm{C}$., must be measured as a "zero value" for each flow rate, since some of the power entering as $\mathrm{W}$ merely compensates for this loss.

Further, if a large value of $\mathrm{W}$ is used to measure a given flow, the temperature increase across the meter section can cause still higher heat losses. This is also readily measurable by using the product loop flowmeter and 
measuring the corresponding values of $W$ and $\Delta T$ with a fixed stage 10 evaporator temperature. Under these conditions a constant true flow through the meter is assured and any discrepancy between flows calculated with various values of $W$ can be attributed to heat losses within the meter. Data of this type are shown in table C-I.

\section{TABLE C-I}

APPARENT HEAT LOSSES AT HIGH METER POWER LEVELS

\begin{tabular}{lccc}
\hline \multicolumn{2}{c}{ Apparent } & Flow Rates, g./min. & \multicolumn{2}{c}{$\begin{array}{c}\text { Stage 10 Evaporator } \\
\text { Temperature, }{ }^{\circ} \mathrm{C} .\end{array}$} \\
\hline 20 watts & 30 watts & $\frac{40 \text { watts }}{189}$ & 262 \\
179 & 183.5 & 265 & 272.5 \\
249 & 251 & 325 & 282 \\
310 & 318 & & \\
\hline
\end{tabular}

The data in table C-I can readily be brought into agreement if effective power levels of 29.5 watts and 38.0 watts are used for measured power input levels of 30 and 40 watts respectively. The values at the 20 -watt level can be assumed to be accurate; lower power input levels do not produce enough temperature change for accurate measurement of $\Delta T$. All flowmeter values presented in this report have been either measured at the 20-watt level or measured at a higher power level and corrected to the 20-watt level through use of the factors given above. 
The gradient of liquid potassium depth in the distillation trays under various temperature conditions can be estimated by calculating the liquid head required to sustain the appropriate interstage flow through the stage configurations. The basic equation for calculating frictional head losses for a fluid flowing in an open channel is given by

$$
F=\frac{2 f L G^{2}}{g D \rho^{2}},
$$

where $F=$ liquid head loss,

$f$ - Fanning friction fastor.

$\mathrm{L}=$ length of flow path,

$G=$ mass flow rate,

$\mathrm{g}=$ gravity constant,

$\mathrm{D}$ = pipe diameter,

$\rho=$ fluid density.

The Fanning friction factor for laminar flow such as is obtained in the molecular stills is approximately given by

$$
f=\frac{4 \mu}{R_{H} G}
$$

where $\mu=$ fluid viscosity, $\begin{aligned} \mathrm{R}_{\mathrm{H}}= & \text { hydraulic radius of the channel, equal to the cross sectional } \\ & \text { area divided by the wetted perimeter. }\end{aligned}$

By substitution, since $D=4 R_{H}$,

$$
F=\frac{2 \mu L G}{g R_{H}^{2} \rho^{2}}
$$

This equation is applicable to straight flow paths; by assuming that $90^{\circ}$ bends impose an additional head loss equivalent to 50 pipe diameters, the total loss for a straight path plus $\underline{n}$ bends is obtained:

$$
F=\frac{2 \mu L G}{g R_{H}^{2} \rho^{2}}+n\left[\frac{2 \mu(50 \mathrm{D}) \mathrm{G}}{g R_{H}^{2} \rho^{2}}\right] \text {, or }
$$




$$
F=\frac{2 \mu G}{g R_{H}^{2} \rho^{2}}\left(L+200 n R_{H}\right) .
$$

The flow paths through each Modex stage can be broken into three passes across the stage, plus one pass under the interstage divider to the next lower stage. Stage evaporation is assumed to occur chiefly in the three main stage passes and in amounts proportional to the area of metal exposed in each pass. Since the stage cut is one-half, the flow entering a stage is twice the interstage flow, decreasing to the interstage flow at the reject end of the stage. The average flow in each pass can be estimated by decreasing the flow entering the pass by half the evaporation rate occurring in that pass.

The liquid head profiles are generated by starting with an assumed liquid depth at the beginning of the first pass in stage 10. The head loss $F$ is computed for the first pass and subtracted from the assumed depth to obtain the depth entering the second pass. This iteration is continued through each stage to the bottom of stage 1 . The computed depths can then be plotted in their appropriate positions along the length of the slill to generate the liquid head profile. Graphical integration to obtain the area under the profile curve leads to the metal inventory in the still for the assumed case.

The equations are readily adapted to machine computation. Some examples of profiles run at $270^{\circ} \mathrm{C}$. for the Modex trays are shown in figures D-1, D-2, and D-3 and a corresponding profile calculated for the 15-stage Prototype tray is shown in figure D-4. 
DWG. NO. G-65-501

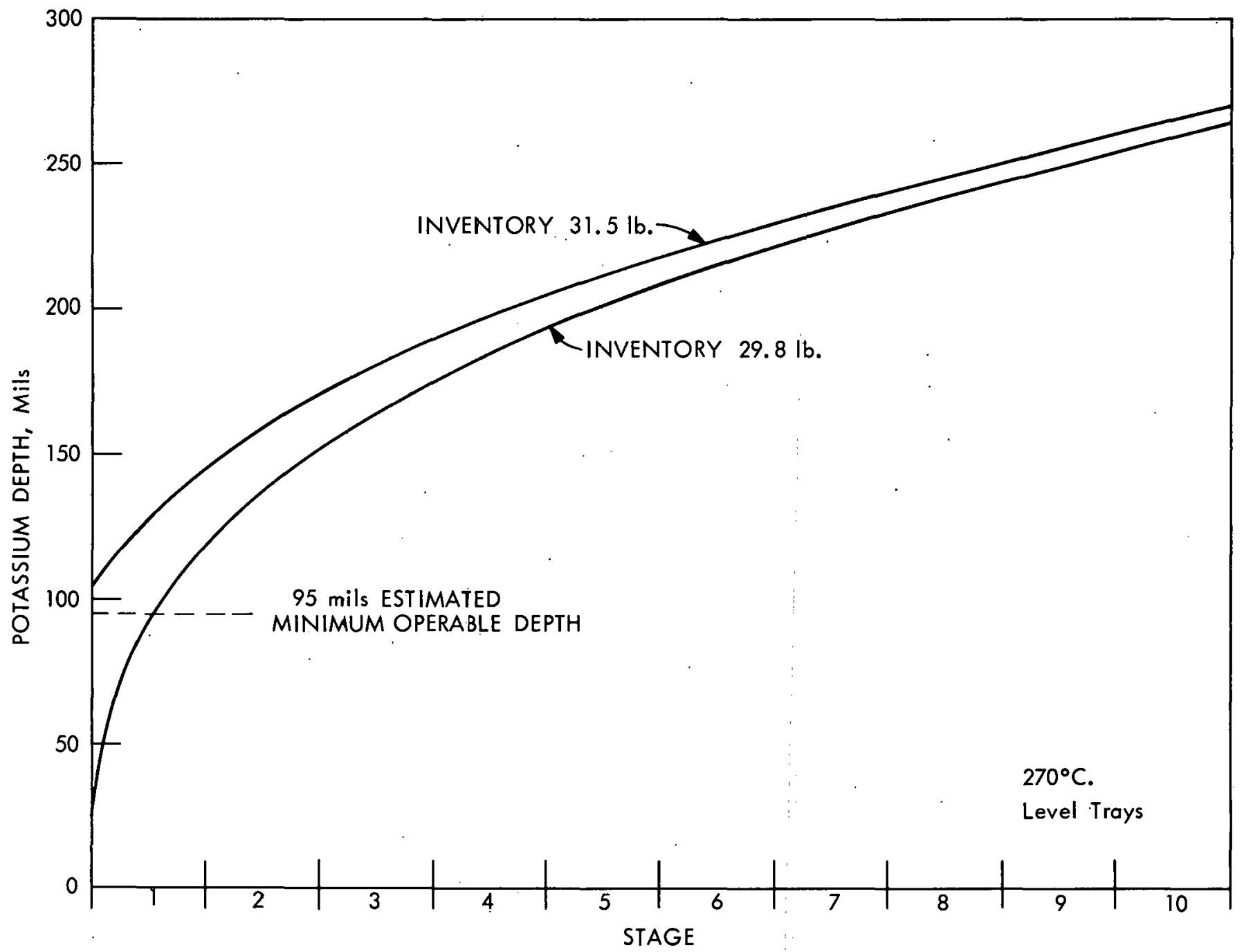

Figure D-1

MODEX TRAY DEPTH GRADIENT 


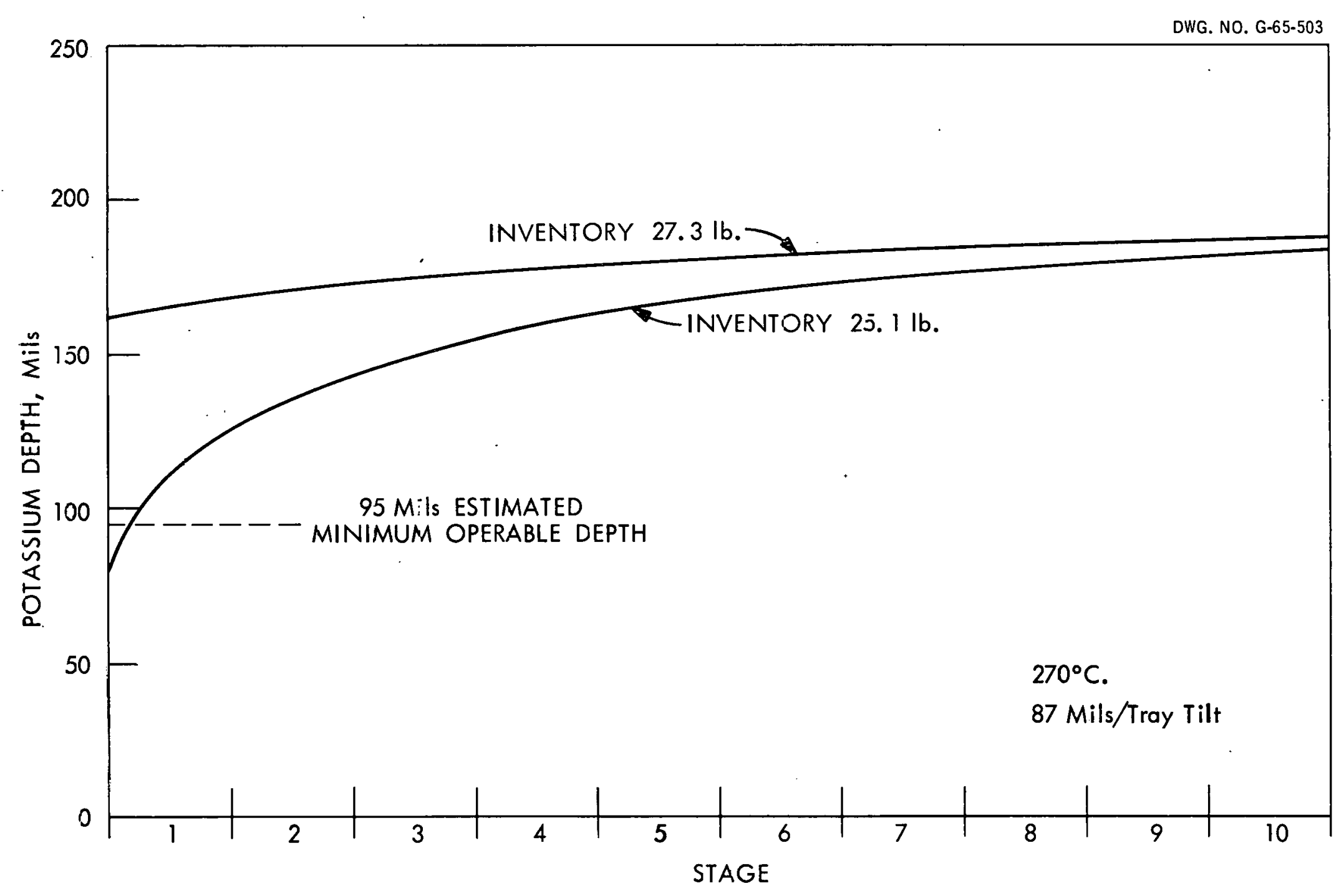

Figure $D-2$

MODEX TRAY DEPTH GRADIENT 
DWG. NO. G-65-485

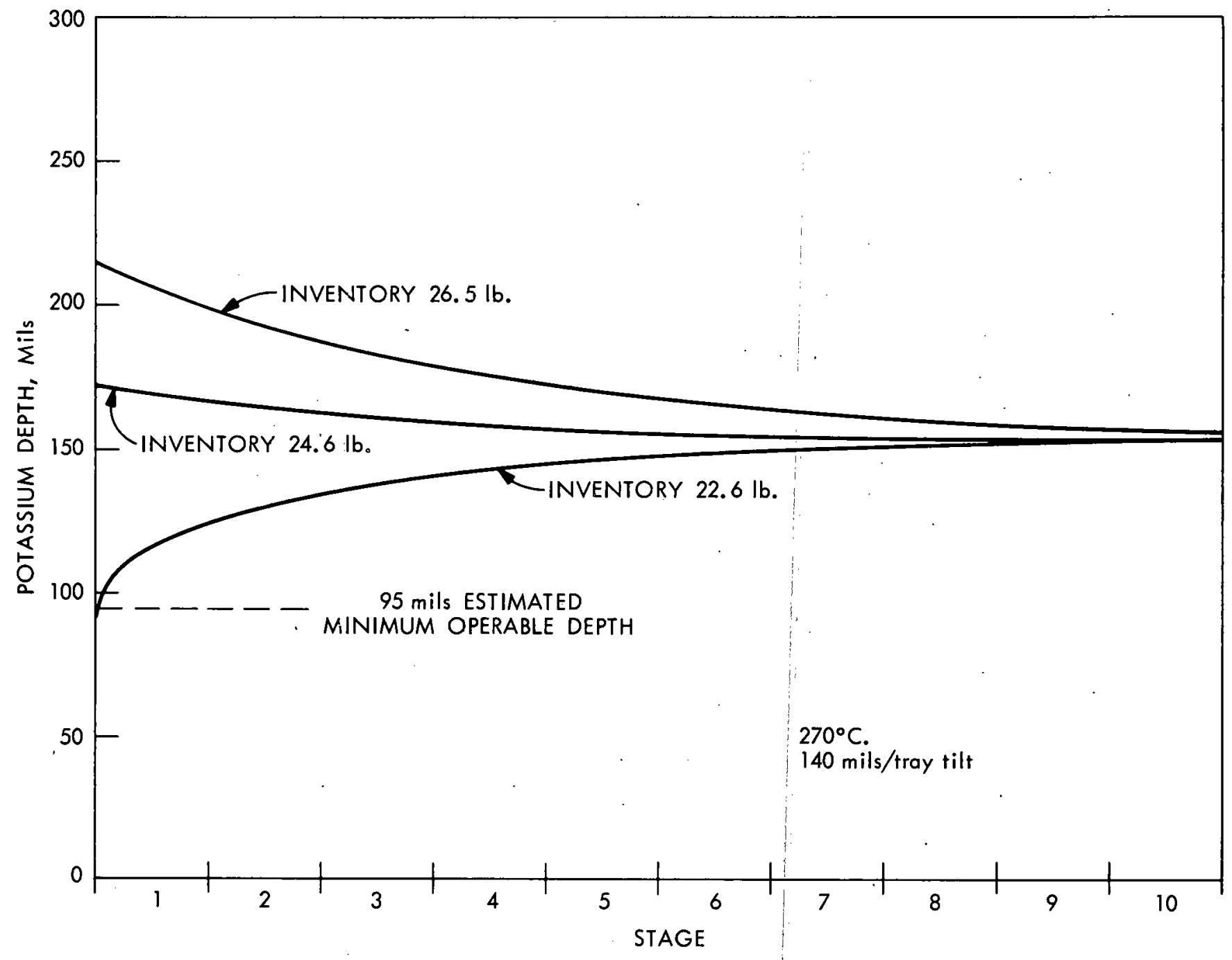

Figure D-3

MODEX TRAY DEPTH GRADIENT 
DWG. NO. G-65-486

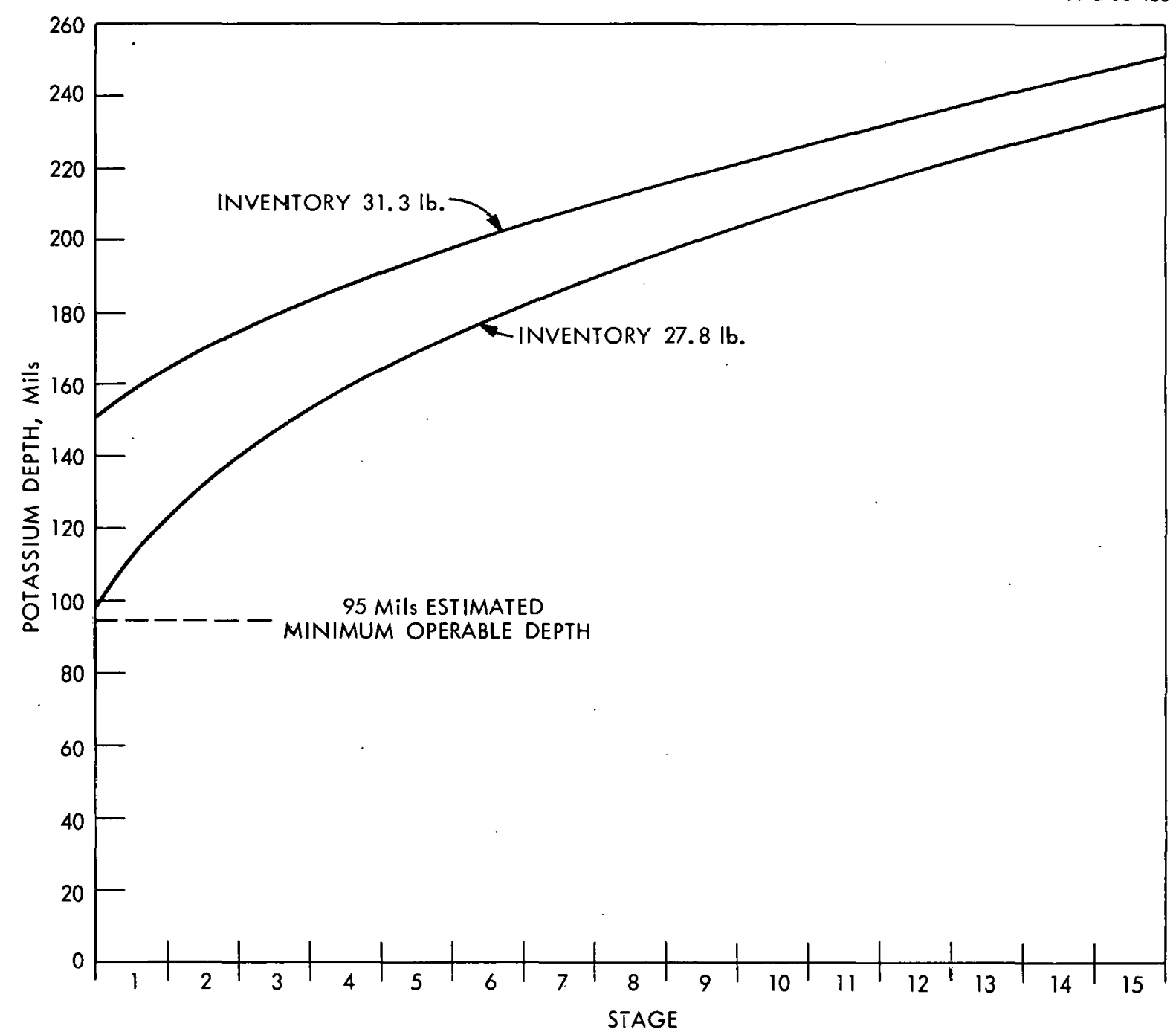

Figure $D-4$

PROTOTYPE LEVEL TRAY DEPTH GRADIENT AT $270^{\circ} \mathrm{C}$. 
In the course of constructing the Modex facility, records were maintained of time required by various crafts in the tray fabrication and installation. Table E-I presents these data.

TABLE E-I

MODEX TRAY FABRICATION AND INSTALLATION

\begin{tabular}{lc}
\hline Craft & $\frac{\text { Hours }}{145^{\prime 2}}$ \\
Machinist & 891 \\
Welder & 470 \\
Sheet Metal & 432 \\
Mechanic & 200 \\
Electrician & 153 \\
Inspection & 177 \\
Instrument & \\
\hline
\end{tabular}

In addition to the labor costs, materials cost for these trays was approximately $\$ 8200$; this amount does not include the value of property items such as mechanical roughing pumps and ion gauge control panels. With applicable ORGDP plant expense allowance, the total value of the Modex installation is estimated to be approximately $\$ 76,000$, of which approximately $\$ 16,000$ is involved in engineering design.

These costs may appear high in comparison with estimated cascade costs, but it must be recalled that the Modex installation is a highly instrumented test facility and furthermore that relatively expensive jigs which were required in fabrication of only these two trays would have materially reduced the cost of any other trays built on the same design. 